\title{
SPECTRUM ABUNDANCE AND THE CHOICE BETWEEN PRIVATE AND PUBLIC CONTROL
}

\author{
Stuart Minor BenJamin*
}

\begin{abstract}
Prominent commentators recently have proposed that the government allocate significant portions of the radio spectrum for use as a wireless commons. The problem for commons proposals is that truly open access leads to interference, which renders a commons unattractive. Those advocating a commons assert, however, that a network comprising devices that operate at low power and repeat each other's messages can eliminate the interference problem. They contend that this possibility renders a spectrum commons more efficient than privately owned spectrum, and in fact that private owners would not create these "abundant networks" in the first place. In this Article, Professor Benjamin argues that these assertions are not well founded, and that efficiency considerations favor private ownership of spectrum.
\end{abstract}

Those advocating a commons do not propose a network in which anyone can transmit as she pleases. The abundant networks they envision involve significant control over the devices that will be allowed to transmit. On the question whether private entities will create these abundant networks, commons advocates emphasize the transaction costs of aggregating spectrum, but those costs can be avoided via allotment of spectrum in large swaths. The comparative question of the efficiency of private versus public control, meanwhile, entails an evaluation of the implications of the profit motive (enhanced ability and desire to devise the best networks, but also the desire to attain monopoly power) versus properties of government action (the avoidance of private monopoly, but also a cumbersome process that can be subject to rent-seeking). Professor Benjamin contends that, on balance, these considerations favor private control. An additional factor makes the decision clearer: Abundant networks might not develop as planned, and so the flexibility entailed by private ownership-as well as the shifting of the risk of failure from taxpayers to shareholders-makes private ownership the better option.

The unattractiveness of a commons for abundant networks casts serious doubt on the desirability of spectrum commons more generally. If private ownership is a more efficient means of creating abundant networks, then the same is almost certainly true for networks that run the risk of interference. Most uses of spectrum are subject to interference, so the failure of the commons advocates' arguments undermines the appeal of a commons for most potential uses of spectrum.

INTRODUCTION .............................. 2008

I. Abundant Networks and Control ............ 2020

* Professor of Law, Duke University School of Law. B.A., Yale University, 1987; J.D., Yale Law School, 1991. I would like to thank Tom Bell, Jamie Boyle, Stuart Buck, Rodger Citron, Sam Dinkin, Gerry Faulhaber, Dale Hatfield, Tom Hazlett, Don Herzog, Evan Kwerel, Wayne Leighton, Doug Lichtman, Ronald Mann, Neil Netanel, Arti Rai, Ted Rappaport, Sanjay Shakkottai, Jim Speta, Doug Webbink, and Srilal Weera for helpful comments. 
A. The Importance of Interference ............... 2021

B. The Design of Abundant Networks ............. 2024

II. The Commons Advocates' Arguments Against

Property Rights in Spectrum .................. 2033

A. Costs of Allocating Spectrum in Small Allotments ... 2033

B. Fears that, Even with Big Allotments, Property

Rights Will Not Result in Abundant Networks ..... 2036

III. Evaluating Government Versus Private

Control of Abundant Networks ............... 2043

A. Protocols and Lobbying ..................... 2045

B. Benefits of Private Competition ................. 2050

C. Benefits of Private Control of Abundant Networks .. 2055

1. Implementing and Updating Successful

Protocols.................................. 2055

2. Adjusting Spectrum Usage and Pricing

Schemes.................................. 2060

D. Concentration of Private Power ................ 2064

E. Benefits of Government Control: The Value of a

Free Network .............................. 2076

1. Should Spectrum for Abundant Networks Be

Free of Charge? .......................... 2078

2. Is Government Control More Likely To Produce

Neutral Networks? ....................... 2082

IV. Should the Government Allot Frequencies in

LARge Bands? ............................. 2090

A. Parcel Size, Transaction Costs, and Combinatorial

Bidding .................................. 2090

B. The Importance of Uncertainty ................ 2094

V. Non-Exhaustive Property Rights ............... 2097

CONCLUSION ......................................... 2101

\section{INTRODUCTION}

There has been much ferment recently in the world of wireless communications. Technologists and legal scholars have argued that new wireless networks can be developed that would allow for a wireless "commons" in which people could transmit freely on open radio spectrum. ${ }^{1}$ One major concern about these proposals is that widespread use of such a commons may result in more traffic than the

1 See, e.g., Yochai Benkler, Overcoming Agoraphobia: Building the Commons of the Digitally Networked Environment, 11 Harv. J.L. \& Tech. 287, $325-26$ (1998); George Gilder, Auctioning the Airwaves, Forbes ASAP, Apr. 11, 1994, at 98, 111-12; Eli M. Noam, Taking the Next Step Beyond Spectrum Auctions: Open Spectrum Access, IEEE Comm. Mag., Dec. 1995, at 66, 69-70. 
network can handle-so many messages being sent that they interfere with one another. ${ }^{2}$ Several leading commentators, though, argue that technology has solved the interference problem. They contend that we can now have wireless networks in which each new device also creates new capacity, such that a wireless network can add users without creating interference. They also take a further step: They assert that such networks will not be created if spectrum is privately owned, and that a commons-in which no one owned spectrum rights-would be a more efficient system for managing the spectrum than would a property rights regime. ${ }^{3}$ In this Article, I critically assess the argument that a government-created commons is a more efficient means of spectrum allocation than is private property, and in particular that it is a more efficient means of producing these new networks. I conclude that private owners will create these capacious networks if such networks are as promising as their advocates suggest, and thatin light of the tradeoffs involved in the choice between public and private control-private control is preferable to public control.

This debate marks a new stage in spectrum policy. For most of the twentieth century, the model of spectrum regulation was straightforward: With respect to any given set of available frequencies, the federal government chose what service (usually only one service, such as broadcast television or FM radio) it would authorize. Then the

The radio spectrum is the range of frequencies suitable for the propagation of radio waves. See Harry Newton, Newton's Telecom Dictionary 657, 744 (19th ed. 2003). It would be a bit ungainly to refer constantly to "the range of frequencies suitable for wireless transmissions" or "the available range of radio frequencies," so in most places I simply refer to "the spectrum." This shorthand should not obscure the fact, however, that spectrum has no independent existence, but instead is just the available range of frequencies.

2 See infra notes $28,42-47$ and accompanying text. Interference occurs when "the electromagnetic field of one device disrupts, impedes or degrades the electromagnetic field of another device by coming into proximity with it." Webopedia, Definition of EMI, at http://www.webopedia.com/TERM/E/EMI.html (last modified July 24, 2003). Interference is not a pure function of waves intersecting. In some situations, a crude receiver is not able to find the intended signal (and thus suffers from interference), but a more sophisticated receiver is able to find the intended signal (and thus avoids interference). See infra notes 60-67 and accompanying text (discussing ways of avoiding interference via more sophisticated receivers); see also Yochai Benkler, Some Economics of Wireless Communications, 16 Harv. J.L. \& Tech. 25, 39 (2002) (“'Interference' describes the condition of a stupid lone receiver faced with multiple sources of radiation that it is trying to decode but, in its simplicity, cannot."). But the greater the degree to which signals overlap with each other, the more sophistication is required of receivers (which may make them prohibitively expensive), and at some point even the best receivers cannot find the desired signal. That is why, even in new networks, interference is such a major concern. See infra notes $45-53$ and accompanying text.

3 See Benkler, supra note 2, at 48; see also Lawrence Lessig, The Future of Ideas: The Fate of the Commons in a Connected World 222, 226, 230, 241-43 (2001) [hereinafter Lessig, The Future of Ideas]; Lawrence Lessig, Commons and Code, 9 Fordham Intell. Prop. Media \& Ent. L.J. 405, 415 (1999). 
government decided how those frequencies would be divided for licensing purposes-e.g., how big a range of frequencies each license would be allotted, how much of the United States each license would cover, and how much power each licensee could use. Finally, it selected the particular licensees by holding comparative hearings. ${ }^{4}$ The FCC decided, for example, which frequencies to allocate for television broadcasting, determined which sets of frequencies it would allot for any given city, and then parceled out licenses to the broadcasters in each city that it deemed most worthy. ${ }^{5}$ If a potential new entrant, or an existing licensee, wanted to provide another service (either in addition to or instead of broadcasting), it was out of luck. This level of government control was striking in comparison to the relatively light regulation of other goods and services (like land and printing presses), but the government justified its heavy hand in this area by arguing that spectrum was uniquely scarce and thus had to be controlled by a central governing authority. ${ }^{6}$

Ronald Coase challenged the validity of the scarcity rationale, and the government control of the spectrum that was understood to rely on it. ${ }^{7}$ In a 1959 article, he argued that there was nothing special

4 See Stuart Minor Benjamin et al., Telecommunications Law and Policy 62-64 (2001).

5 The government (through the FCC) determined worthiness via comparative hearings, at which each applicant could present evidence about itself and its programming. See id. at $81-90$.

6 See Second Annual Report of the Federal Radio Commission to the Congress of the United States 166, 168, 170 (1928) (statement by Commission Relative to Public Interest, Convenience or Necessity) (emphasizing "paucity of channels," "the limited facilities for broadcasting," and fact that "the number of persons desiring to broadcast is far greater than can be accommodated"); KFKB Broad. Ass'n v. Fed. Radio Comm'n, 47 F.2d 670, 672 (D.C. Cir. 1931) (stating that "because the number of available broadcasting frequencies is limited, the commission is necessarily called upon to consider the character and quality of the service to be rendered"); Nat'l Broad. Co. v. United States, 319 U.S. 190, 213 (1943) (asserting "certain basic facts about radio as a means of communication-its facilities are limited; they are not available to all who may wish to use them; the radio spectrum simply is not large enough to accommodate everybody. There is a fixed natural limitation upon the number of stations that can operate without interfering with one another. Regulation of radio was therefore as vital to its development as traffic control was to the development of the automobile."); Red Lion Broad. Co. v. FCC, 395 U.S. 367, 388 (1969) (declaring that "only a tiny fraction of those with resources and intelligence can hope to communicate by radio at the same time if intelligible communication is to be had, even if the entire radio spectrum is utilized in the present state of commercially acceptable technology. . . . Where there are substantially more individuals who want to broadcast than there are frequencies to allocate, it is idle to posit an unabridgeable First Amendment right to broadcast comparable to the right of every individual to speak, write, or publish."); Stuart Minor Benjamin, The Logic of Scarcity: Idle Spectrum as a First Amendment Violation, 52 Duke L.J. 1, 38-45 (2002) (discussing scarcity rationale); Laurence H. Winer, The Signal Cable Sends-Part I: Why Can't Cable Be More Like Broadcasting?, 46 Md. L. Rev. 212, 218-27 (1987) (same).

7 R.H. Coase, The Federal Communications Commission, 2 J.L. \& Econ. 1 (1959). As many commentators have noted, the mere fact of scarcity does not necessarily justify gov- 
about spectrum, and that it could and should be sold like any other form of property. ${ }^{8}$ The initial response to Coase's article was not encouraging: When he made these arguments in testimony to the FCC, the first question a Commissioner asked him was, "[I]s this all a big joke?"9 Many economists came to advocate auctions of spectrum licenses as property, but policymakers were slow to respond. ${ }^{10}$ Meanwhile, other commentators advocated that users be allowed to offer whatever services they deemed appropriate, rather than the one (or sometimes two) that the FCC authorized. ${ }^{11}$ These arguments were consonant with Coase's: One ordinary element of property rights is the owner's ability to use that property as she sees fit, as long as her use does not interfere with her neighbors. The spectrum theorists were proposing just such a rule for spectrum.

More than thirty years after Coase argued in favor of auctioning spectrum rights, his position started to gain political traction. In 1993, Congress authorized auctions of some spectrum licenses. ${ }^{12}$ In 1997,

ernment control. See, e.g., Benjamin, supra note 6, at 41-43; Thomas W. Hazlett, The Rationality of U.S. Regulation of the Broadcast Spectrum, 33 J.L. \& Econ. 133, 138 n.15 (1990); Winer, supra note 6, at 221-22.

8 Coase, supra note 7 , at $20-21$.

9 See Thomas W. Hazlett, The Wireless Craze, the Unlimited Bandwidth Myth, the Spectrum Auction Faux Pas, and the Punchline to Ronald Coase's "Big Joke": An Essay on Airwave Allocation Policy, 14 Harv. J.L. \& Tech. 335, 343 (2001) (quoting Commissioner Philip S. Cross) (alteration in original).

10 See, e.g., Arthur S. De Vany et al., A Property System for Market Allocation of the Electromagnetic Spectrum: A Legal-Economic-Engineering Study, 21 Stan. L. Rev. 1499, 1557-59 (1969) (advocating auctioning of TV, voice, and FM frequencies); Jora R. Minasian, Property Rights in Radiation: An Alternative Approach to Radio Frequency Allocation, 18 J.L. \& Econ. 221, 263 (1975) (discussing possibility of spectrum auctions); Douglas W. Webbink, Radio Licenses and Frequency Spectrum Use Property Rights, Comm. \& L., June 1987, at 3, 20-22 (describing FCC's use of lotteries and auctions to assign spectrum licenses).

In 1977, two FCC Commissioners suggested that the odds of the government consigning the comparative hearings process "to the scrapheap" in favor of licensing by lottery "are about the same as those on the Easter Bunny in the Preakness." Formulation of Policies Relating to the Broadcast Renewal Applicant, Stemming from the Comparative Hearing Process, 66 F.C.C.2d 419, 434 n.2 (1977) (Separate Statement of Commissioners Benjamin L. Hooks and Joseph R. Fogarty). Nonetheless, by 1985, FCC Chairman Fowler had requested limited authority from Congress to hold auctions. Webbink, supra, at 22.

11 See, e.g., Pablo T. Spiller \& Carlo Cardilli, Towards a Property Rights Approach to Communications Spectrum, 16 Yale J. on Reg. 53, 69 (1999) (arguing for "granting the licensee the ultimate choice of application of the spectrum"); Howard A. Shelanski, The Bending Line Between Conventional "Broadcast" and Wireless "Carriage," 97 Colum. L. Rev. 1048, 1079 (1997) (suggesting that "the fundamental rule should be to de-zone spectrum usage where possible"); see also Arthur De Vany, Implementing a Market-Based Spectrum Policy, 41 J.L. \& Econ. 627, 628, 630-32 (1998) (advocating unbundling of broadcast product and spectrum band).

12 Omnibus Budget Reconciliation Act of 1993, Pub. L. No. 103-66, $\$ 6001,107$ Stat. 312 , 379-86. 
Congress mandated (rather than merely authorized) auctions, and it made that mandate applicable to most spectrum bands. ${ }^{13}$

At the same time, government control over permissible uses fell out of political favor. The FCC has moved toward giving licensees greater flexibility in the services they can offer. In many frequency bands the FCC authorizes one or more additional services, and recently the government promulgated rules allowing licensees in a few bands to choose from a wide range of possible services. ${ }^{14}$ Moreover, in 2000, the FCC issued a notice of proposed rulemaking and an accompanying policy statement that proposed replacing government control over spectrum uses with broad spectrum rights. ${ }^{15}$ Similarly, a 2002 FCC report on spectrum policy advocated curtailing FCC control over licenses and instead implementing broad, exclusive, and transferable spectrum rights, in which licensees choose what services to provide on their spectrum. ${ }^{16}$ Meanwhile, a report by the FCC's Office of Plans and Policy argued in favor of an auction in which broad property rights for hundreds of megahertz $(\mathrm{MHz})$ are sold in one pro-

1347 U.S.C. $\$ 309$ (i)-(j) (2000); see Benjamin et al., supra note 4, at 144-46 (discussing move from hearings to lotteries to auctions). It bears noting that FCC licenses had long been auctioned in the secondary market. The government gave out licenses free of monetary charge, but the licensees were not so insulated from considerations of profit as to give those licenses to third parties gratis. Licenses often changed hands, almost always as a result of market transactions in which the buyer paid handsomely for the license. Indeed, more than half of all broadcast licenses have been sold at least once, and many have changed hands multiple times. See Evan Kwerel \& Alex D. Felker, Using Auctions to Select FCC Licensees 9 n.12 (FCC Office of Plans \& Pol'y, Working Paper No. 16, 1985) (noting that majority of spectrum licenses had been sold at least once).

14 See Service Rules for the 746-764 and 776-794 MHz Bands, 15 F.C.C.R. 476, II 2 (2000); see also Principles for Promoting the Efficient Use of Spectrum by Encouraging the Development of Secondary Markets, 15 F.C.C.R. 24,178, II 20 (2000) ("Licenses and spectrum usage rights should be easily transferable for lease or sale, divisible, or aggregatable. Licensees/users should have flexibility in determining the services to be provided and the technology used for operation consistent with the other policies and rules governing the service.").

15 See Principles for Promoting the Efficient Use of Spectrum by Encouraging the Development of Secondary Markets, 15 F.C.C.R. 24,178, T 1 (2000); Promoting Efficient Use of Spectrum Through Elimination of Barriers to the Development of Secondary Markets, 15 F.C.C.R. 24,203, II 2 (2000).

16 Report of the FCC Spectrum Policy Task Force 35-45 (2002), available at http:// hraunfoss.fcc.gov/edocs_public/attachmatch/DOC-228542A1.pdf; see also Promoting Efficient Use of the Spectrum Through Elimination of Barriers to the Development of Secondary Markets, FCC 03-113 \ा 7 (2003) (report and order) (permitting wireless radio licenses to lease spectrum rights, as part of a plan "to ensure that spectrum is put to its highest valued use, which generally can be most efficiently determined by operation of market forces"), available at http://hraunfoss.fcc.gov/edocs_public/attachmatch/ FCC-03-113A1.doc. 
ceeding ${ }^{17}$ and several papers-including one by the recently departed Chief Technologist and Chief Economist of the FCC and another by a different former Chief Economist-went further, advocating the privatization of almost all spectrum rights, via a massive "big bang" auction or other mechanism. ${ }^{18}$

Flexibility has not been limited to licensed (and auctioned) portions of the spectrum. The FCC has also created a few unlicensed bands that allow for flexible uses. ${ }^{19}$ The FCC does not mandate any particular service on those bands, but instead allows most uses and simply requires FCC approval of the equipment to be used. ${ }^{20}$ The FCC sets the standards applicable to the devices, including limits on the power that entities can use and their emissions outside of the frequency bands, leaving providers to create services within those con-

17 Evan Kwerel \& John Williams, A Proposal for a Rapid Transition to Market Allocation of Spectrum 16-19, 33-36 (FCC Office of Plans \& Pol'y, Working Paper No. 38, 2002), available at http://hraunfoss.fcc.gov/edocs_public/attachmatch/DOC-228552A1.pdf.

Hertz is a measure of cycles per second in a waveform. One hertz $(\mathrm{Hz})$ is one cycle per second. One kilohertz. $(\mathrm{KHz})$ is one thousand cycles per second, one megahertz $(\mathrm{MHz})$ is one million cycles per second, and one gigahertz $(\mathrm{GHz})$ is one billion cycles per second. So a radio station operating at $99.5 \mathrm{MHz}$ is generating a sine wave at a frequency of 99,500,000 cycles per second. See Jade Clayton, McGraw-Hill Illustrated Telecom Dictionary 174, 304, 323, 382, 436 (3d ed. 2001).

18 See Gerald R. Faulhaber \& David Farber, Spectrum Management: Property Rights, Markets, and the Commons, 2002 Proc. Telecomm. Pol'y Res. Conf. (forthcoming 2003), http://rider.wharton.upenn.edu/ faulhabe/SPECTRUM_MANAGEMENTv51.pdf;

Hazlett, supra note 9, at 551-55; Spiller \& Cardilli, supra note 11, at 82 (stating that FCC should "publicly auction fully transferable warrants, each enabling an existing specific operating license to be converted to a full property right"); Lawrence J. White, "Propertyzing" the Electromagnetic Spectrum: Why It's Important, and How to Begin, Media L. \& Pol'y, Fall 2000, at 19, 20-21 (proposing that spectrum rights be transformed into private property). Spiller and Cardilli advocate a big bang auction for virtually all spectrum. Spiller \& Cardilli, supra note 11, at 82 . Faulhaber and Farber similarly suggest a big bang auction, but they propose that resulting property rights be subject to an easement allowing low-power noninterfering uses. See, e.g., Faulhaber \& Farber, supra. Such an easement has much to recommend it, but it is inconsistent with the commons advocates' proposals. See infra note 275 and accompanying text. Hazlett and White, meanwhile, advocate granting exclusive property rights in virtually all spectrum, whether through auction or other means. See, e.g., Hazlett, supra note 9; White, supra, at 20-22. Hazlett suggests that the common law rule of priority-in-use could govern spectrum allocation, granting property rights to those who have managed to put frequencies to productive use. See Hazlett, supra note 9, at 552.

19 See 47 C.F.R. $\$ 15.407$ (2002) (listing technical requirements for "Unlicensed National Information Infrastructure").

20 Note that this is not true open access to anyone who wants to transmit. The FCC regulates access by controlling the transmitters that can be used on this spectrum-exactly the sort of regulation that an abundant network would require. See infra notes 77-80 and accompanying text (noting regulations necessary for abundant networks to work as planned); infra note 48 and accompanying text (noting FCC's regulation of devices on current unlicensed spectrum). 
straints. ${ }^{21}$ And in December 2002, the FCC launched an inquiry into allowing unlicensed transmitters to operate in a few additional bands when others were not using those frequencies. ${ }^{22}$

Probably the most successful, and certainly the best known, of the unlicensed bands is the $2400-2483.5 \mathrm{MHz}$ band, which has seen a rapid increase in usage in recent months due in significant part to the popularity of Wi-Fi (or 802.11) ${ }^{23}$ and Bluetooth. ${ }^{24}$ Some commentators have pushed the government to go much further and create large spectrum commons in desirable portions of the spectrum as the only use of those frequencies. ${ }^{25}$ One concern about such proposals is that widespread use of such a commons might result in messages interfering with one another. In response, though, a few major voices have suggested that new networks can be created that would eliminate interference problems. The two most prominent are Larry Lessig and Yochai Benkler, but there are others as well-notably David Reed,

21 Amendment of the Commission's Rules to Provide for Operation of Unlicensed NII Devices in the $5 \mathrm{GHz}$ Frequency Range, 12 F.C.C.R. 1576, $9 \mathbb{1}$ 32-55 (1997) [hereinafter UNII Order]; Modification of Parts 2 and 15 of the Commission's Rules for Unlicensed Devices and Equipment Approval, FCC 03-223 (released Sept. 17, 2003) (proposing greater flexibility in portions of unlicensed spectrum).

22 Additional Spectrum for Unlicensed Devices Below $900 \mathrm{MHz}$ and in the $3 \mathrm{GHz}$ Band, 17 F.C.C.R. 25,632 (2002). The FCC's actions and proposals regarding unlicensed spectrum are still fairly modest, however. The FCC has not set aside major portions of the most valuable spectrum-the frequencies falling roughly between $300 \mathrm{MHz}$ and 3000 $\mathrm{MHz}-$ for such unlicensed transmissions. See infra text accompanying notes 183-84 (identifying this range as spectrum's "prime beachfront"). It has allocated relatively small portions of the most desired frequencies for unlicensed uses and larger portions of a few higher-frequency bands that have somewhat less desirable propagation characteristics. See Report of the FCC Spectrum Policy Task Force, supra note 16, at 54-55; Additional Spectrum for Unlicensed Devices Below $900 \mathrm{MHz}$ and in the $3 \mathrm{GHz}$ Band, 17 F.C.C.R. 25,632, ๆाा 2-8. Its December 2002 proposals involve some prime broadcast spectrum, but unlicensed transmitters would be permitted only when broadcasters were not using those frequencies. See id.

23 The Institute of Electrical and Electronics Engineers created the 802.11 standard as a protocol that wireless transmitters could use to communicate with one another and thereby create a wireless local area network. See Newton, supra note 1, at 24-25 (describing specifications of 802 standards). The whole family of 802.11 protocols are sometimes referred to as "Wi-Fi," short for "Wireless Fidelity." See Implementation of Section 6002(b) of the Omnibus Budget Reconciliation Act of 1993: Annual Report and Analysis of Competitive Market Conditions with Respect to Commercial Mobile Services, FCC 03-150 IIT 180-84 (2003) (discussing deployment of devices with Wi-Fi capability), available at http:// hraunfoss.fcc.gov/edocs_public/attachmatch/FCC-03-150A1.pdf. As the FCC notes, Wi-Fi allows for fast data transfer speeds- - up to $11 \mathrm{Mbps}$ [megabits per second] for $802.11 \mathrm{~b}$ and up to $54 \mathrm{Mbps}$ for 802.11a and 802.11g." Id. \I 180 .

24 See generally Bluetooth, The Official Bluetooth Website, at http:// www.bluetooth.com/dev/specifications.asp (last visited Oct. 17, 2003); see also Additional Spectrum for Unlicensed Devices Below $900 \mathrm{MHz}$ and in the $3 \mathrm{GHz}$ Band, 17 F.C.C.R. 25,632, III 3-6 (discussing development of unlicensed bands and rise of Wi-Fi, Bluetooth, and Home RF).

25 See supra notes 1 and 3 and accompanying text. 
Kevin Werbach, and Stuart Buck. ${ }^{26}$ They contend that a new paradigm is now technologically possible, in which an effectively infinite number of users can communicate without interfering with one another. ${ }^{27}$ They envision low-power, computationally complex user devices that receive and resend other people's messages. Wi-Fi still relies on access points that act as antenna/transmitters, and receivers that act as ordinary receivers. Wi-Fi does not offer effectively infinite spectrum, as it is subject to the same interference problems that limit the growth of other networks and also does not scale (i.e., add nodes) well. ${ }^{28}$ The new abundant networks (as I call them) seek to avoid these problems by using complex algorithms and having each receiver transmit other people's signals, thus increasing capacity. These networks offer a vision of spectrum that is no longer scarce, and that allows us to communicate more freely.

Benkler, Buck, Lessig, Reed, and Werbach (to whom I will refer as "the commons advocates") further argue that these abundant networks will not arise if private parties obtain property rights in spectrum. Abundant networks represent the most efficient use of spectrum, in their view, but private owners will not create them. They claim that the costs of aggregating enough frequencies to support such networks will be too great. ${ }^{29}$ A government-created abundant network, they contend, is the most efficient outcome. ${ }^{30}$ They thus assert

26 See Benkler, supra note 2, at 43 (discussing implications of processing gain); Stuart Buck, Replacing Spectrum Auctions with a Spectrum Commons, 2002 Stan. Tech. L. Rev. 2, II 6, at http://stlr.stanford.edu/STLR/Articles/02_STLR_2/article_pdf.pdf (noting developments such as spread spectrum and ultra-wideband transmissions); Lessig, The Future of Ideas, supra note 3, at 230-31; David P. Reed, Comments for FCC Spectrum Policy Task Force on Spectrum Policy 11 (2002) (noting efficiency of networked systems transmitting "at low power, with dynamic directivity and repeating of signals"), available at http:// gullfoss2.fcc.gov/prod/ecfs/retrieve.cgi?native_or_pdf=pdf\&id_document $=6513202407$; Kevin Werbach, Open Spectrum: The New Wireless Paradigm 5-7 (New Am. Found, Spectrum Series Working Paper No. 6, 2002) (citing three efficiency enhancing technologies: spread spectrum, cooperative networking and software-defined radio).

27 See infra notes $61-67$ and accompanying text on the properties of these proposed networks.

28 See Report of the FCC Spectrum Policy Task Force, supra note 16, at 13 (noting interference in Wi-Fi transmissions); Hazlett, supra note 9, at 498-504 (noting interference problems with Wi-Fi and other networking standards); David P. Reed, Open Spectrum Resource Page, at http://www.reed.com/OpenSpectrum/ (last visited Aug. 8, 2003) ("Fans of 802.11 should realize that 802.11 does not in practice scale very well at all."); Piyush Gupta et al., An Experimental Scaling Law for Ad Hoc Networks 3 (2001), at http:// decision.csl.uiuc.edu/ prkumar/ps_files/exp.pdf (demonstrating declines in throughput in an 802.11 network resulting from adding nodes); infra notes 51.53 and accompanying text (discussing prevalence of interference in citizens band radio).

${ }^{29}$ See Benkler, supra note 1 , at 364-65; Buck, supra note 26 , II 103. See generally infra Part II.A.

30 See, e.g., Benkler, supra note 2. 
that the government should leave a large swath of spectrum unlicensed and available for users to interact among themselves.

These commentators' support for the idea of jettisoning spectrum rights has given it new prominence. All of them are serious technologists, and Benkler and Lessig are two of the leading academics in the world of telecommunications. The question, though, is whether they are persuasive in asserting that the possibility of abundant networks undercuts the arguments in favor of property rights in spectrum, and that government rather than private ownership is the more efficient means to create abundant networks. My answer is that the possibility of abundant networks calls into question one aspect of the government's allotment of spectrum-namely, the division of spectrum into small parcels-but it does not cast doubt on the efficiency of private ownership. If spectrum is allotted in large swaths, there is every reason to expect that private owners will create abundant networks (assuming, of course, that these networks work as promised).

This raises the issue of how big a swath of frequencies abundant networks would occupy. Currently, radio stations are allocated 200 kilohertz each; television stations are allocated 6 megahertz; and broadband PCS licenses (which are designed to allow users to send and receive voice, video, and data) range from 5 to 15 megahertz. ${ }^{31}$ These license sizes are not mandated by technology. Radio spectrum is not a series of discrete chunks, and there is no set amount of spectrum that a given service requires. Indeed, improvements in technology allow people to send more information over the same bandwidth. ${ }^{32}$

Abundant networks do not require any particular size of spectrum frequencies. At a minimum, they need enough spectrum to allow for spread spectrum transmissions. If they are as bandwidthefficient as current cellular networks that use spread spectrum, then maybe all that is needed are the same 5-15 megahertz allocations that broadband PCS networks use. We should not necessarily be bound to the size and capabilities of broadband PCS allocations, however. A greater size swath would allow for a greater data transfer speed. The

31 See generally FCC Broadband PCS Band Plan, available at http://wireless.fcc.gov/ auctions/data/bandplans/pcsband.pdf (last visited Oct. 31, 2003).

32 Television broadcasters, for example, can send five or more digital television signals over their six megahertz allocations. Advanced Television Systems, 12 F.C.C.R. 12,809, q 20 (1997); Advisory Comm. on Pub. Interest Obligations of Digital Television Broadcasters, Charting the Digital Broadcasting Future, at xi-xii (1998), available at http:/ www.ntia.doc.gov/pubintadvcom/piacreport.pdf. In short: "With airwaves, as with all other media, the more you spend, the more you can send; it all comes down to engineering and smart management." Peter Huber, Law and Disorder in Cyberspace: Abolish the FCC and Let Common Law Rule the Telecosm 75 (1997). 
projected size would depend mainly on the desired speed, and thus on the intended use. Commons advocates envision abundant networks as allowing for Internet access and data transmission. ${ }^{33}$ Cable modems and DSL currently provide such services at speeds of 1-2 megabits per second. ${ }^{34}$ We might, though, want abundant networks to provide faster service. A 100 megahertz swath, for example, could allow for data transfer rates 500 times as fast (or 1 gigabit per second). ${ }^{35}$

Although 100 megahertz would be sufficient for the uses of abundant networks that their advocates foresee, we could of course set aside still more spectrum for an abundant network: 200 megahertz, or 500 , or $1000 .^{36}$ Dedicating 500 or 1000 megahertz for a single network raises three problems, however. The first is efficiency: The increase in capacity created by adding spectrum to a given network that has sufficient spectrum will be at best linear. That is, for any given network, doubling its spectrum will, at most, double its capacity-and in fact due to practical considerations (power constraints at the network's nodes, or user devices) its capacity likely will be less than double. ${ }^{37}$

33 See Yochai Benkler, Siren Songs and Amish Children: Autonomy, Information, and Law, 76 N.Y.U. L. Rev. 23, 62 (2001) (stating that abundant networks "will not supplant absolutely owned wired and wireless networks in delivering real time communications with assured quality of service. They will enable, however, a wide range of uses, from Internet access to online games, overnight (or during dinner) delivery of video on demand, and, potentially, local nonessential video conferencing among friends or for town hall meetings.").

34 See Stuart Minor Benjamin et al., Telecommunications Law and Policy 258 (Supp. 2003) (noting speeds of cable and DSL); see also Inquiry Concerning High-Speed Access to Internet Over Cable and Other Facilities, 17 F.C.C.R. 4798 n.37 (2002) (noting speed of cable modem). Mbps stands for megabits per second, so 1 mbps means a data transfer speed of one million bits per second. Gbps, meanwhile, stands for gigabits per second (one billion bits per second). See Newton, supra note 1, at 351, 493.

35 With user devices equipped with multiple antennas, a 100-megahertz bandwidth can support $1 \mathrm{gbps}$ or higher. See Ashok Mantravadi et al., Spectral Efficiency of MIMO Multiaccess Systems with Single-User Decoding, 21 IEEE J. Selected Areas Comm. 382 (2003). Even with a single antenna system, we can expect $150-200$ mbps with 100 megahertz of bandwidth. See Theodore S. Rappaport, Wireless Communications: Principles and Practice, $40-52$ ( $2 \mathrm{~d}$ ed. 2001).

36 Above $100 \mathrm{MHz}$, additional megahertz would be of limited value: The limit on abundant networks' services would be the delay created by the many hops, not the data transfer (or bit) rate. The delay in multihop networks is nontrivial, and, importantly, the bigger the network, the longer the delay. See Sanjay Shakkottai et al., Unreliable Sensor Grids: Coverage, Connectivity and Diameter 10 (2003), available at http://www.ece.utexas.edu/ \%7Eshakkott/Pubs/sensor-ton.pdf. That is, abundant networks would be optimized for asynchronous uses and real-time transfers of small amounts of data (e.g., voice conversations), but they would not be optimized for real-time video because the delay created by the many hops would undermine quality of service. See supra note 33; see also infra note 89 and accompanying text. And as the network expands in size, delays increase. See Shakkottai et al., supra, at 10.

37 See Piyush Gupta \& P. R. Kumar, The Capacity of Wireless Networks, 46 IEEE Transactions on Info. Theory 388 (2000). 
Second, the greater the size of an abundant network, the greater the cost of the government dedicating spectrum to such a network. These costs raise particular concerns in light of the possibility of an abundant network not developing as hoped; in that case, dedicating hundreds of megahertz of spectrum to one would be a huge misallocation of resources. ${ }^{38}$ Third, setting aside hundreds of megahertz for a single abundant network makes it less likely that there will be competition between such networks.

The choice of how much spectrum-if any-to allocate for any given abundant network, and for abundant networks in toto, is therefore primarily a policy choice, rather than a technological choice. Significantly, the more spectrum that is dedicated for a given abundant network, the more likely that there will be enough room for only one. As I discuss in Part III.D, hundreds of megahertz of spectrum are unutilized or underutilized. These massive swaths of spectrum are available for dedication as abundant networks. If spectrum were allocated in parcels of 100 megahertz, or even 200 , there would be enough room for five or more competing abundant networks. In light of the benefits of competition, allowing for multiple networks seems to be the wiser course.

That still leaves the question of how those networks will be controlled: Each could be controlled by a private entity; ${ }^{39}$ each could be controlled by the government; or some could be controlled by private entities and others by the government. There are real advantages to having private entities provide them-private entities have both a greater incentive to choose the best protocols and a greater ability to respond quickly to changes in technology or in the marketplace. Indeed, Benkler and Lessig do not suggest that the entire available spectrum should be commons, but rather propose that there be both commons and private ownership. ${ }^{40}$ But once there are competing private networks, what is the advantage of adding a government network? We don't do that with newspapers, television stations, or colas (and there are only two major companies that make colas), so why do it here?

I find that the advantages of having the government create an abundant network are outweighed by the disadvantages. Having a single abundant network would provide greater capacity, but at the cost of competition. And having a government-created network compete alongside private ones would avoid the danger of monopoliza-

\footnotetext{
38 See infra notes $263-68$ and accompanying text.

39 A private entity could be a consortium, of course.

40 See Lessig, The Future of Ideas, supra note 3, at 222, 226, 242; Benkler, supra note 2, at 83 .
} 
tion, but at the cost of diminished incentives to create the best network. Given the uncertainties regarding whether these networks will develop as hoped, it makes more sense that shareholders, rather than taxpayers, bear the risk of failure.

Part I of this Article discusses the nature of the proposed abundant networks. Such networks will require significant control on the part of some regulator-whether public or private. Absent such control, interference problems would arise, defeating the vision of effectively infinite spectrum. In Part II, I address the commons advocates' arguments that private entities will not create abundant networks. Their main argument relies on the transaction costs of aggregating spectrum, but those costs can easily be overcome through allotment of spectrum in large swaths. As for economic incentives, creators of abundant networks should have at least as great an ability to capture the value of those networks as do creators of other kinds of networks. Given that the question for a spectrum owner is a comparative one (which network will be most remunerative), there is every reason to expect that an owner will create an abundant network if such a network is as valuable as its advocates suggest.

The fact that private firms will create these networks does not mean that they are the most efficient means of doing so. Part III considers the comparative advantages of private versus government control. There are many choices and tradeoffs in the design of protocols, which allows for competition among protocols. And competition seems desirable, as it stimulates innovation and allows for more niches to have their interests met. The profit motive, meanwhile, gives private companies an advantage in determining the state of the art, implementing it, and responding to technological and market developments. Government control, on the other hand, has the advantage of preventing any private entity from gaining monopoly power, but would open up the possibility of rent-seeking in the choice of protocols. As to whether private or government control will respond better to the needs of users, there is little reason to prefer one over the other. These considerations suggest that competition among private firms is the most desirable outcome. Part IV considers the question whether, on balance, it is a good idea for the government to allot spectrum in large enough swaths to make room for abundant networks. That discussion highlights the uncertainties regarding whether these networks will work as planned-uncertainties that, in my view, further tip the balance against government control of abundant networks. Part $\mathrm{V}$ considers the implications of my arguments. Commons are appropriate when interference is not a problem and private ownership would create high transaction costs. They also may make sense when 
the proposed use is a secondary service that would not interfere with the main service. But abundant networks would be the only use of the spectrum devoted to them, and the commons advocates have failed to make the case for the government providing them. Rather than the government foisting such networks upon us, we should let private entities choose whether to create them (and, of course, take the risk of them failing).

My conclusion should not obscure the fact that the commons advocates have contributed significantly to the debate on spectrum policy. Before they laid out their arguments, the debate was over how to transition from a command-and-control regime to property rights; the idea of a commons was not taken very seriously. The commons advocates changed that-focusing attention on new forms of communication that challenged old paradigms of spectrum usage, and putting forward a set of arguments why a commons might make more sense. Their arguments, however, rely on a set of idealized decisionmakers. I would agree with them that the best possible decisionmaking process entails the government creating a commons that gives maximum freedom to users, utilizing protocols that reflect the state of the art and allow for the maximum range of services consistent with avoiding interference, and updating those protocols as circumstances warrant. The problem is that this first-best process is not the one that is likely to arise with government creation of an abundant network. ${ }^{41}$ In this paper I try to look realistically at the choice between public and private sponsorship, and between single and multiple networks, in order to determine what option is most attractive in light of the abilities that government and private entities have and the incentives that they face. Ultimately, in my view, this is a choice between second-bests, and the more efficient option is competition among private firms.

\section{I}

Abundant Networks and Control

A major question for the use of spectrum, or any resource, is whether some entity will exercise any control over it. The notion of unlicensed spectrum may seem to entail transmission without any controlling agents. This would represent a stark alternative to a world of either government control or private control (via, most obviously, property rights). Instead of having any gatekeeper, the airwaves would be a medium through which users could communicate with

41 Huber, supra note 32, at 75 ("Markets find ways of reassembling private pieces into public spaces when that is the most profitable thing to do. They may take more time than an omniscient central authority, but finding [such] authority takes even longer."). 
each other as they saw fit. Users might choose to constrain their actions in a variety of ways, but no regulator-public or privatewould impose limits on them. The first question, then, is whether such an unregulated world is consistent with the abundant networks proposed by the commons advocates. The answer is no.

\section{A. The Importance of Interference}

One key aspect of wireless transmissions is that they are subject to interference-and the danger of interference undercuts arguments for totally open access. Every transmitter creates some interference. Each time a person uses a cordless telephone, or even turns on a light, there is a transmission of energy through the air that thereby creates a tiny amount of interference for nearby users of nearby frequencies. ${ }^{42}$ In some cases the interference is so small that it does not create a noticeable loss of signal quality. ${ }^{43}$ The real fear is of more significant interference-one set of radio waves overlapping with another set to a sufficient degree that a receiver can hear neither clearly.

Insofar as such harmful interference is likely to arise in any given band, truly open access - in which anyone can transmit as she sees fit-is unattractive. ${ }^{44}$ The reason is that any given user has an interest in ensuring that her message gets through, even if that means increasing power and/or the number of messages sent (to create redundancy) such that others' messages cannot be heard. The costs created by the sender are borne by the users as a whole, but the benefits accrue to the sender. ${ }^{45}$ This is, of course, a variation on the theme

42 See Benjamin, supra note 6, at 11; Bruce M. Owen \& Gregory L. Rosston, Spectrum Allocation and the Internet, in Cyber Policy and Economics in an Internet Age 197, 215 (William H. Lehr \& Lorenzo M. Pupillo eds., 2002).

43 See Benjamin, supra note 6 , at 11-12.

44 In using this terminology, I am distinguishing open access from a regulated commons. See Elinor Ostrom, Governing the Commons: The Evolution of Institutions for Collective Action 23, 222 n.23 (1990) (distinguishing between open access regimes, which are open to all, and commons, which are often limited to specific users); Siddhartha Raja \& Francois Bar, Transition Paths in a Spectrum Commons Regime 5-6 (2003) (paper presented at Telecommunications Policy Research Conference, 2003) ("While open spectrum is open to anyone to use as they wish and please, commons spectrum is in fact, not open to everyone freely. To use the commons, one must belong to a group of users who follow certain rules, such as transmission power restrictions, politeness and pre-certification of devices by the FCC. Open spectrum does not have any such restrictions."), available at http://intel.si.umich.edu/tprc/papers/2003/235/Raja-Bar-TPRC2003.pdf.

45 As Ellen Goodman, Stan McCoy, and Devendra Kumar note:

When an unlicensed user decides to transmit in a shared spectrum band, the benefits from the transmission go solely to the transmitting party, while the harms caused by the potential interference are felt equally by all users of the spectrum. Thus, each individual user, acting rationally, would decide to increase transmissions in the shared band (because that user does not absorb the interference costs incurred by others as a result of its increased transmis- 
of the tragedy of the commons; each individual is tempted to defect, and enough do so that the resource becomes overwhelmed. ${ }^{46}$ There is every reason to expect such a tragedy of the commons if constraints are not placed on communications. ${ }^{47}$

The government recognizes as much: The unlicensed spectrum that the FCC has created is not an unregulated commons in which anyone can transmit as she pleases. The FCC imposes transmission standards and requires that it certify all equipment used on this spectrum. ${ }^{48}$ Significantly, even with these limits, users have often encoun-

sion), resulting in congestion in the band when all users acted accordingly-the

so-called "tragedy of the commons."

Ellen Goodman et al., An Overview of Problems and Prospects in U.S. Spectrum Management, in Telecommunications Convergence: Implications for the Industry \& for the Practicing Lawyer 2002, at 327, 354 (PLI Patents, Copyright, Trademarks, and Literary Property Course, Handbook Series No. 698, 2002).

46 See, e.g., Durga P. Satapathy \& Jon M. Peha, Spectrum Sharing Without Licenses: Opportunities and Dangers 1 (1996), http:/www.contrib.andrew.cmu.edu/usr/dsaq/web.pdf (stating that unlicensed spectrum is subject to "Tragedy of the Commons resulting from the fact that device designers lack an incentive to conserve the shared spectrum resource"); Report of the FCC Spectrum Policy Task Force, supra note 16, at 40 ("Because there is no price mechanism in the commons model to use as a tool for allocating scarce resources among competing users, there is always the risk that free access will eventually lead to interference and over-saturation, i.e., the "tragedy of the commons.'"); Thomas W. Hazlett, Spectrum Flash Dance: Eli Noam's Proposal for "Open Access" to Radio Waves, 41 J.L. \& Econ. 805, 815-16 (1998) (noting that open access systems fail because of congestion and costs of "collision avoidance").

47 See Gregory L. Rosston, The Long and Winding Road: The FCC Paves the Path with Good Intentions 22 (Stanford Inst. for Econ. Policy Research, Discussion Paper No. $01-08,2001$ ) ("The introduction of unlicensed spectrum requires a central planner to set out the 'rules of the road' or protocols to ensure that unlicensed users are good citizens."), available at http://siepr.stanford.edu/papers/pdf/01-08.pdf; see also Durga P. Satapathy \& Jon M. Peha, A Novel Co-Existence Algorithm for Unlicensed Fixed Power Devices (2000) (paper presented at the IEEE Wireless Communications and Networking Conference, Sept. 2000), available at http://www.ece.cmu.edu/ peha/WCNC2000.pdf; Durga P. Satapathy \& Jon M. Peha, Etiquette Modifications For Unlicensed Spectrum: Approach and Impact, 1 Proc. 48th Ann. Int'l IEEE Vehicular Tech. Conf. $272-76$ (1998); Durga P. Satapathy \& Jon M. Peha, Performance of Unlicensed Devices with a Spectrum Etiquette, Proc. 1997 IEEE Globecom 414-18; Jon M. Peha, Wireless Communications and Coexistence for Smart Environments, IEEE Pers. Comm., Oct. 2000, at 66; S. Michael Yang et al., On the Use of Unlicensed Frequency Spectrum, Use Rule Evolution, and Interference Mitigation 1 (2001), at http://www.jacksons.net/tac/First\%20Term/On\%20the\%20use\% 20 of $\% 20$ unlicesed $\% 20$ frequency $\% 20$ spectrum $\% 20$ research $\% 20$ paper4.pdf; see also infra note 69 and accompanying text.

48 See 47 C.F.R. $\$ 15.407$ (2002) (listing technical requirements for "Unlicensed National Information Infrastructure Devices"); 47 C.F.R. $\$ 15.247$ (2002) (listing technical requirements for unlicensed spread spectrum devices); U-NII Order, supra note 21 , II 32 55; Benkler, supra note 1, at 332-33 (noting constraints placed on unlicensed spectrum); Buck, supra note 26, II 53 (noting that "the FCC's equipment regulations for the Unlicensed National Information Infrastructure specify that all transmissions in the 5.15-5.25 $\mathrm{GHz}$ band must have a peak power spectral density of less than $2.5 \mathrm{~mW} / \mathrm{MHz}$, that any emissions in the adjoining bands must be attenuated by at least 27 decibels, and so on ad nauseam" (citations omitted)). 
tered considerable interference on the unlicensed spectrum. ${ }^{49}$ This phenomenon is particularly striking with respect to the FCC's main attempt at creating a commons where ordinary people could communicate with one another-citizens band (CB) radio. The idea behind $\mathrm{CB}$ radio was that anyone could buy a simple transmitter and then communicate freely with her fellow citizens. A citizen who wanted to operate an amateur (or ham) radio was obligated to get a license from the FCC, and could receive that license only if she passed a test. ${ }^{50} \mathrm{By}$ contrast, those who wanted to operate a $\mathrm{CB}$ radio did not have to take any test, and after 1983 they did not even have to obtain any license, but instead could operate freely without a license. ${ }^{51}$ The FCC did, however, attempt to exercise control over $\mathrm{CB}$ users by mandating the power levels and equipment that could be used on the citizens band. Notwithstanding this degree of control, a tragedy of the commons occurred: Some users operated amplifiers at power levels above those that the FCC permitted; their messages got through, but at the cost of interfering with the messages of other users. ${ }^{52} \mathrm{CB}$ users, in other words, behaved exactly as economic theory would predict, with the result that many users became crowded out. ${ }^{53}$

49 See, e.g., Hazlett, supra note 9, at 429 (noting that "[w]hen unlicensed entry thrives, the characteristic pattern is that over-crowding ensues," and citing repeated congestion of unlicensed bands).

50 See 47 C.F.R. $\S 97.17$.

51 See 47 U.S.C. $\$ 307$ (e)(1) (2000); Elimination of Individual Station Licenses in Radio Control Radio Services and Citizens Band Radio Service, 48 Fed. Reg. 24,884 (June 3, 1983) (codified at 47 C.F.R. $\S 95.401,95.407$ (f), 95.420 (1994)).

52 See Amendment of Parts 2 and 97 of the Commission's Rules to Require Type Acceptance of Equipment Marketed for Use in the Amateur Radio Service and Amendment of Part 2 of the Commission's Rules to Prohibit the Marketing of External Radio Frequency Power Amplifiers Capable of Operation on Any Frequency from 24 to $35 \mathrm{MHz}$, 67 F.C.C.2d 939, ЯI 5-8 (1978) (noting serious interference caused by illegal use of powerful amplifiers on citizens band); Radio Frequency (RF) Interference to Electronic Equipment, 70 F.C.C.2d 1685, II 3-4, 7 (1978) (noting concerns that amplifiers that boost output power of $\mathrm{CB}$ sets in violation of Commission Rules have created significant interference); Order to Show Cause Why the License for Radio Station KQQ-8472 in the Citizens Band Radio Service Should Not Be Revoked, 75 F.C.C.2d 294, II 5 (1979) (noting that illegal high-power amplifiers create interference, resulting in degradation of $C B$ service and "a 'domino effect,' i.e., many licensees, in attempting to outperform their CB neighbors, compete with one another via impermissible equipment to ensure that their transmissions are not drowned out by others with more powerful operations"); Type Acceptance of Equipment Marketed for Use in the Amateur Radio Service, 46 Fed. Reg. 18,979, III 2-3 (Mar. 27,1981 ) (noting serious interference both within and without citizens band created by illegal high-powered CB amplifiers); Press Release, FCC, Compliance and Info Action: Federal Communications Commission Unveils Joint Criminal Investigation (1997) (noting problems created by CB amplifiers operating at illegally high power levels), $1997 \mathrm{WL}$ 602954.

53 See, e.g., Wayne Overbeck \& Rick D. Pullen, Major Principles of Media Law 284 (1985) (noting that radio broadcast band in 1926 had same problem as citizens band today-both had "layer upon layer of signals, with the louder ones covering up weaker 
Commons advocates, too, recognize the dangers posed by interference. ${ }^{54}$ Their argument is not that commons arrangements are attractive despite significant interference. Rather, they contend that new network designs can eliminate the dangers posed by interference, with the result that a commons is an efficient-indeed, the most efficient-option. That is, they assert that fears of interference need no longer drive spectrum allocation policy, such that a commons is a viable solution.

\section{B. The Design of Abundant Networks}

Commons advocates put forward analogies intended to illustrate the folly of sales of spectrum rights. Eli Noam has analogized selling spectrum rights to selling flying rights for planes. He notes that we could sell various "lanes" between cities to the highest bidder, leaving those who want to fly planes to negotiate with the owners of various lanes, but that this would make little sense. ${ }^{55}$ Benkler similarly suggests an analogy to trade rights. He notes that, at the time that Britain was beginning to trade with India, it could have decided to create 1000 exclusive property rights to trade with India and then auctioned those rights. He suggests that:

Free trade, an absence of property rights in the act of trading with India, is the correct economic solution, not a market in exclusive rights to trade, no matter how flexible or efficient. We do not believe that there is a naturally-bounded resource called "the act of trading with India" whose contours could efficiently be delineated for clearance through property-based markets. ${ }^{56}$

ones"); Jon M. Peha, The Path Towards Efficient Coexistence in Unlicensed Spectrum, IEEE 802.16 WirelessHUMAN (Wireless High-Speed Unlicensed Metropolitan Area Network) Standards 2 (2000) ("When utilization [of CB radios] became high, and interference great, many users responded by buying radios with greater transmit power. This reinforced the scarcity, causing even more users to increase their transmit power."), available at http:// www.ieee802.org/16/human/contrib/80216hc-00_03.pdf.

54 Indeed, in a recent essay Eli Noam stated flatly:

Eventually, any resource whose utilisation is of value, yet whose use is without a charge, will be over-utilised. Just as in an earlier generation Citizens Band radio became an intolerably congested airwave Babel, so will the open spectrum also become used by anybody who wants to broadcast TV pictures to their neighbourhood, video-cam the front door of their shop, or bounce signals from large amplifiers known as repeaters. This is the classic problem of the "tragedy of the commons," in which the open pasture became overgrazed. Inevitably, the open spectrum will be squeezed into a few overgrazed frequency patches while the "real" applications take place on more orderly bands.

Eli Noam, The Third Way for Spectrum, Fin. Times (London), March 13, 2003, http:// msl1.mit.edu/ESD10/docs/ft_spectrum_policy_e_noam_mar_14_2003.pdf.

55 Eli Noam, Spectrum Auctions: Yesterday's Heresy, Today's Orthodoxy, Tomorrow's Anachronism, 41 J.L. \& Econ. 765, 765-66 (1998).

56 Benkler, supra note 2, at 27. 
The key to both analogies is that the relevant resources are effectively limitless. If, as seems plausible, a greater number of ships can travel to India than actually want to go there, and a greater number of planes can fit in the air than want to fly, there would seem to be no reason to confer any exclusive rights at all. Property rights are useful as a means of protecting resources that are limited in some way. If shipping and air lanes are effectively infinite, creating any sort of property system seems inappropriate. The problem is that network capacity ${ }^{57}$ is not limitless-or, more precisely, its capacity is limitless only in limited circumstances, and thus is not truly infinite-and therefore these analogies do not fit. ${ }^{58}$

The commons advocates tell an important story about the way that people traditionally have viewed uses of spectrum. For most wireless services, the main consideration has been transmitting with enough power to get a clear signal to a receiver. The model here has been broadcasting, in which a radio or television station sends out a single programming stream along a channel (which is just a specified range of frequencies). The main consideration limiting the number of potential channels is interference. So regulators dedicate a given channel to just one broadcaster, and in fact may create buffers around that channel, in an attempt to minimize interference. Having broadcasters using nearby frequencies (or, of course, the same frequencies) might lead to interference that would make it hard for viewers/listeners to pick up a clean signal. 59

57 I am distinguishing here the capacity of a given abundant network, which can increase with the addition of new users, from the capacity of any given user device, which actually decreases with the addition of new users. See infra note 70 and accompanying text.

58 Indeed, Noam and Benkler's analogies do not quite work in their test cases. Air lanes may be effectively infinite (in that there is an adequate supply for all conceivable levels of demand), but landing spots are not. So some mechanism must exist in order to apportion airport runways and airport gates. We could imagine leaving runway space as an open resource available to anyone, but that might result in more planes trying to land than can be accommodated (there are a lot of small planes out there), massive confusion and delays, and quite possibly crashes, as each plane attempted to land on its own. The more obvious answer here is to create some sort of mechanism for regulating the timing of landings and access to airport gates, and indeed that is exactly what has happened. See Hazlett, supra note 9, at 421 n.482; Hazlett, supra note 46 , at 815 -19. Similarly, there are plenty of shipping lanes, and probably plenty of docks, but almost assuredly some docks are better located than others and thus have greater value. Thus it is probably the case that the supply of well-placed docks is not infinite; if so, then a sorting mechanism for those docks might be appropriate. So it may be that air and shipping lanes are effectively infinite, but that still leaves other aspects of air travel and trade with India subject to interference.

59 See Benjamin, supra note 6, at 11-16 (discussing allocation of channel, fear of interference, and possible creation of buffers). 
As the commons advocates point out, this story is correct as far as it goes but is radically incomplete. There are other possible paradigms. One obvious alternative is that there need not be one signal that is transmitted from a single location. Cellular telephony presents an example. Cellular service providers install base stations that create "cells" throughout a city, allowing callers to transmit only between themselves and the nearest base station. Users send transmissions to each other via these stations, so many different relatively low-power conversations occur on the same wavelength.

Significantly, transmissions are not the only relevant measure of power. The computational power of receivers can also be relevant. We can see this by examining basic radios. Radios often have fairly crude receivers that are not sophisticated enough to pick out the desired signal from undesired signals on nearby frequencies. The receivers lack the ability to differentiate among signals, and the FCC has responded by allowing only one signal on each channel in a given geographic area. ${ }^{60}$ More sophisticated receivers would create opportunities for more signals to be transmitted in any given range of frequencies; the more selective receiver would have a greater ability to pick out the desired signal from among all the other transmissions being sent out.

More dramatically, much more sophisticated receivers, combined with the breaking up of a given message into packets, can bring about a quite different set of possibilities. The main example here is a technology known as spread spectrum, which uses low-power transmissions that hop or spread among a wide range of possible frequencies. ${ }^{61}$ The transmitter sends small packets of data accompanied by sophisticated codes across a wide range of frequencies. Receivers monitor that range of frequencies, listening for the code. A transmitter can send packets at very low power, because the receiver does not need to be able to receive consistently a single streaming radio wave at a fixed point on the spectrum. Instead, it need only pick up the various packets that are sent out and reassemble them. Such reassembling can work as long as the receiver has the relevant algorithm and the computational power to put the pieces of the message together. ${ }^{62}$

60 The FCC has done a good deal more, as well, to keep the airwaves clear. In fact, there is a strong argument that its actions unnecessarily have created idle spectrum. I argue that such actions are inconsistent with the First Amendment in Benjamin, supra note 6 .

61 See Newton, supra note 1, at 748 (defining "spread spectrum"); see also Amendment of Parts 2 and 15 of the Commission's Rules Regarding Spread Spectrum Transmitters, 12 F.C.C.R. 7488, I 3 (1997) (describing spread spectrum devices).

62 See Kevin Werbach, Here's a Cure for Bandwidth Blues, ZDNet, Nov. 28, 2001 (discussing properties of spread spectrum), at http://zdnet.com.com/2100-1107-531165.html. 
As Benkler notes, this involves a tradeoff of computational power for transmitting power. ${ }^{63}$ The transmission can be at low power because so much work is being done by the receiver. In contrast with ordinary broadcasts, which involve a relatively crude receiver, spread spectrum relies on the existence of a receiver that can quickly process signals on a wide range of frequencies and decipher the messages that contain the appropriate codes. Another way of looking at this is that the conventional way for a transmitter to distinguish its signal has been to boost its power so that it can be differentiated from the background noise; spread spectrum, instead, allows for distinguishing signals via algorithms, so that the signal's power need not rise above the level of background noise.

Spread spectrum technologies are widely used today. To return to the cellular telephony example, the most widely used form of digital cellular transmission is code division multiple access (CDMA), a form of spread spectrum technology. Each call is given a unique code and is then transmitted in pieces over a range of frequencies, which are reassembled on the receiving end so quickly that real-time conversations are possible. ${ }^{64}$

One final technological development completes the "abundant capacity" story: the ability of receivers to enhance the capacity of the network. This idea (sometimes called "cooperation gain") ${ }^{65}$ is that the consumer device will not only send and receive its own messages but also will help to process others' messages. The end-user devices would both communicate the owner's transmissions and serve as a repeater of others' transmissions. Each packet would be relayed from device to device until it reached its intended recipient.

The vision of abundant capacity depends on both of these developments. Without the computational complexity, low-power transmissions would not be deciphered. Ordinary (e.g., traditional broadcast) low-power transmissions can be heard only if they are the highest power transmissions in a given frequency range. To put the point differently, if the networks do not rely on smarter receivers, then old-fashioned dumb receivers will continue to pick out the strongest signal, and the number of signals that can be sent on any given set of frequencies will be low.

But computational complexity is not sufficient to create networks of significant size (and therefore usefulness). Without cooperation gain, if a user of a device wants to send a message to someone who is a

63 See Benkler, supra note 2, at 43.

64 See Qualcomm, How CDMA Works, at http://www.qualcomm.com/ProdTech/cdma/ training/cdma25/m5/m5p01.html (last visited Sept. 21, 2003).

65 See Reed, supra note 26 ; Benkler, supra note 2 , at $44-45$. 
few dozen miles away, the device will have to transmit at a high enough power level for the transmission to traverse that distance-a level high enough to create the dangers of interference that reduce the number of potential users. Put another way, low-power spread spectrum devices on their own (i.e., without base stations or repeaters) do not allow for communications from one end of a metropolitan area to another, because the signal weakens the longer it travels. Cellular telephony avoids this problem by having base stations located throughout a community, as those base stations serve to relay the messages to other stations. If, as the commons advocates propose, we want to have community networks that do not rely on base stations, then other repeaters will have to exist-in the form of the devices themselves. ${ }^{66}$ The key to creating networks that can accommodate as many users as want to communicate is having user devices that help others' messages to be sent.

The idea, remember, is that engineers could design networks such that many more messages could be communicated-so many that spectrum constraints would no longer be relevant. With everybody forwarding everyone else's low-power messages, the limit on the number of users we could add might be higher than the number of devices that would ever be in use. Every user device would create additional capacity (because of its role as a repeater), so there would be no reason to fear additional users. Even if at some point the network could not handle any more devices, that point would be so high that it would be irrelevant to the actual networks-it would be an abstraction.

Thus, creating networks with effectively infinite capacity (in the sense that the transport capacity of the network increases when users are added) relies on having devices that (a) have great computational abilities, (b) transmit at low power levels, and (c) help to forward others' messages on to their desired destinations. ${ }^{67}$

This highlights that the envisioned networks would need to be controlled. The notion of a spectrum commons might conjure up visions of a world in which everyone can transmit as she sees fit, without any external constraints. But the desired network will not arise under these conditions. The reason is a classic collective action

66 If instead we have base stations serve this function, then the network is just an ordinary cellular network.

67 All the devices would have to transmit at low power and have sophisticated computational capabilities. It may not be that every device needs to enhance others' communications (through forwarding them), but repeaters will need to be ubiquitous throughout the network so that the devices can transmit at low power and still get their messages through, and such ubiquity will require a very high number of repeaters. 
problem: It may be in the interest of all users to use low-power devices that repeat others' messages, but it will be in the interest of any given user that everyone else abide by these constraints while she transmits at higher power, and without repeating. As to power, at least some users are likely to decide that they would rather not rely on repeaters and/or would like to send real-time video to a friend, and so will want to operate at higher power; ${ }^{68}$ and some entrepreneur will create high-powered devices for them. ${ }^{69}$

A similar point applies to the forwarding of others' messages. Many consumers will, if given the choice, prefer devices that allow them to communicate but do not forward others' messages. An important point bears noting here: In an abundant network, the transport capacity of the network increases as users are added (and thus is effectively infinite), but the transmitting capacity per user is not. Instead, users' ability to transmit their own messages decreases as the network becomes larger. ${ }^{70}$ When a device uses its transmission capacity to forward another's message, it is not using its capacity on its own messages. Forwarding a packet occupies some of the capacity that could otherwise be used for the individual's own packets. ${ }^{71}$ Significantly, the bigger the network, the more repeating any given node has to do. ${ }^{72}$ Adding nodes increases network transport capacity, but for each device it creates greater repeating burdens.

68 See supra notes $45-47$ and accompanying text; supra note 36 ; infra note 89 and accompanying text.

69 See Ellen P. Goodman, Spectrum Rights in the Telecosm to Come, 41 San Diego L. Rev. (forthcoming February 2004) (manuscript at 74, on file with New York University Law Review) ("Unlicensed devices, if unconstrained, are likely to adopt a greedy approach to the consumption of these spectrum resources.").

70 See Gupta \& Kumar, supra note 37.

71 See Atul Adya et al., A Multi-Radio Unification Protocol for IEEE 802.11 Wireless Networks 1 (Microsoft, Research Technical Report No. MSR-TR-2003-44, 2003) (noting that user devices cannot receive and transmit at same time: "A fundamental reason for low network capacity is that wireless LAN (WLAN) radios cannot transmit and receive at the same time. Consequently, the capacity of relay nodes is halved."), available at ftp:// ftp.research.microsoft.com/pub/tr/tr-2003-44.pdf. Indeed, "[e]arly simulation experience with wireless ad hoc networks suggests that their capacity can be surprisingly low, due to the requirement that nodes forward each others' packets." Jinyang $\mathrm{Li}$ et al., Capacity of Ad Hoc Wireless Networks, 2001 Proc. 7th ACM Int'l Conf. on Mobile Computing \& Networking 61, available at http://www.pdos.lcs.mit.edu/papers/grid:mobicom01/paper.pdf.

72 See Gupta \& Kumar, supra note 37. One can try to avoid this decrease in user capacity, but, as always, there are tradeoffs. One idea is to substitute the mobility of user devices (i.e., the fact that the owners of them move around) for immediate forwarding. Avoiding a decrease in user capacity thus comes at the expense of a great increase in the time it takes for a message to be communicated, because the network is relying on the physical circulation of user devices, which might take minutes or hours. See Matthias Grossglauser \& David Tse, Mobility Increases the Capacity of Ad-Hoc Wireless Networks, 10 IEEE/ACM Transactions on Networking 477 (2002) (exploring multiuser diversity as method of increasing per-user throughput), available at http://www.eecs.berkeley.edu/ 
Serving as a repeater also consumes battery power. Not only forwarding others' packets but also idle time-in which a user device is listening for other packets so that it can repeat them-will consume a considerable amount of the user device's energy and therefore battery power. ${ }^{73}$

Note further that the burdens are greater if others defect. If a user's neighbors configure their devices so that they do not repeat (or turn them off), her device will have to devote that much more of its capacity to repeating others' messages. The only way for her to avoid that burden is to refuse to repeat, which increases the burden on everyone else and encourages further defection.

In light of the costs to a user of serving as a repeater, and the absence of direct benefits, it would be stunning if some users did not seek to rely on others' willingness to forward messages. Indeed, we have seen similar free riding in other cooperative networks. ${ }^{74}$ In the networks envisioned by the commons advocates, however, having access to a few other devices will not be sufficient (and indeed would be little different from a cellular network). Low-power transmissions

$\sim$ dtse/ton_mob_final_3.pdf; David Tse, Capacity of Mobile Ad-Hoc Networks, at http:// www.eecs.berkeley.edu/ dtse/adhoc.html (last visited Oct. 17, 2003) (suggesting that node mobility allows tradeoff between user capacity and delay, and might be appropriate for services that tolerate delays of minutes or hours); see also infra notes 110-21 and accompanying text (discussing tradeoffs involved in the design of abundant networks). This is different from the proposed abundant networks, in that messages are moved not so much through repeating as through actual movement. In any event, it would not appear to achieve the goals of the commons advocates, as it does not allow for any isochronous communications (instant messaging, telephone calls, etc.), and thus excludes many of the most desired forms of communication. See Newton, supra note 1, at 436 ("Isochronous transmission means 'two-way without delay.' Normal everyday voice conversations are isochronous.").

73 See, e.g., Vikas Kawadia \& P.R. Kumar, Power Control and Clustering in Ad Hoc Networks (2003) (paper presented IEEE INFOCOM 2003) ("For current off-the-shelf hardware, the power consumption in the transceiver electronics for transmitting, receiving or even remaining idle, but awake, is almost an order of magnitude higher than the power consumed when sleeping, i.e., turning the radio off."), available at http:// decision.csl.uiuc.edu/ prkumar/ps_files/clustering.pdf.

74 Napster, for instance, was a system that allowed users to download music files stored on others' computers. Significantly, users could download music files from other computers without having to give other computers access to their music files. That is, users had the choice of using Napster only for their own benefit or also helping others to get copies of music. The users knew that the system depended on the willingness of computer users to make their music files available, but nonetheless the data indicate that seventy percent of Napster users did not make their computers available for others' downloading. See Eytan Adar \& Bernardo A. Huberman, Free Riding on Gnutella, First Monday, Oct. 2000, at http://www.firstmonday.dk/issues/issue5_10/adar/index.html. Napster worked because a relatively small percentage of computers opened themselves up to all comers (indeed almost fifty percent of files were supplied by a mere one percent of users, id.), and no more was necessary for the system to work. 
over great distances require a mesh of repeaters; widespread defection (i.e., refusal to forward messages) will undercut the system..$^{75}$

A commons without controlling agents thus would not achieve the goal of effectively infinite spectrum-or anything close to it. We could still have an unconstrained commons, but it would not look like the network that commons advocates envision and instead likely would be a jumble of frequently interfering devices. This is an instantiation of the tragedy of the commons discussed above. ${ }^{76}$ Here, such overwhelming comes in the form of people both grabbing (using higher power devices than everyone should use) and free riding (relying on others to repeat messages but failing to do so themselves).

The discussion above demonstrates that the commons advocates' vision of abundant networks entails a controlled environment. Indeed, the commons advocates acknowledge this point: Their envisioned networks entail a central regulatory authority that would impose requirements on all device manufacturers designed to ensure that the devices use an appropriate set of protocols and standards. ${ }^{77}$ They are not proposing true open access, but instead a regulated commons. ${ }^{78}$

75 See, e.g., Li et al., supra note 71 ("[F]or total capacity to scale up with network size the average distance between source and destination nodes must remain small as the network grows. Non-local traffic patterns in which this average distance grows with the network size result in a rapid decrease of per node capacity."); see also Feng Xue \& P.R. Kumar, The Number of Neighbors Needed for Connectivity of Wireless Networks, at http://decision.csl.uiuc.edu/ prkumar/ps_files/connect.pdf (2002) (noting disagreement among wireless engineers over number of neighbors to which each node must be connected for mobile multihop network to operate successfully).

76 See supra text accompanying notes 45-53.

77 See Benkler, supra note 1, at 362 (noting the importance of "administrative regulations by the FCC or protocols and standards set by the industry to prevent defection and degradation of the quality of performance all industry members can deliver to their customers"); Benkler, supra note 2 , at $77-78$ (discussing regulation of wireless commons by FCC or public trust); Buck, supra note 26 , $\mathbb{\text { II }} 37-41$ (suggesting regulation by FCC along with management by local spectrum management group).

78 See supra note 44 (distinguishing open access from regulated commons). Werbach's most recent paper disagrees with Benkler's suggestion of ex ante rules, and proposes instead that people transmit freely and use tort law to sort out interference concerns. See Kevin Werbach, Supercommons: Toward a Unified Theory of Wireless Communication 58-62 (Aug. 29, 2003), available at http://intel.si.umich.edu/tprc/papers/2003/196/ Supercommons.pdf. In order to determine whether the defendant has tortiously interfered with the plaintiff, however, a judge will have to determine what rights against interference the plaintiff has. Once tort law enters the picture, in other words, there will be rules for wireless transmissions. Instead of being ex ante rules, they will be post hoc and may be more case specific. It bears noting that Werbach also proposes that one who transmits according to acceptable protocols be protected from liability. Id. at 62-63. Insofar as judges rely on those protocols to determine tort liability, there is little difference between Benkler's and Werbach's proposals. Perhaps more important, if Werbach's proposed system yielded a much less controlled system, in which people really could transmit fairly 
And the level of regulation involved is significant. To return to the example of repeating, it will not be sufficient for a device to be able to forward others' messages; it must actually do so. This is relevant because a user might want to set up a use (such as a webcam) that occupies all of her device's transmission capacity. In theory the device would be available to serve as a repeater, but in reality it would be using all its capacity to send its own messages, and thus would not repeat others' messages. This problem can be avoided only if the controller of the abundant network mandates not only power limits and repeating capability but also minimum amounts of listening time and quiet time. ${ }^{79}$

The upshot is that, in order to create a "commons" with effectively infinite network transport capacity, an entity will have to be able to exercise meaningful control over the design of the user devices (and thus of the network). ${ }^{80}$ In order for the system to work, some sort of regulator (whether public or private) will need to be in a position to ensure that the devices operate at low power, that they utilize authorized methods of encoding, and that many (if not all) of the devices provide cooperation gain by helping others' messages along their way. The promise of abundance depends on significant control. So the transport capacity of a given network is extraordinarily abundant-or, more accurately, it might be extraordinarily abundant, if the technology develops-only under a set of fairly tightly prescribed and enforced rules.

freely, we would expect the interference discussed above. See supra notes $45-54$ and accompanying text.

79 See infra notes 110-21 and accompanying text for more detail on protocols for abundant networks.

80 The Report of the FCC Spectrum Policy Task Force stated:

Although the commons model is in many ways a highly deregulatory "Darwinian" approach, as its proponents point out, productive use of spectrum commons by unlicensed devices, particularly in lower spectrum bands, typically requires significant regulatory limitations on device transmitter power that preclude many other technically and economically feasible spectrum uses that rely on higher-power signal propagation over longer distances, or that require greater protection from interference.

Report of the FCC Spectrum Policy Task Force, supra note 16, at 40; see also Mike Chartier, Enclosing the Commons: A Real Estate Approach to Spectrum Rights, in Practical Steps to Spectrum Markets 14 (2001) (noting Lessig's proposal for abundant networks characterized by "smart" devices and stating that "[t]he problem with this is that right now the FCC decides what 'smart' is. Contrary to a free space where innovation can flourish, the current system requires literally micro-management by the FCC to precisely define the algorithms these alleged 'smart' devices must use."). 
II

The Commons Advocates' Arguments Against Property Rights in Spectrum

These abundant networks sound wonderful, and the advocates stress how valuable users might find them. ${ }^{81}$ Nonetheless, the advocates worry that they won't be created if there are private property rights in spectrum. Why would that be? Why wouldn't entrepreneurs rush to create them? The contention is that aspects of private property rights create costs, such that the most efficient route is not the one that is taken. Commons advocates contend that, although an abundant network is the optimal use of spectrum, certain costs apply that end up making private abundant networks unattainable.

\section{A. Costs of Allocating Spectrum in Small Allotments}

The main argument commons advocates marshal against property rights in spectrum involves transaction costs. The basic point is fairly straightforward. Imagine, for instance, that the FCC decides to divide 100 megahertz of spectrum into 100 separate units of one megahertz each. If someone wants to create an abundant network that will cover 100 megahertz, she will have to undertake negotiations with each owner of a one-megahertz slice. ${ }^{82}$ Such negotiations would be quite expensive, and thus would add considerably to the cost of creating the envisioned network. ${ }^{83}$

81 Buck elaborates:

A commons in the spectrum could offer several benefits, including greater freedom to experiment with local variations on spectrum usage, a greater incentive to develop technologies for spectrum sharing (such as spread spectrum radios or ultra-wide-band technology), and a greater harnessing of widely-dispersed information about spectrum usage. Additionally, regulating the spectrum as a commons might facilitate efficient transactions among competing users, and make economies of scale feasible for cross-boundary uses.

Buck, supra note 26 , II 11. And Benkler explains:

As best we can foresee, these [spectrum commons] networks will not supplant absolutely owned wired and wireless networks in delivering real time communications with assured quality of service. They will enable, however, a wide range of uses, from Internet access to online games, overnight (or during dinner) delivery of video on demand, and, potentially, local nonessential video conferencing among friends or for town hall meetings.

Benkler, supra note 33, at 62 .

82 I use 100 megahertz as an illustrative bandwidth for an abundant network. As I noted above, there is nothing magical about 100 megahertz (or any other number of megahertz), and an abundant network could cover a much smaller, or much bigger, range. See supra note 36 and accompanying text.

83 See Benkler, supra note 1, at 364-65. 
Closely related to this argument is a concern about the possibility of holdouts. ${ }^{84}$ Not only would the creator of a broadband network have to negotiate with dozens of spectrum owners, but if any one of them refused to agree, then the network could not exist as planned. Each spectrum owner has an incentive to let others sell first, and then hold out for a price that allows it to appropriate the bulk of the surplus created by the aggregation of spectrum. ${ }^{85}$ The possibility of such strategic behavior is an added cost of creating abundant networks. ${ }^{86}$

84 Indeed, holdout costs are often treated as a subset of transaction costs.

85 See, e.g., Buck, supra note 26, II 103 (noting that with allotment of spectrum into small parcels "the holdout problem might arise, as a license holder of a prime area of spectrum could demand too much money for relinquishing his license to the would-be aggregator").

86 At least in theory, holdout costs per se should not transform abundant networks from a profitable to an unprofitable proposition for aggregators. Such problems will arise if the holdout overestimates the available surplus to be divided and thus asks for a fee that would transfer all the aggregator's profit to the holdout. (If the aggregator refused, there would be no network; if it agreed, it would operate at a loss.) If we assume that both parties are rational, they should reach an agreement that leaves the aggregator able to make a profit, and thus with an incentive to create an abundant network. In this way, holdout costs should be a purely distributional issue-how much of the value will the aggregator have to surrender to the holdout. By contrast, even with rational bargainers, transaction costs may well exceed the surplus created by the value of the network, because each bargainer would want to be compensated for its time; if no deal could result because of the costs of those negotiations, any given negotiator still will prefer that option to one in which it negotiates and is not paid for its time. Holdout fees, on the other hand, are designed not to capture the costs of negotiating, but instead to capture some of the value that the enterprise creates. Such fees are above and beyond any actual expenses incurred by the holdout. The result is that a rational holdout generally would not prefer an option that prevents the creation of an abundant network, because then it would be losing out on a potential windfall. Thus, assuming rationality, transaction costs may well outweigh the value created by an abundant (or any other) network, but holdout costs should not.

This reasoning only goes so far, however. Even if a rational holdout would not want to prevent the network from being created, the mere fact of the possibility of holdouts increases transaction costs. That is, the costs of negotiation with a holdout may be high, in part because the buyer has to present evidence to the holdout of how much surplus is created and convince her that it is accurately assaying those costs. See Kenneth J. Arrow, The Property Rights Doctrine and Demand Revelation Under Incomplete Information, in Economics and Human Welfare: Essays in Honor of Tibor Scitovsky 23, 29-34 (Michael J. Boskin ed., 1979). The very fact that someone tries to hold out, in other words, increases costs. And by the time the rational holdout realizes that the remaining surplus in the project is sufficiently low that even its minimal demands for additional negotiation and information about that surplus impose a cost on the buyer that outweighs that remaining surplus, this cost will have been incurred; the holdout will receive this information only in the course of such costly negotiations in the first place.

So if holdout costs are higher for one option than for another, they may have the same distorting effect as transaction costs in leading entities to choose the option with lower holdout costs. See Robert D. Cooter \& Daniel L. Rubinfeld, Economic Analysis of Legal Disputes and Their Resolution, 27 J. Econ. Literature 1067, 1078 (1989) ("The problem of dividing the surplus created by settlement is a source of instability that can lead to bargaining breakdowns."). Holdout costs are thus relevant to the analysis in this Article insofar as they decrease the likelihood that an entity will prefer to create an abundant 
These costs are real: Transaction and holdout costs will add to the expense of creating abundant networks. In some cases a particular use will be so much more profitable than the alternatives that, even if the proposed use has high transaction costs and other options have few or no such costs, the value of the use outweighs the added costs involved. But that will not always be so. The challenge presented by transaction and holdout costs is that sometimes the most efficient alternative will not be undertaken because its superiority over other options does not outweigh these costs. ${ }^{87}$

The important point to recognize, though, is that these costs are not inherent in the selling of property rights in spectrum. They are purely a function of the allotment of spectrum into small pieces. If the government chooses to allot spectrum in large (say, 100-megahertz) units, rather than much smaller ones, then an abundant network can be created with small transaction costs (one negotiation or auction) and no holdout costs. And, crucially, the government can create such allotments under either a public or a private ownership scheme. If the government wants to reduce the barriers to creating the capacious networks envisioned by the commons advocates, it can allot spectrum in big chunks and then assign them as it sees fit.

This does not necessarily mean either that spectrum should, in fact, be allotted in big chunks or that abundant networks will arise if spectrum is so allotted. As I will discuss in Part IV, the first contention is a contestable policy question and the second is an uncertain prediction. The point here is that transaction and holdout costs are not a result of property rights, but instead result from the division of spectrum into small slices of frequencies. ${ }^{88}$

network, given the other options available to that entity. That is, holdout costs (like transaction costs) entailed by the most efficient alternative may lead an entity to choose instead a less efficient alternative, if the latter has lower holdout costs.

87 See, e.g., Harold Demsetz, When Does the Rule of Liability Matter?, 1 J. Legal Stud. 13, 27 (1972) (noting that transaction costs can cause "the foreclosure of the use of possibly cheaper cost-avoidance techniques"); Michael A. Heller \& Rebecca S. Eisenberg, Can Patents Deter Innovation? The Anticommons in Biomedical Research, 280 Sci. 698, 698-99 (1998) (noting that transaction costs of obtaining agreements from many different property owners can thwart efficient development).

88 Benkler makes an additional argument about the alleged inconsistency of private property rights and abundant networks-namely that with private property rights "the difficulty of assembling a broad swath of frequencies would render unlikely the initial development of more than one such band [i.e., abundant network]." Benkler, supra note 1, at 363. Benkler suggests that this likely will lead to equipment manufacturers controlling that single band, and that "[w]ithout regulatory intervention, it is unlikely that these manufacturers would offer competitors nondiscriminatory access to their spectrum." Id. at 363-64. The results of having only one band for an abundant network may or may not produce the effects that Benkler predicts, see infra Part III.D, but the important point here is that his assumption of having only one band rests on his presupposition that the spectrum will be 


\section{B. Fears that, Even with Big Allotments, Property Rights Will Not Result in Abundant Networks}

A different argument against having property rights in spectrum is that, even if spectrum is allotted into chunks sufficiently large that each can support an abundant network, the private owners of such chunks will not have sufficient incentive to create such a network because it will be less remunerative for them. The argument in the previous section that transaction and holdout costs may effectively preclude otherwise efficient uses of spectrum is quite different from the argument that private owners of spectrum rights will not have sufficient incentive to create the desired networks even if they do not have to aggregate spectrum.

If each allotment of spectrum were big enough to support one of the envisioned networks, why wouldn't owners of those allotments create them? Why wouldn't it be more remunerative for an owner to create such a network? At the outset, note that there are no costs associated with aggregating spectrum (it has already been aggregated into sufficiently big pieces), and instead transaction costs now apply to the disaggregation of spectrum. If the owner wants to divide its spectrum into smaller units (e.g., so that firms can offer an entirely different service, such as traditional television broadcasting), ${ }^{89}$ it will incur the transaction costs of auctioning (or negotiating the transfer of) those smaller units. ${ }^{90}$ Given that, all else equal, it would be less

allotted in small slices, giving rise to "the difficulty of assembling a broad swath of frequencies," id. at 363. As the previous discussion in text highlights, however, allotment of broad swaths of frequencies-so that each allotment is big enough to support an abundant network -is totally consistent with property rights in spectrum. The aggregation hurdle that, in Benkler's view, will lead to the development of only one band with an abundant network and thus to equipment manufacturers blocking potential competitors need not exist in a property rights regime.

89 Abundant networks almost certainly would not be optimized for real-time video with high quality of service, and, in any event, would not be consistent with traditional, highpower television broadcasting. See Shakkottai et al., supra note 36 (discussing increases in delay flowing from increases in size of multihop network); see also Yochai Benkler, From Consumers to Users: Shifting the Deeper Structures of Regulation Toward Sustainable Commons and User Access, 52 Fed. Comm. L.J. 561, 577 (1999-2000) (arguing that abundant networks will work well for some communications, "[w]hile such a system may not perfectly serve all real-time communications with assured quality of service"); Benkler, supra note 33, at 62 (acknowledging that abundant networks likely would "not supplant absolutely owned wired and wireless networks in delivering real time communications with assured quality of service"); supra note 36 (discussing fact that abundant networks will not be optimized for real-time video). Regarding traditional high-power broadcasting, one of the central aspects of abundant networks is that no one will transmit at high power over the spectrum dedicated to such networks. See supra notes 61-67 and accompanying text.

90 In addition, the owner will incur the cost of determining what size allotments will maximize the total amount of money that it receives for its spectrum. Both this cost and the cost of auctioning currently consume a fair amount of energy within the government, 
costly for owners of large swaths to use their full allotment for a single purpose-such as an abundant network-than to subdivide it, why wouldn't owners create those networks?

One possible answer is that although an abundant network would create significant value for users, spectrum owners would be unable to capture this value. Maybe people will want to use the system and will derive great benefits from it, but spectrum owners will not profit from these abundant networks and thus will not create them. There is no reason, however, to assume that this will be the case. The owner of spectrum can find remuneration from a variety of sources. It might, for example, charge on a per-minute basis for transmission time used, or per message sent. ${ }^{91}$ Commons advocates might respond that usage will be difficult to track and perhaps not be worth tracking, because each communication will be too cheap to meter. ${ }^{92}$ On this reasoning, regimes relying on such usage charges either will not work or will impose such significant transaction costs that they will undermine the efficiency of the scheme. ${ }^{93}$

Assuming this is true, however, there are other ways of reaping revenues that would not pose these problems. The owner of an abundant network might charge a flat monthly fee for all the capacity that a person wants to use. Or, if the spectrum owner found that consumers wanted to avoid the hassles of monthly charges, it might charge a royalty fee on the end-user equipment (i.e., the device that sends and receives messages) that compensates it for its spectrum. ${ }^{94}$

and in this scenario the private owner would take on this task. See infra Part IV.A on the relevance of the costs of disaggregating the spectrum to proposals to allot the spectrum in big chunks.

91 Eli Noam suggests another possibility-a spot market in which people pay instantaneously for the messages they want to send. See Noam, supra note 55 , at 765 . Noam proposes such a system as an alternative to property rights, but there is no reason why a spectrum owner could not create such rolling instantaneous auctions.

92 Metering would be possible even in a distributed network (i.e., where messages did not go through a central gateway). Each user device, for example, could be equipped with a program that counted each message that a user initiated and sent. The program could have the device automatically contact a billing agent periodically (say, every month) during a moment of quiet time to give the count for that period, allowing the billing agent to bill the user on a metered basis.

93 This conclusion is by no means ineluctable. A number of commentators have noted that the technology exists to support instantaneous micropayments that would be fairly cheap to administer; the real question is whether there is a market for such a system. See Ronald J. Mann \& Jane K. Winn, Electronic Commerce 460-61 (2002) (discussing micropayments, and noting that micropayment systems have been developed); Noam, supra note 55 (proposing instantaneous spectrum auctions and micropayments).

94 See Kwerel \& Williams, supra note 17, at 7 ("A market system would also provide the opportunity for private spectrum licensees in flexible bands to compete with the government for the provision of spectrum for low-power devices, just as private facilities that charge admission compete with public parks. Licensees might find it profitable to do so by 
Using either method, an owner can capture revenue from a service that is too cheap to meter.

It bears noting, in this regard, that Benkler suggests that the pricing of government-created abundant networks would be via enduser devices, that charging customers this way is the most efficient means of paying for abundant networks, and that such pricing is inconsistent with private ownership. ${ }^{95}$ The first proposition seems correct and the second is plausible (though highly questionable), ${ }^{96}$ but the third is untenable. There is no reason to think that private companies (and the capital markets that supply them with funding) could not utilize royalty fees. ${ }^{97}$ This is not mere speculation. We have seen all manner of compensation-including royalty fees, flat monthly charges, and usage pricing-with existing wireless (and, for that matter, wired $)^{98}$ services. Spectrum licensees have, for example, managed to get remunerated for cellular telephony, satellite services, Internet access, etc. through combinations of these revenue streams. And other players as well (such as companies like Qualcomm that create the algorithms by which communications are transmitted) have found ways to earn revenue that need not depend on per-minute usage. Indeed, Qualcomm receives income via the sort of royalty fees that Benkler advocates. ${ }^{99}$ Simply stated, there are many different bus-

charging manufacturers of such devices to operate on their spectrum."); see also id. at 31 ("One possible arrangement would be for a licensee or group of licensees covering a particular band throughout the U.S. to charge manufacturers a fee for the right to produce and market devices to operate in that band.").

95 See Benkler, supra note 1, at 351 ("[T] he value of communications over time using an unlicensed device is expressed in the price of the equipment."); Benkler, supra note 2, at 51-52,54, 69 (suggesting that private ownership will result in usage pricing and that with government networks, costs will be bundled into price of user device; stating that usage pricing is inefficient). As I discuss below, however, the lack of pricing flexibility is actually a disadvantage. See infra notes 176-79 and accompanying text.

96 See infra note 179 (discussing advantages of pricing flexibility).

97 Indeed, it is not at all clear (to put it mildly) why one should assume that an actor not subject to the profit motive-such as a government entity-would be more likely to find the most efficient pricing mechanism than a profit-seeking entity would be. I can make an educated guess about what combination of royalty fees, monthly charges, per-minute charges, etc. would be most efficient, but those with an economic stake have at least as much insight plus a greater incentive to find the most efficient mechanism. See Part III.B.

98 Wire, after all, is just "spectrum in a tube." See Hazlett, supra note 9, at 338; see also Howard A. Shelanski \& Peter W. Huber, Administrative Creation of Property Rights to Radio Spectrum, 41 J.L. \& Econ. 581, 584 n.11 (1998) ("Fiber-optic transmission is highfrequency radio in a glass conduit.").

99 See Eric Nee, Qualcomm Hits the Big Time, Fortune, May 15, 2000, at 213, 216 (noting that "Qualcomm collects a royalty of about $\$ 10$ for each CDMA phone sold"); Yonhap English News, Qualcomm Rakes in 1.52 Trillion Won in CDMA Royalty in South Korea (Sept. 17, 2003) (noting that "[u]nder a royalty-bearing agreement, South Korean handset manufacturers ... should pay Qualcomm 5.25 percent of every CDMA cell phone sold at home and 5.75 percent for exports"), 2003 WL 56870894. 
iness models that allow for compensation for wireless services, including abundant networks. There is no reason to believe that spectrum owners will not be able to receive compensation for the value that they create.

One might refine the problem by casting it as one of differential ability to realize potential gains: Perhaps capturing the value of an abundant network is more difficult than capturing the value of other kinds of wireless services, with the result that companies will choose somewhat less valuable services that allow for greater capture of value. But why would realizing revenue from abundant networks be any more difficult than realizing revenue from other systems? Indeed, the means for capturing the value of abundant networks seem comparable to those for services like Internet access and easier than those for over-the-air broadcasting. As to the former, some forms of Internet usage are probably too cheap to meter; but for Internet access, as for abundant networks, revenue streams are available via monthly flat fees or fees embedded in equipment charges.

Broadcasting, meanwhile, does a notoriously bad job of capturing consumers' willingness to pay because it relies on advertisers. If broadcasters charged per person or per program, they would get some sense of how much value consumers placed on the programming. Instead, broadcasters charge viewers nothing and rely on advertising revenue as a proxy. As many scholars have pointed out, this creates a big disconnect between value to users and payment to spectrum owners, as users do not pay directly. ${ }^{100}$

This might suggest another argument: Maybe there are implementation costs that would apply to an abundant network and not to other uses of spectrum. This is almost assuredly true. Every possible wireless use entails some costs that are unique to it. ${ }^{101}$ The cost struc-

100 Advertisers pay per eyeball, so the revenue stream to broadcasters does not capture increments of viewer interest beyond the willingness to watch. That is, advertisers generally focus on the size and demographics of the audience, and so pay based on who is watching. Even if the same number of viewers like program $A$ just enough to watch it but love program $B$, the broadcaster will receive the same revenue for both. The value created by a program that viewers particularly love is not reflected in the revenue received by broadcasters. See Cass R. Sunstein, Democracy and the Problem of Free Speech 62-63 (1993) (describing failure of advertising-driven model of broadcasting to reflect consumer preferences); C. Edwin Baker, Giving the Audience What It Wants, 58 Ohio St. L.J. 311, 319-22 (1997) (same).

101 The same point applies to a related argument, namely that abundant networks might not appear because they require a large number of subscribers, and an entrepreneurial company might not be willing to underwrite a massive investment knowing that it needs a large number of subscribers before it breaks even. That is, abundant networks would be profitable only if they had lots of subscribers, so the start up costs are significant. The problem with this argument is that the same is true for almost all networks: The fixed costs entailed in creating the infrastructure are very great (and the marginal cost of adding sub- 
ture of broadcasting is different from that of wireless telephony, which is different from that of satellites, etc. A claimed advantage of abundant networks, however, is that their costs are lower than the costs for other networks: The idea is that abundant networks use spectrum more efficiently (they allow for many more communications on a given slice of spectrum) and have minimal infrastructure costs (because each user device is also a repeater). The differential costs of setting up various networks should work in favor of abundant networks. And, if they do not, that suggests that these networks in practice do not meet their potential in theory.

A different possible argument is that no spectrum owner would participate in the creation of one of these abundant networks, out of fear that such a network would be so successful that it would overwhelm the existing market. That is, owners would refrain from creating abundant networks as a way of protecting their networks already in place. There is evidence that entrenched incumbents in highly concentrated-particularly monopoly-markets are often slow to implement new technologies that might threaten their existing service. ${ }^{102}$ But the market for wireless services has many competing playersincluding established cellular companies, new entrants, and formerly new entrants that have established themselves-that have offered a continuing supply of new wireless services. ${ }^{103}$ This competition is sig-

scribers is low), so the cost of supplying service to the first few customers is extraordinarily high. The creator of such a network must have the stomach to operate at a loss until enough subscribers join the network. Network creators-and the capital markets-are willing to do this for other kinds of networks, and there is no reason to believe that the same would not be true for abundant networks.

Indeed, this point applies with particular force in light of some of the advantages of abundant networks: They have much less infrastructure than conventional networks do, and they scale easily. Each added user also represents added capacity. As a result, the start up costs, and the break-even point in terms of the number of subscribers, should be lower for abundant networks than for other networks.

102 See Howard A. Shelanski, Competition and Deployment of New Technology in U.S. Telecommunications, 2000 U. Chi. Legal F. 85. Professor Shelanski looked at the implementation of ten sample technologies-four that were deployed under monopoly conditions, three under concentrated oligopolies (with two or three firms in competition), and three under competitive oligopolies (markets with more than three competing firms). He found that " $[w]$ hile there is substantial variation in deployment times for different technologies under a given market structure-from four to fourteen years under monopoly, four to twelve years under duopoly/triopoly, and two to seven years under competitionaverage deployment times speed up as markets become more competitive." Id. at 115; see also Philip J. Weiser, The Internet, Innovation, and Intellectual Property Policy, 103 Colum. L. Rev. 534, 581 (2003) (noting that "incumbent monopolies will often fail to develop and deploy radically new technologies").

103 Some of these new services are offered by existing incumbents (such as the recent introduction of video over cellular phones and the combination of PDAs with cellular phones). Others are offered by former upstarts that became established players because of the success of a new product (such as Research In Motion Limited, the maker of Blackber- 
nificant, because studies have also shown that disruptive technologies-and innovations more generally-are introduced more rapidly in competitive markets. ${ }^{104}$ For example, analog cellular dramatically weakened the market position of pagers, and digital cellular is doing the same to analog cellular. ${ }^{105}$ Indeed, some companies are deploying wireless broadband mesh networks that are similar to abundant networks (although they do not meet abundant networks' promise of effectively infinite spectrum). ${ }^{106}$ Simply stated, there is no reason to expect that all the players would refrain from introducing abundant networks. If these abundant networks will be so successful, we should expect someone to create them and reap the rewards from a better system. 107

Maybe the problem instead is that these abundant networks will not be as remunerative because people will simply pay more money for other services. The problem would be that abundant networks were not sufficiently valuable to people, rather than that their value could not be captured. If, after all, the demand for Britney Spears music broadcasts is at all levels of supply greater than the demand for the capability offered by abundant networks, then we should expect that no abundant networks will be created; Britney Spears will rule the airwaves.

ries, see Blackberry, About Us, at http://www.blackberry.net/about/index.shtml (last visited Aug. 24, 2003); Blackberry, Key Features, at http://www.blackberry.com/products/ blackberry/key_features.shtml (last visited Aug. 14, 2003)). Still others are offered by companies that remain relative upstarts (such as personal broadband service via antenna arrays by ArrayComm, see ArrayComm, iBurst System Overview, at http://www.arraycomm.com/ prods/ib_sys_overview.htm (last visited Aug. 14, 2003)).

104 See Shelanski, supra note 102, at 114-18; Weiser, supra note 102, at 585 (suggesting that competition produces more innovative, and more disruptive, technologies); see also Richard N. Langlois, Technological Standards, Innovation, and Essential Facilities: Toward a Schumpeterian Post-Chicago Approach, in Dynamic Competition and Public Policy: Technology, Innovation, and Antitrust Issues 193, 207 (Jerry Ellig ed., 2001) ("[I]nnovation normally proceeds fastest when a large number of distinct participants are trying multiple approaches simultaneously."); infra notes 142-48 and accompanying text.

105 Indeed, in the cellular market, both new entrants and existing players are offering the disruptive technology. That is, companies providing the older service also provide the newer one, even though by doing so they cut into the market share of the older service.

106 See Invisible Networks, Cost-Effective Rollout of Wireless Broadband Networks, at http://www.invisible.uk.net/how/ (last visited Oct. 27, 2003); MeshNetworks, Inc., Ad Hoc Peer-to-Peer Routing Technology, at http://www.meshnetworks.com/pages/help/ printable_pages/technology/intro_technology.htm (last visited Aug. 24, 2003); Nokia Networks, Nokia Rooftop Wireless Routing: White Paper (2001), at http://www.americasnet work.com/americasnetwork/data/articlebrief/americasnetwork/412002/34898/article.pdf; Radiant Networks, Extend the Reach of Your Broadband Network, at http:// www.radiantnetworks.com/meshworks/mwlesummary.asp (last visited Aug. 14, 2003); see also Adya et al., supra note 71 , at 1 .

107 See infra notes 195-99 and accompanying text for a discussion of the related concern that one firm might buy all the available spectrum. 
If people simply will pay more for services other than those provided by abundant networks, then the entire case for those networks is undermined. That lack of popularity should tell us something. The reason that cellular telephony providers will be able to bid more for a given slice of spectrum than will companies that want to broadcast shows about law professors is that consumers value the former more than the latter. Willingness to pay provides a unit of measurement for determining which services people actually value most highly. This is a basic reason to have auctions: People can claim that all sorts of services are valuable, but willingness to pay has proven to be more reliable than mere conjecture as an indicator of value.

The case for abundant networks is that they will be immensely valuable to people. Each of us will be able to transmit as much information as we would like, to whomever we choose. Indeed, this is a key element of the advocates' arguments for such networks: They would be the best possible use of spectrum because they would allow people to communicate far more freely and efficiently. And, in light of the considerable amounts of money that people are willing to pay for cellular telephones, there is every reason to believe that users would be willing to pay for their use of these new abundant networks.

Moreover, abundant networks have a huge advantage: Conventional networks have a limit on the number of users they can add, because of the danger of interference. The whole point of abundant networks is that they eliminate this limit. This means, as I discussed in Part I, that abundant networks can accommodate many more users than conventional networks can-effectively everyone who would want to transmit. For a potential creator of such a network, this means that it can receive much less money per user than a conventional network does and still be able to outbid the conventional network proprietor for spectrum because it will have so many more users. Instead of, say, 100,000 cellular telephones producing thirty dollars a month in revenue, it can have 10,000,000 abundant network devices producing fifty cents a month; if so, it will be able to bid more for spectrum. Moreover, the creator of the abundant network would have every reason to believe that it would, in fact, gain lots of customers. Who wouldn't willingly, or even happily, pay fifty cents a month for access to a network that provides everything a cellular network does?

Perhaps the concern is that bids at auctions will not fully reflect the value of these abundant networks, because willingness to pay does not reflect the preferences of those who are unable to pay. It is true that willingness to pay excludes those without disposable income. And the less disposable income a person has, the less her views will be 
reflected in the bid for a good. This point, of course, is not limited to spectrum auctions, but instead applies to all auctions-indeed all economic activity. But the commons advocates have given us no reason to suppose that abundant networks will be any more subject to this distortion than any other network is. ${ }^{108}$ More important, there is no reason to assume so. All wireless services tend to skew toward those with disposable income. Because they allow for so many people to communicate, however, abundant networks support a business model that involves lower prices and more users. Bids from cellular providers will not reflect the value of their networks to those who are willing to pay ten dollars a month for a cellular telephone; such potential payers will not be able to afford cellular service and thus will contribute nothing to the cellular company's business plan (and therefore to its bid for spectrum). Bids from providers of abundant networks will capture those who would pay ten dollars a month, as well as those who can afford to pay much less than that.

III

\section{Evaluating Government Versus Private Control of Abundant Networks}

The discussion so far indicates several things: As to the networks themselves, it may be possible for engineers to develop networks that, through computational complexity and cooperation gain, can accommodate an effectively infinite number of users. Such a system would work, however, only if the devices deployed on the network are designed according to fairly tight specifications. With respect to the question of who might create these networks, either private ownership or government control can produce abundant networks. As long as spectrum is allotted in large enough slices, there are no costs that

\footnotetext{
108 Note that if we decide that having auctions for spectrum rights is unattractive, that does not condemn property rights in spectrum. Auctions are one way that the government can distribute property rights, but there are other mechanisms that do not involve monetary payment for spectrum. Indeed, the FCC has utilized two of them-comparative hearings to choose the most meritorious applicant and lotteries. See Benjamin et al., supra note 4, at 81-86, 144-45 (discussing FCC's use of hearings and lotteries); supra note 18 (noting that some advocates of property rights do not push for auctions). When discussing the distribution of spectrum rights in this Article, I often simply refer to "auctions"-in part because they are the dominant current mode of governmental distribution, in part because that is how buyers of spectrum licenses dispose of them to third parties, in part because auctions are my preferred means of distribution, and in part because saying "auctions, lotteries, comparative hearings, or bestowing rights on current incumbents" would be ungainly. See supra text accompanying notes 12 and 13 (noting prevalence of auctions as means of distributing spectrum); supra note 13 (noting that licensees transfer their licenses via private auction); see also Kwerel \& Felker, supra note 13 (discussing advantages of auctions). But auctions and property rights need not stand or fall together.
} 
would inhibit private owners' creation of abundant networks. And if the abundant networks are as efficient as their advocates suggest, we should expect that private owners of spectrum rights will create them.

Just because private owners can create these networks, however, does not mean that they are the best entities to control spectrum. The next step is to compare different models of control. As I noted in the introduction, there are five possible models: a single abundant network controlled by the government; a single network controlled by a private entity; multiple networks controlled by the government; multiple networks controlled by private entities; or multiple networks, some controlled by private entities and others by the government. Assuming that someone could design and implement a successful abundant network, ${ }^{109}$ how should we evaluate these various options?

The conventional arguments for preferring competition among private owners as a means of allocating a given resource are well known. Private companies in a competitive market, motivated by a desire for profits, have a great incentive to find the most efficient and popular uses of a given resource. Government entities have no similar incentive, because a better use will not enrich them. Instead, government actors respond to their own constituencies and influences. This may be fine insofar as those influences reflect the public interest, but it is more troubling if instead they reflect well-organized private interests (or government actors' own interests). The main disadvantage of private ownership is the danger of private concentrations of power. A monopolist lacks the appropriate incentives, so the likelihood of a monopoly is a serious problem. On the other hand (and related to the point above), government participation in the market can lead to rentseeking behavior on the part of companies vying for the government's favor.

These familiar arguments play out in distinctive ways in the spectrum context, and specifically in the context of commons advocates' proposals for abundant networks. Much of this distinctiveness flows from the nature of the protocols that will define the network. I begin, then, with some relevant features of those protocols specifically, and protocols more generally.

109 To be clear, for purposes of this Part, I am assuming that the commons advocates are correct in suggesting both that the engineering of these networks will work as planned and that users will value these networks and thus will want to use them. In Part IV.B, I will address the question whether these networks will be as successful as planned, and the significance of the answer to this question. 


\section{A. Protocols and Lobbying}

Any protocol entails some limitations and encodes some technological choices. This is a function of having a protocol. If we are going to have truly open access (where anyone can transmit as she pleases), then there is no need for any limiting protocols. But once we decide to limit usage to those who follow certain rules, those limitations are embodied in the protocols we adopt.

The limitations entail choices that may benefit some services at the expense of others. To pick one obvious example, there may be power limits (as there are in the FCC's unlicensed bands and as there would be in abundant networks). ${ }^{110}$ These limits may make some services impossible (e.g., traditional broadcasting) and others difficult (e.g., point-to-point communications over long distances), while having no effect on, and therefore optimizing on that network, other forms of communication (e.g., multi-hop packetized transmissions, as in an abundant network).

As I discussed in Part I.B, the protocols for abundant networks will have to be designed with fairly tight specifications in order for the networks to work as planned, and they will have to cover a wide range of issues. ${ }^{111}$ One example arises from the fact that user devices must not only be capable of repeating but also must have minimum amounts of listening and quiet time (so that they actually serve as repeaters). ${ }^{112}$ How long and how frequent would the periods have to be during which a device was not trying to send or receive its own messages and thus was able to repeat others' messages? What sort of queuing would be required? Would the protocol include a requirement of listen-before-talk (requiring the user device to determine whether a neighbor is trying to send a message before sending its own), or listen-while-talk (requiring collision detection while the message is being sent), or some other means of collision avoidance? Under what, if any, circumstances could a device refuse to act as a repeater even though it was otherwise able to do so (e.g., if the battery was low)?

110 The FCC's current unlicensed bands are usable only by devices with certain power limits. See supra note 21 and accompanying text; supra note 48.

111 See Theodore S. Rappaport et al., Wireless Communications: Past Events and a Future Perspective, IEEE Comm. Mag., May 2002, at 148, 158 ("The multi-hopping technique increases the network capacity by spatial domain reuse of concurrent but physically separated multihop sessions in a large-scale network (i.e., reduces interference), conserves transmit energy resources, and increases the overall network throughput at the expense of a more complex routing-protocol design.").

112 See supra note 79 and accompanying text. 
These are only a few of the many choices that are entailed in the selection of protocols for an abundant network. There are also questions of antenna design, standards and techniques for error correction, and strategies to overcome signal propagation effects, to name just a few. ${ }^{113}$ The list of potential limits is long, and the choices are very complex. ${ }^{114}$ There are three major annual international conferences that focus on the design of these networks, each presenting papers that debate these questions and put forward competing approaches. ${ }^{115}$ Indeed, there are competing approaches on almost every issue relevant to the protocols for abundant networks. ${ }^{116}$ Deciding what needs to be included in a protocol, what approaches to take, and what the permissible ranges will be, is a daunting undertaking, involving dozens of choices.

Just as importantly, the choices underscore the fact that there are always tradeoffs, and there is no perfectly neutral platform. ${ }^{117}$ Each aspect of the protocols will create winners and losers among the kinds of devices that use the network and the services they offer. ${ }^{118}$ Some services will be easy to provide, others more difficult. ${ }^{119}$ And this will, in turn, mean that some companies' products and services will be winners and others will be losers. In mobile telephony, for example, the choice was first between analog standards, then between CDMA,

113 See Ian F. Akyildiz et al., A Survey on Sensor Networks, IEEE Comm. Mag., Aug. 2002 , at $102,105,108,111-13$ (describing some of numerous open research questions pertaining to design of low-power multihop mesh networks).

114 See Rappaport et al., supra note 111, at 158-60 (discussing many choices and tradeoffs entailed in abundant network design).

115 There is IEEE Infocom, see IEEE Infocom, IEEE Infocom: The Conference on Computer Communications, at http://www.ieee-infocom.org (last modified Mar. 12, 2003) (an annual joint conference of the IEEE computer and communications societies); MobiCom, see MobiCom, MobiCom: The ACM Annual International Conference on Mobile Computing and Networking, at http://turing.acm.org/sigs/sigmobile/mobicom/ (last visited Oct. 24, 2003) (annual conference on mobile computing and networking); and MobiHoc, see MobiHoc, MobiHoc: The ACM International Symposium on Mobile Ad Hoc Networking and Computing, http://sigmobile.org/mobihoc/ (last visited Oct. 24, 2003) (annual conference on mobile ad hoc networking and computing).

116 See Akyildiz et al., supra note 113.

117 See Hazlett, supra note 9, at 498 ("Disputes over standards underscore that 'open access' is only nominally open, and that scarcity continues to force trade-offs between radiated power levels, equipment cost, functionality"(e.g., mobile vs. fixed), bandwidth, and signal reliability.").

118 See Goodman, supra note 69 , at 76 ("[I]nherent in any agreement to abide by certain technical protocols is a bias towards a set of technical architectures that can be supported."); Rappaport et al., supra note 111, at 153-60 (discussing ways that different protocol designs enable, and optimize, different kinds of services).

119 Benkler, for example, envisions protocols that probably would not allow for realtime streaming video, but would optimize other forms of communication. See supra note 33 and accompanying text; supra note 89 and accompanying text. 
TDMA, ${ }^{120}$ and GSM, ${ }^{121}$ and now between various third-generation platforms. Not only the creators of various standards but also the companies that supply products and services based on those standards have a huge amount at stake in the choice between them. Even the more minimally specified standards for ultrawideband service produced winning and losing companies.

These aspects of protocols open the door to lobbying. ${ }^{122}$ The determination of which networking standards will be approved for an abundant network has great consequences for potential providers of products and services. Each potential provider has an interest in the controller of the network creating a standard that favors its own devices and services-ideally excluding (or at least not optimizing) the devices and services of other providers-so that the favored provider can have a privileged status, enabling it to charge supracompetitive prices. ${ }^{123}$ Each provider thus would want to lobby to gain a regulatory advantage. The incentives of potential service providers are the same whether the network regulator is the government or a private entity that controls spectrum; either way, a provider would want preferred status. A private network owner that competes with other private network owners, however, would have no reason to respond to lobbying by artificially limiting the vigor of competition among service providers. The network owner's interest in maximizing its profits gives it an incentive to choose the standard that consumers value most highly. ${ }^{124}$ The government, by contrast, lacks that incentive, as the rewards for government actors are not directly tied to market success. Other forms of currency become relevant, and lobbyists are adept at

120 TDMA stands for "time division multiple access."

121 GSM stands for "global system for mobile" communications.

122 See James B. Speta, A Vision of Internet Openness by Government Fiat, 96 Nw. U. L. Rev. 1553, 1573 (2002) (reviewing Lessig, The Future of Ideas, supra note 3) ("A secondary cost of creating spectrum commons is the residual government authority retained, creating opportunities for rent-seeking political behavior."). As Speta pointedly notes, Lessig acknowledges as much in the very book that argues for spectrum commons. See id.; Lessig, The Future of Ideas, supra note 3, at 74 ("It is an iron law of modern democracy that when you create a regulator, you create a target for influence, and when you create a target for influence, those in the best position to influence will train their efforts upon that target."); id. at 237 ("It is an iron law of politics that the organized beat the unorganized and that the vested have interests that get organized over the unknown.").

123 See Speta, supra note 122, at 1573 (noting that "incumbents are much more successful, over the long-run, at using law than markets to protect themselves").

124 Note that this applies to vertically integrated companies as well as those that are not vertically integrated. See infra text accompanying notes $153-54$. 
supplying them. The result is that the providers' attempts at lobbying are more likely to be successful. ${ }^{125}$

This has been borne out in practice. Not for nothing is the FCC called-as even an FCC chairman acknowledged-"Firmly Captured by Corporations." 126 The history of government spectrum policy is filled with examples of successful attempts at gaining preferential status via regulation. Broadcast licenses are perhaps the most notorious example with respect to spectrum allocation, but there are also examples involving standards. ${ }^{127}$ When the government has chosen standards to be used on a given set of frequencies, private entities have lobbied furiously to obtain a privileged position. ${ }^{128} \mathrm{~A}$ good recent example is the standard for digital television. There were competing standards, and the companies involved devoted huge lobbying resources to persuading the FCC to choose their standard and not that of their competitors. ${ }^{129}$ Even after the creators of the competing standards converged on a shared standard, the battles did not end: A new battle arose over the question of how specific the standard would be. Television manufacturers wanted the standard to cover a broad array of attributes, and with some specificity (i.e., narrow permissible ranges within those attributes), which would have had the effect of protecting their market from encroachment by computer manufacturers. The computer industry, meanwhile, pushed for a minimally specified standard that would provide greater flexibility, in the hope that this would allow them to make monitors that would work for both computers and

125 See Speta, supra note 122, at 1571 (arguing that "both government funding and government regulation are subject to capture that itself is likely to impede innovation more than markets would").

126 Reed E. Hundt, The Progressive Way, Speech at the Center for National Policy (May 6,1996 ), available at http://www.benton.org/Policy/TV/rhundt_ progressive.html.

127 See Hazlett, supra note 7, at 166-71 (noting that incumbent broadcasters sought, and obtained, preferred status and barriers to entry via regulation). Indeed, Lessig acknowledges this point about the power of broadcast incumbents (and incumbents more generally). See Lessig, The Future of Ideas, supra note 3, at 74 ("[C]ommercial broadcastersNBC and CBS in particular-were effective in getting the government to allocate spectrum according to their view of how spectrum should be used."); see also supra note 122 (noting Lessig's stated concerns about power of vested interests).

128 See Timothy F. Bresnahan, New Modes of Competition: Implications for the Future Structure of the Computer Industry, in Competition, Innovation and the Microsoft Monopoly: Antitrust in the Digital Marketplace 155, 200-01 (Jeffrey A. Eisenach \& Thomas M. Lenard eds., 1999) ("The information needed to decide on the appropriate technological direction is very difficult to understand, and key parts of the information are proprietary. Rather than being secret, the proprietary parts are spin controlled by interested parties. These are bad conditions for collective decision making; the individual decision with money on the table is the best option.").

129 See Benjamin et al., supra note 4, at 340. For a description of the digital television battles, see generally Joel Brinkley, Defining Vision: The Battle for the Future of Television (1997). 
television. ${ }^{130}$ Each side, in other words, pressured the government to create a standard that would enhance its competitive position. The FCC decided to try to devise a standard that would have the minimum specification necessary to ensure that digital television would work as planned, but it found that determining that level of specificity was hard to do-especially as the dueling parties did not agree on the identity of the essential categories of specifications.

Indeed, politically powerful players might push for not only a highly specified standard but also a short (and unnecessarily constricted) list of authorized providers, on the theory that the government would choose entities for this list not on the basis of formal payments (as we would expect a private firm to do), but instead based on influence. That is, rather than auction a given benefit (such as the right to sell user devices) to the highest bidder, the government might choose its beneficiaries through a process in which no direct compensation is paid. If so, companies will have an incentive to make private bids for the benefits, in the form of whatever currency the choosing government entity prefers-campaign contributions, in-kind contributions, whatever. The revenues foregone by the government become rents that bidders seek, and those bidders will confer some of these rents on the government in order to gain the preferred position. This has long been the case with spectrum allocations that the government distributes gratis: The government does not receive monetary contributions, but instead in-kind contributions from its grateful licensees. ${ }^{131}$ And there is little reason to expect otherwise here. ${ }^{132}$ Significantly, this pattern also results in ossification of the network, because government beneficiaries will have an incentive to entrench themselves, and the rents they receive will help them to do so. ${ }^{133}$

130 See Advanced Television Systems and Their Impact Upon the Existing Television Broadcast Service, 11 F.C.C.R. 17,771, TI 4-19 (1996).

131 See, e.g., Gretchen Craft Rubin, Quid Pro Quo: What Broadcasters Really Want, 66 Geo. Wash. L. Rev. 686, 688 (1998) (reviewing A Review of Rationales \& Rationalizations: Regulating the Electronic Media (Robert Corn-Revere ed., 1997)). Note that this is not a problem that is limited to one governmental entity. The FCC has often acted at the behest of powerful rent-seeking groups, and Congress has been even worse. See Benjamin et al., supra note 4, at 325-67; Benjamin, supra note 6, at 16-17 (noting that incumbent broadcasters enjoyed greater success in Congress than in FCC in their battle against low-power radio); Rubin, supra, at 688 .

132 Note that this would also apply to the potential continuation of a company's status as a chosen supplier: The beneficiary would have an incentive to maintain its privileged position, and the government would lack a profit incentive to auction the position to the highest bidder.

133 This possibility of entrenchment is not merely a matter of theory: On many occasions in spectrum policy, incumbents have been able to forestall planned changes in spectrum use. See Benjamin, supra note 6 , at 70-71. Broadcast television provides a vivid example. Broadcasters (who had been given their spectrum gratis and recognized that they 
The potential for lobbying and rent-seeking is greatest in the context of a single government-controlled abundant network, but it arises whenever the government controls a network (even if others are privately controlled). The more control the government has, the greater the payoff for favored providers. And, from the perspective of such providers, having a preferred position on one network among many is still preferable to having no preferred position at all.

\section{B. Benefits of Private Competition}

The previous section highlights that there can be competition not only within protocols (i.e., among devices complying with a given set of protocols) but also among protocols (because different protocols will optimize different uses and thus will offer different options to device manufacturers and users). Commons advocates frequently extol the benefits of competition, but the competition on which they focus occurs only in the space that has been created by a set of protocols after they have been chosen. ${ }^{134}$

Competition among protocols-or any platforms-imposes significant costs if we are going to end up with a single standard in the end, as the resources spent on the failed standards could have been spent on the successful ones. In particular, if a given standard is better than all the others, and will not be improved in the course of competition, then competition among several standards is a deadweight loss: Firms will spend resources on developing (and users will spend time familiarizing themselves with) a bunch of inferior standards that will

would not be compensated if some of "their" spectrum were transferred to another use) successfully thwarted the transfer of spectrum to land mobile use in the 1980s by arguing for high-definition television. In 2006, they are supposed to surrender the extra spectrum allotment that each received for digital television (the original goal of high-definition television has morphed into the current digital-television scheme, see Benjamin et al., supra note 4, at 359-60), but no one expects that to happen. See Benjamin et al., supra note 34 , at 111; Jenna Greene, Digital TV a Remote Possibility, Legal Times, July 30, 2001, at 1 (quoting representative Ed Markey as saying, "There's no longer a soul in the industry who thinks the transition will be over by 2006.").

134 See Benkler, supra note 2, at 28 (suggesting wireless commons with competition among device manufacturers working within set of protocols). In his work on the Internet, Lessig has emphasized the benefits that come from competition on many different vertical layers. An article he wrote with Mark Lemley on the benefits of broadband competition notes the different layers of the Internet market and states that "we have no good way to know which layer in this chain of services will become the most crucial. Thus, multiplying the layers of competition provides a constant check on the dominance of any particular actor." Mark A. Lemley \& Lawrence Lessig, The End of End-to-End: Preserving the Architecture of the Internet in the Broadband Era, 48 UCLA L. Rev. 925, 942 (2001). Applying that principle here would seem to suggest competition among protocols. 
fade away. The resources spent on those weaker standards are wasted. ${ }^{135}$

More broadly, no matter how the market develops, or how much knowledge we have about standards, competition entails a broader set of inefficiencies. ${ }^{136}$ That is, there are still costs inherent in having different platforms. A device manufacturer, for example, will have to spend more resources making a given product compatible with five different standards than it would making it compatible with one. And if the devices using these different standards do not interconnect, ${ }^{137}$ users will either have to purchase services on all the platforms or forego communicating with some people.

The most significant of these costs arise only to the extent that the market in fact converges on a single standard. Insofar as competing protocols will exist, the resources spent developing, implementing, and using them are not wasted. But the market may indeed converge on a single standard, and in any event the costs inherent in competition will exist.

The conventional wisdom is that the benefits of competition outweigh its costs. In the case of protocols for abundant networks, the benefit-cost ratio favors competition even more than usual. That is because the benefits of competition are particularly great in an industry characterized by innovation and uncertainty about which is the best approach (i.e., set of protocols). ${ }^{138}$ The inefficiencies described above loom large insofar as we are confident both that the protocol chooser (whether public or private) can identify the best standard in advance and that the standard will not improve as a result

135 See Mark R. Patterson, Coercion, Deception, and Other Demand-Increasing Practices in Antitrust Law, 66 Antitrust L.J. 1, 74 n.323 (1997) (stating that "before [some] markets settle on a single winning product, there can be a period of competition among several products, which can result in considerable wasted investment by buyers in the eventual losing competitors").

136 See Robert P. Merges \& Richard R. Nelson, On the Complex Economics of Patent Scope, 90 Colum. L. Rev. 839, 870 (1990) (stating that "rivalrous inventive efforts generate a great deal of inefficiency").

137 See infra notes $207-12,220-22$ on the importance of interconnection, the possibility that companies will voluntarily interconnect, and the possibility of mandating it.

138 Note that there are different ways to define the "best" system. Is it one that optimizes the services that the greatest number of potential users would want? Should it focus on actual users of other wireless services? Should it take into account strength of preference (e.g., what if a relatively small percentage of users would strongly prefer one design, because it optimized their dream use, but a much higher percentage had a slight preference for a different design?)? The difficulties with defining "best" highlight the benefits of competition: With competing protocols, no central decisionmaker (whether public or private) has to answer those questions. Every entity can choose to utilize whatever metric it pleases. See also infra notes 201-19 and accompanying text (discussing likelihood of competing protocols remaining over time). 
of competition. If we can have confidence in both propositions, then competition holds little allure. With respect to abundant networks, however, it is difficult to know in advance which is the best system. That's why we have competition-to provide real-world feedback, and to spur innovation.

There is little reason to think that any single entity will be able to know in advance which is the best set of protocols to choose. ${ }^{139}$ The engineering is too complex, and the tradeoffs too numerous, for us to have confidence in a particular protocol-chooser. ${ }^{140}$ Multiple networks have the advantage of allowing for competition among standards and real-world trials. With competition among several networks, the market gains the most valuable kind of informationknowledge about what consumers actually want, and what actually works best when implemented on a massive scale. If there is only one network, there will be one set of protocols and we will never know if other protocols would be more desirable. If a number of abundant networks are created, however, different standards can compete, and users can choose among them. Engineers can see which protocols work as planned, and users can choose which features they value the most. And, as new protocols become available, they can more easily be introduced by a competitor. ${ }^{141}$

Relatedly, competition among network protocols also will likely produce greater innovation, or dynamic efficiency. ${ }^{142}$ As I noted above, studies have found that monopolies tend to retard innovation. ${ }^{143}$ The same is true with respect to networking standards. ${ }^{144}$ In

139 See supra notes $111-21$ and accompanying text.

140 See Bresnahan, supra note 128 , at 155,200 (noting that in standards race "it is extremely difficult to forecast the future. Brilliant people are about to invent a great many new things, which will interact in a complex system to determine the outcome. No one, and certainly no policymaking body, has the cognitive capacity or the knowledge to pick 'better."'); Dale N. Hatfield, The Current Status of Spectrum Management, in Balancing Policy Options in a Turbulent Telecommunications Market: A Report of the Seventeenth Annual Aspen Institute Conference on Telecommunications Policy 29, 41 (Robert M. Entman ed., 2003), available at http://www.aspeninst.org/AspenInstitute/files/ CCLIBRARYFILES/FILENAME/0000000137/balanceturbtelecom.pdf (noting difficulty for any decisionmaker of sorting through competing engineering studies).

141 See Michael L. Katz \& Carl Shapiro, Systems Competition and Network Effects, $8 \mathrm{~J}$. Econ. Persp. 93, 110 (1994) (noting that selecting single standard necessarily limits product variety by "prevent[ing] the development of promising but unique and incompatible new systems").

142 See Kenneth J. Arrow, Economic Welfare and the Allocation of Resources for Invention, in Essays in the Theory of Risk-Bearing 144, 156-60 (1971) (stating that competition is best catalyst for innovation); Langlois, supra note 104, at 217 (noting that competition among platforms creates "more possible entry points for innovation"); supra note 104.

143 See supra notes 102-04 and accompanying text.

144 See Weiser, supra note 102, at 585 ("In the Internet context in particular and the information industries more generally, standards competitions can often be procompetitive 
other words, a competitive wireless market is not only likely to produce valuable new services (such as abundant networks, if they are as wonderful as promised), but also a competitive market for abundant networks is likely to produce continuing innovation. ${ }^{145}$

This has been the case with respect to wireless telephony standards. The European Community's government standard-setting body selected a single standard (GSM) as the only permitted standard for European wireless telephony, whereas the FCC made no selection and instead allowed for a standards competition. The FCC's approach led to competition that is now widely regarded as having brought greater innovation (in the form of competing standards, most notably CDMA and TDMA), the benefits of which exceed the costs. ${ }^{146}$ Europe's approach had the advantage of ensuring compatibility from the start, but at the great cost of settling on an inferior standard. The same is true with respect to video game platforms. The fierce competition among the dueling standards-including Nintendo, Sega, Sony, and Microsoft-produced both static efficiency (in the form of falling prices) and dynamic efficiency (in the form of innovation). ${ }^{147}$ Indeed, such valuable competition is currently occurring with respect to wireless networking standards. Both private firms and private standardsetting bodies have rolled out innovative standards and upgraded

by increasing innovation in a manner that would not occur under cooperative efforts that settle on a lowest common denominator standard."); see also Robert J. Aiken \& John S. Cavallini, When Are Standards Too Much of a Good Thing? Will They Provide Interoperability for the National Information Infrastructure?, in Standards Policy for Information Infrastructure 253, 261 (Brian Kahin \& Janet Abbate eds., 1995) (stating that "the overzealous creation and use of [official] standards, either through formal standards processes or by government purchasing practices, poses the risk of impeding the introduction of necessary new technologies and services"); Lemley \& Lessig, supra note 134, at 942-46, 961 (discussing benefits of competition, and noting that "the empirical evidence suggests quite strongly that it is competition, not monopoly, that best spurs creativity").

145 It bears noting that Benkler treats having more than one abundant network as valuable. His stated concern is that private ownership will not produce this useful competition, because of the difficulty of assembling spectrum. See Benkler, supra note 1, at 363 (stating as drawback of private ownership that "the difficulty of assembling a broad swath of frequencies would render unlikely the initial development of more than one such band"). As I discussed in Part II.A, supra, however, the difficulty of assembling a broad swath of frequencies can be overcome via the simple measure of auctioning large swaths.

146 See Kathleen M.H. Wallman, The Role of Government in Telecommunications Standard-Setting, 8 CommLaw Conspectus 235, 246-47 (2000); Weiser, supra note 102, at 586; Rappaport et al., supra note 111, at 148-49, 151-53 (discussing "brilliant system concepts that ultimately failed" and eventual universal acceptance of CDMA).

147 Indeed, that is only a partial list of the major innovators in the video game market. See David S. Evans, The Antitrust Economics of Multi-Sided Platform Markets, 20 Yale J. on Reg. 325, 365 (2003) (noting that "[i]n the case of video games in the US, there was successive entry by Magnavox (1972), Atari (1975), Coleco (1976), Fairchild (1976), Mattel (1979), Nintendo (1985), Sega (1989), Sony (1995), and Microsoft (2001)"). On the benefits of this competition, see Weiser, supra note 102, at 587-89. 
them in response to competitive pressures, resulting in more and better choices for users. ${ }^{148}$

Competition also has the advantage of promoting greater product differentiation. ${ }^{149}$ The more networks there are, the more likely they are to respond to the desires of relatively small segments of the population. Maybe only ten or twenty percent of the population would want the capability to use their wireless networks in a particular way (say, having a multiuser real-time dissection of the latest episode of a favorite television show as it is airing). If there is a single protocol, and having the capability for a multiuser discussion would create significant tradeoffs, ${ }^{150}$ then that segment might find that its interest is not met. ${ }^{151}$ Or, even worse, maybe this small segment would have sufficient political and economic power to persuade the protocolchooser to select standards that optimize their preferred service, at the expense of services that would be more popular with less powerful groups. Having a single set of protocols encourages battles over those protocols (because the stakes are so high), and makes it more likely that less powerful groups will not have their interests attended to. But the more networks, the more likely that someone will cater to each niche preference in the way that it structures its protocols.

These advantages of competition are sufficiently great that, even assuming that there ultimately will be one network standard (and thus one network), there are still good reasons to have this standard chosen via competition. We will not know in advance whether abundant networks will converge on a single standard, and in any event the competition is likely to produce a better standard. As long as there is going to be a single controlling entity (either the government from the outset or the biggest network after the competition), we might well

148 The IEEE promulgated a number of different 802.11 standards (e.g., 802.11a, $802.11 \mathrm{~b}, 802.11 \mathrm{~g}$ ) in response both to user demand and changes in wireless technology. Meanwhile, private firms have continued to offer (and upgrade) their own standards. Airgo Networks, for example, has introduced a wireless networking standard that increases transport capacity via MIMO (multiple-input, multiple-output) antennas, and other companies are developing still other standards. See John Markoff, Start-Up Plans to Introduce Alternate Wi-Fi Technology, N.Y. Times, Aug. 18, 2003, at C2 (describing Airgo's offering and noting that other companies are planning their own new offerings).

149 See Langlois, supra note 104, at 217 (noting that competition among platforms allows for "experimenting with organizational and design alternatives").

150 And, of course, there are always tradeoffs. See supra notes 110-21 and accompanying text.

151 See Katz \& Shapiro, supra note 141 , at 110 (stating that "the primary cost of standardization is loss of variety: consumers have fewer differentiated products to pick from"); see also Joseph Farrell \& Garth Saloner, Standardization, Compatibility, and Innovation, 16 Rand J. Econ. 70, 71 (1985) (stating that "reduction in variety" is one of "important social costs" of standardization). 
prefer the competition option, because it would be more likely to produce the highest valued network. ${ }^{152}$

\section{Benefits of Private Control of Abundant Networks}

\section{Implementing and Updating Successful Protocols}

The previous Section discussed the benefits of competition, in light of the enormous technical complexity that is entailed in creating protocols for an abundant network, and the range of choices that is involved. These aspects of protocols also suggest reasons to choose private firms over government actors. That is, even absent competition, private ownership entails some advantages. Private firms, in addition to being better able to marshal the force of competition, are better suited than government actors to operate in an environment of rapidly changing technology. The engineering resources within the FCC, for example, are fairly small compared with those in the private sector, and private firms have no incentive to share their knowledge with government actors if they will not benefit by doing so. ${ }^{153}$

More importantly, private control presents particular advantages in terms of implementing and updating desired protocols. Designing a network that operates as planned is only part of the story. In addition to these technical matters are ones involving users' responses-do they flock to the network, do they use it as intended, do they like the

152 See Weiser, supra note 102 , at 585 (stating that "even if the industry structure will ultimately rely on a single standard, competition policy should still err on the proprietary side of the line, allowing rival standards to battle it out in the marketplace"); see also Michael L. Katz \& Carl Shapiro, Technology Adoption in the Presence of Network Externalities, 94 J. Pol. Econ. 822, 825, 838-39 (1986) (discussing question whether market chooses socially optimal standard).

153 According to Jeffrey Rohlfs:

[G]overnment setting of technical standards is often proposed, but government setting of standards involves a whole set of problems of its own. The most obvious problem is that public policymakers may be clueless about which is the best technology. The technological choice inherently involves uncertainties on the forefront of technical knowledge. Public policymakers do not generally have the high level of technical expertise required to evaluate such uncertainties. The problem is compounded, because the most knowledgeable persons (viz., those whose jobs are to develop the competing technologies) usually have incentives to deceive the policymakers-in particular, to exaggerate the strengths of their own technology and the weakness of the opposing technology. Because public policymakers lack sufficient knowledge, they may choose the wrong technology and get an important new industry off on the wrong foot.

Jeffrey H. Rohlfs, Bandwagon Effects in High-Technology Industries 49 (2001); see also Kalpana Srinivasan, FCC Knows It Doesn't Know, San Antonio Express-News, March 13, 2001, at 5E (noting concerns among FCC Commissioners about lack of engineering expertise in FCC, and finding that "[i]n the FCC division responsible for wireless matters, about 100 of the 315 employees are lawyers. Only 35 are engineers."); supra note 128 . 
services offered, would they prefer that other services be optimized for use on the network, etc. Moreover, over time the state of the art changes as new technologies become available. Consumer preferences also change, sometimes in response to technological changes and sometimes for other reasons. These facts pose great challenges for the creator of a network, as it must adopt protocols that not only will work but also will have features that users desire, and then must decide whether and how to update protocols as technology and/or consumer preferences change.

For purposes of this Part, I am assuming that an abundant network can work as planned. ${ }^{154}$ But that still leaves the questions of who has a greater incentive and ability to implement the most successful system, and who has a greater incentive and ability to make changes to the system as new possibilities arise. It makes a great deal of sense to ensure that whoever controls a given set of wireless frequencies has the ability and incentive to make the best choice at the outset and to change the use of those frequencies as circumstances warrant.

These considerations cut in favor of private ownership. As to incentives, the profit motive comes to the fore: A private owner's choice of the best system, and its modification of that system as new opportunities become available, will enhance its profitability; and the desire for profits is a strong stimulus. This is a basic precept of economic theory, and there is every reason to believe that the profit motive will have the same effect on spectrum usage that it has in other areas of economic activity. As to ability, a private owner can change its uses as quickly and frequently as it desires, subject only to those limitations imposed by the government or to which it agrees via contract. Assuming that the government gives private firms broad flexibility to create and modify networks as they see fit, a firm could adopt a protocol as quickly as its directors could meet. Private companies can and do change technologies and business models rapidly. Upgrades in cellular telephony and the embrace of wireless Internet access are only two of many examples. Simply stated, private firms would have every incentive to upgrade their networks to the most efficient use (so as to beat their competitors), and they would have the ability to do so quickly.

Government officials will never have the same incentives to find the most efficient solution. The profit motive is absent. Political

154 See supra note 109 and accompanying text. 
forces replace market forces as the relevant stimuli. ${ }^{155}$ This is a familiar point from political theory, but it bears noting here that, for government actors, upgrading a network simply means more work for the same pay.

As to ability, government officials generally will not have the same flexibility that private owners would have. Government agencies are subject to requirements of public deliberation. For example, the Government in the Sunshine Act prohibits multimember agencies like the FCC from meeting unless they give seven days' advance public notice and the meeting is held in public. ${ }^{156}$ Moreover, setting out protocols for a new network is the sort of significant agency action with prospective effect that would be subject to the requirements of notice-and-comment rulemaking. ${ }^{157}$ Such rulemaking requires a notice of the proposed rulemaking, an opportunity for interested parties to comment, and a final rule issued with a statement of its basis and purpose, but those requirements have been interpreted to require a fairly lengthy and exhaustive process. Such ossification of agency processes means that many decisions that seem straightforward take years to satisfy all the procedural hurdles. Most significant agency

155 See also supra notes $122-33$ and accompanying text (discussing rent-seeking behavior, government control, and entrenchment).

1565 U.S.C. $\S 552 \mathrm{~b}(\mathrm{e})(1)(2000)$; see also 5 U.S.C. $\S \S 552 \mathrm{~b}$ (c) \& (d)(1) (permitting agencies to close meetings, but only if majority of members vote to do so). Moreover, a meeting is defined as "deliberations of at least the number of individual agency members required to take action on behalf of the agency where such deliberations determine or result in the joint conduct or disposition of official agency business," so three members of the FCC cannot deliberate together unless they call a formal meeting (with advance notice, of course). 5 U.S.C. $\$ 552 \mathrm{~b}(\mathrm{a})(2)$. For criticism of these requirements, see Jim Rossi, Participation Run Amok: The Costs of Mass Participation for Deliberative Agency Decisionmaking, 92 Nw. U. L. Rev. 173, 230 (1997) (arguing that "[t]he Sunshine Act's requirements impair the ability of agency members to deliberate, adversely affect the establishment of agency agendas, and promote inefficient practices within agencies").

157 See 5 U.S.C. $\$ 551(4)$ (defining "rule"); 5 U.S.C. $\$ 553$ (setting out requirements for informal, or notice-and-comment, rulemaking); see also Jeffrey $\mathrm{H}$. Rohlfs \& J. Gregory Sidak, Exporting Telecommunications Regulation: The United States-Japan Negotiations on Interconnection Pricing, 43 Harv. Int'l L.J. 317, 352 (2002) (noting that "[t]he vast majority of the FCC's policy initiatives advance through the notice-and-comment process of the Administrative Procedure Act. With few exceptions, the agency does not announce major policy shifts through adjudication."). There are exceptions to the requirement of notice-and-comment rulemaking, but none would appear to apply here. See 5 U.S.C. $\S 553$ (b) (listing exceptions for interpretative rules, general statements of policy, rules of agency organization, and situations in which agency, for good cause, finds that rulemaking is impracticable); U.S. Tel. Ass'n v. FCC, 28 F.3d 1232, 1234 (D.C. Cir. 1994) (stating that standards are substantive rules requiring notice and comment, rather than policy statements, if agency intends to bind itself to particular legal policy positions); Tenn. Gas Pipeline v. FERC, 969 F.2d 1141, 1144 (D.C. Cir. 1992) (noting that good cause exception is limited to emergency situations). And the FCC seems to agree, as it has consistently employed notice-and-comment rulemaking in setting out standards for new networks. See infra note 159 and accompanying text. 
actions now require a few years (and thousands of person hours) to complete-and then the litigation begins. ${ }^{158}$ There is no reason to expect otherwise with respect to the adoption of protocols for abundant networks. The FCC decisionmaking process is therefore likely to be painfully slow, occupying many months. ${ }^{159}$

This disparity in flexibility between private and government actors is not carved in stone, of course. Congress could eliminate it by allowing the FCC (or some other government agency) to choose protocols for abundant networks without any procedural constraints. But such an action would be unattractive (not to mention unlikely). Private owners are constrained by the market, but government actors face no similar constraint. Procedural requirements supply constraints in the form of public-regarding obligations designed to increase transparency and accountability. ${ }^{160}$ Giving a set of government officials unconstrained authority seems difficult to defend, and it is not surprising that Congress has in fact never made such a grant.

Perhaps more realistic, and palatable, is Benkler's suggestion that the government provide by statute or regulation that all uses of spec-

158 See, e.g., Richard J. Pierce, Jr., The APA and Regulatory Reform, 10 Admin. L.J. 81, 82-83 (1996) ("There is a broad consensus among scholars that ossification of the rulemaking process is the largest single implementation problem today. The notice and comment rulemaking process requires an agency to commit at least five years and tens of thousands of staff hours to the process of issuing or amending a single major rule." (citations omitted)); see also Thomas O. McGarity, Some Thoughts on "Deossifying" the Rulemaking Process, 41 Duke L.J. 1385 (1992); Paul R. Verkuil, Rulemaking Ossification-A Modest Proposal, 47 Admin. L. Rev. 453 (1995).

159 As Rohlfs and Sidak note:

On any rule making of substantial importance, the FCC will publish a notice of proposed rule making (NPRM), which may be dozens of pages long. In response, interested parties file detailed comments and reply comments, often accompanied by expert affidavits of economists or engineers. . . Equipped with a voluminous public record, the FCC's staff then writes for the Commission a "report and order" that may run a hundred pages or more. . . . The report and order carefully footnotes arguments and factual propositions raised or challenged by commentators.

Rohlfs \& Sidak, supra note 157; see also ACLU v. FCC, 823 F.2d 1554, 1581 (D.C. Cir. 1987) ("Notice and comment rulemaking procedures obligate the FCC to respond to all significant comments, for 'the opportunity to comment is meaningless unless the agency responds to significant points raised by the public." (citations omitted)); Lisa Blumensaadt, Horizontal and Conglomerate Merger Conditions: An Interim Regulatory Approach for a Converged Environment, 8 CommLaw Conspectus 291, 307 (2000) (noting that "the FCC's public notice and comment rulemaking process is lengthy and can be cumbersome"); Hatfield, supra note 140, at 36 (noting that "major reallocations proceedings can take years to resolve").

160 See Richard B. Stewart, The Reformation of American Administrative Law, 88 Harv. L. Rev. 1669, 1669-76 (1975) (describing traditional means of cabining agency discretion, including agency conformance to "specific legislative directives," availability of judicial review, and application of "decisional procedures" designed to both ensure agency compliance with directives and facilitate judicial review). 
trum be reviewed every ten years. Thus Benkler suggests that, given the experimental nature of such a system, the government should create an abundant network but reconsider its decision after ten years. ${ }^{161}$ At such time, the government should be prepared to abandon its commons if the network fails to develop as hoped. ${ }^{162}$ Indeed, this is part of a larger plan of reconsideration for Benkler; he proposes that any auctioned spectrum rights be reevaluated after ten years to see if that spectrum would be better used as a governmentsponsored abundant network. ${ }^{163}$

This does not, however, provide for the same level of flexibility as a private firm would have. ${ }^{164}$ Most obviously, it does not allow for changes at anything other than the prescribed intervals, even if it is clear by year five or seven that an abundant commons has not developed as planned. Moreover, unless the review entails no deliberative process and is utterly unconstrained (in which case we are back to the problems identified above), it will take a fair amount of time and energy for such a review to occur in year ten. Even statutorily mandated periodic reviews can go on for years. Indeed, the FCC's biennial reviews of media regulations often drag on for more than two years after they are due, ${ }^{165}$ and the first triennial review of the AT\&T

161 Benkler, supra note 2 , at 35 .

162 Id.

163 Id. Of course, he assumes that the private rightsholder will not have created a privately-sponsored abundant network. See supra Part II.

164 Furthermore, it may inhibit investment incentives. If the government sells spectrum rights but reserves the right to reclaim the spectrum ten years later without compensating the rightsholders, the rightsholders' fear of uncompensated losses will limit their incentive to invest in the use of their spectrum. This is a familiar point from economic theory: Diminishing an occupant's expectation of long-term ownership also diminishes the occupant's willingness to make long-term investments. See Thomas G. Krattenmaker, The Telecommunications Act of 1996, 29 Conn. L. Rev. 123, 133-34, 153 (1996) (arguing that statutory right of renewal of radio and television licenses allows licensees to make "better long-term investments in programming and talent"). Indeed, the government recognized as much in deciding to give spectrum incumbents a very strong renewal expectancy. See Principles for Promoting the Efficient Use of Spectrum by Encouraging the Development of Secondary Markets, 15 F.C.C.R. 24,178, 920 (2000); Benjamin et al., supra note 4, at 111-12. That is, after the Telecommunications Act of 1996, incumbents know that their license will be renewed unless they commit "serious violations" of the Communications Act or the FCC's rules, or commit other violations "which, taken together, would constitute a pattern of abuse." 47 U.S.C. $\$ 309(\mathrm{k})(1)(2000)$.

165 See, e.g., 1998 Biennial Regulatory Review-Review of the Commission's Broadcast Ownership Rules and Other Rules Adopted Pursuant to Section 202 of the Telecommunications Act of 1996, 18 F.C.C.R. 3002 (2003) (taking actions as part of 1998 biennial review); 1998 Biennial Regulatory Review-47 C.F.R. Part 90-Private Land Mobile Radio Services, 17 F.C.C.R. 9830 (2002) (same). 
breakup spent so many years bouncing between courts and agencies that the planned succeeding triennial reviews never took place. ${ }^{166}$

The proposed ten-year reviews also do nothing to enable government actors to respond to changes in technology and/or consumer preferences. It is important not only that the government be able to change from government to private control and vice-versa, but also that government actors have the ability and incentive to update network standards. The proposed ten-year reviews leave the government in the same position as it would be in without such reviews: having to invoke cumbersome processes to make changes, and having little incentive to do so.

\section{Adjusting Spectrum Usage and Pricing Schemes}

One consistent development in wireless technology has been the decrease in the amount of spectrum that is required to send a given signal over the airwaves. ${ }^{167}$ Indeed, this is one of the key developments behind the push for abundant networks: Sophisticated engineering is permitting greater and greater data transfer rates over the same bandwidth, making abundant networks more feasible today than they were yesterday. ${ }^{168}$ And the progress is ongoing. ${ }^{169}$

If 100-megahertz abundant networks were created, and a few years later improved network designs allowed for abundant networks that had the same functionality but occupied only 20 megahertz, the benefits of updating the network design and freeing up 80 megahertz would be considerable. Those 80 megahertz could be used to provide valuable new services-perhaps services that abundant networks do

166 See Jerry A. Hausman et al., Does Bell Company Entry into Long-Distance Telecommunications Benefit Consumers?, 70 Antitrust L.J. 463, 466 (2002) (noting that parties to AT\&T divestiture agreed to triennial reviews, but "[b]ecause of various appeals to the D.C. Circuit and subsequent remands ... the first triennial review was not completed by either 1990 or 1993, when the next reviews were scheduled to take place. A second triennial review never happened.").

167 See supra note 32 and accompanying text.

168 Commons advocates seize on this progress; indeed, they rely on further developments in network design as enabling the creation of abundant networks. But their focus is on the advances that will have to occur in order for abundant networks to work. They fail to focus on the significance of the possibility that, after abundant networks are created, continued advances will enable abundant networks to occupy fewer megahertz.

169 Engineers are working on network designs that would allow 1 gbps network throughput over $25 \mathrm{MHz}$, rather than $100 \mathrm{MHz}$. The projects have been submitted in response to a Defense Advanced Research Projects Agency Advanced Technology Office request for proposals for networks with such capability. See Proposed Information Pamphlet for Defense Advanced Research Projects Agency Advanced Technology Office 7, http://www.eps.gov/EPSData/ODA/Synopses/4965/BAA03-31/BAA03-31\% 28PIP\%29FINAL.doc (last modified June 6, 2003) (listing metrics for throughput and spectral occupancy). 
not optimize, or four new competing abundant networks, or something else entirely. ${ }^{170}$

This possibility favors private control of the original 100megahertz swath. The problem for government actors is that they have little incentive to economize on spectrum, because they do not profit from such conservation. (And, as I noted above, the procedures entailed in changing the use of spectrum are cumbersome.) This is a familiar point from property theory; one of the main arguments for transferable spectrum rights is that they create an incentive for the rightsholders to use the most bandwidth-efficient technologies, because every bit of bandwidth they conserve in their service is bandwidth from which they can reap additional revenue by selling it to someone else for another service. ${ }^{171}$ Commentators have made this point with respect to unlicensed uses of spectrum, noting that unlicensed or otherwise shared spectrum creates no incentive for system

170 One might imagine that abundant networks could render spectrum so abundant as to be valueless. If so, opening up 80 megahertz for other uses would not have much value (although, even then, adding four 20-megahertz networks would enhance competition and thus have value). But the notion that abundant networks will so fully serve all our needs that there is no demand for other uses of spectrum is pretty far fetched. See infra notes 231-32 and accompanying text.

171 Promoting Efficient Use of Spectrum Through Elimination of Barriers to the Development of Secondary Markets, FCC 03-113 II 7-8 (2003) (report and order) (allowing most wireless radio licensees to lease spectrum usage rights to third parties, in furtherance of "spectrum policy under which licensees have much greater ability and incentive to make unused spectrum - whether by frequency bandwidth, geographic area, or time (or any combination thereof)_available to third parties"), http://hraunfoss.fcc.gov/edocs_public/ attachmatch/FCC-03-113A1.doc; Dale N. Hatfield, Perspectives on the Next Generation of Communications, Keynote Address at the Opening Plenary Session of the Vehicular Technology Conference (Sept. 26, 2000) (transcript available at http://www.fcc.gov/oet/ speeches/perspec_next_generation.doc) (stating that transferability of licenses will give "existing licensees a greater incentive to employ more spectrally efficient technologies since they could profit directly by leasing the additional spectrum for other uses"); Gregory L. Rosston \& Jeffrey S. Steinberg, Using Market-Based Spectrum Policy to Promote the Public Interest (FCC Office of Eng'g Tech., Working Paper, 1997), available at http:// www.fcc.gov/Bureaus/Engineering_Technology/Informal/spectrum.txt (stating that "flexibility increases users' incentives to expand spectrum capacity by enabling them to profit from investments in more efficient use of spectrum, either by using spectrum for additional purposes or by transferring the authorization to use part of the spectrum to a party that values it more highly").

The FCC has listed numerous benefits of auctions. See FCC Wireless Telecomm. Bureau, FCC Report to Congress on Spectrum Auctions 14 (1997) ("[T]he competitive bidding process provides incentives for licensees of spectrum to compete vigorously with existing services, develop innovative technologies, and provide improved products to realize expected earnings. In this way, awarding spectrum using competitive bidding aligns the licensees' interests with the public interest in efficient utilization of the spectrum."), available at http://wireless.fcc.gov/auctions/data/papersAndStudies/fc970353.pdf; id. at 2 ("The Commission's auctions program has demonstrated the ability to award licenses to productive users, to encourage the emergence of innovative firms and technologies, to generate valuable market information, and to raise revenues for the public."). 
designers to conserve bandwidth, and that private ownership would create such an incentive. ${ }^{172}$ And this is not just a matter of theory. Actors that do not have this profit motive-including both government entities and private licensees that are not permitted to transfer extra spectrum or use it for any other purpose-have a history of wasting spectrum. ${ }^{173}$ Given the incentive structure, such failures to conserve bandwidth should not surprise us. ${ }^{174}$

Closely related to the possibility of a network needing fewer megahertz as technology improves is a possibility raised by commons advocates: Even without changing protocols, the amount of spectrum necessary for an abundant network to work as planned would change from moment to moment. ${ }^{175}$ Allowing for varying usage requires flexibility among controllers of spectrum rights: Private owners can negotiate agreements in advance that allow for instantaneous sharing, or set up mechanisms for such sharing. The government could, similarly, set up such arrangements, but (a) again, greater procedural hurdles would lie in its path, and (b) it would have a limited incentive to go to the trouble. The flexibility advantages of private ownership discussed above thus apply here as well: A private owner has greater incentive and ability to create spectrum uses that allow for instantaneous changes in spectrum usage as a way of maximizing the value of spectrum.

One last example involves pricing. As I noted above, Benkler suggests that the cost of the technology behind abundant networks would be built into the price of the user device, and then everyone could transmit free of additional charges; indeed, no company would be in a position to charge anything for use of the network. ${ }^{176}$ This might be the most efficient form of pricing (and a private owner could utilize it), ${ }^{177}$ but of course it might not. ${ }^{178}$ Flexibility in pricing

172 See Rosston \& Steinberg, supra note 171 , at 7, 17 (stating that unlicensed and shared spectrum users have less incentive to use spectrum efficiently than would private holders of exclusive licenses); Satapathy \& Peha, supra note 46, at 5 (noting that unlicensed spectrum presents no incentive for system designers to conserve bandwidth).

173 See Benjamin, supra note 6, at 19-20, $97-98$ (discussing examples of wasting of spectrum, all by entities without economic incentive to do otherwise).

174 Note that this incentive structure exists even if surplus spectrum is sold at auction. Government actors do not reap those revenues, so they lack a profit incentive to find surplus spectrum. If the spectrum owner (here, the government) does not share in the bounty created by improvements in technology, its incentive to act on these improvements is dulled.

175 See Benkler, supra note 2, at 57-60. Benkler treats this as an argument against private property rights in spectrum, but, as the text indicates, it actually seems to support such rights.

176 See supra note 95 and accompanying text.

177 See supra note 97 and accompanying text. 
regimes would allow for experimentation in business models to determine the most efficient system and might well produce a more successful build-out of an abundant network. ${ }^{179}$ The profit motive gives

178 Benkler suggests that the unavailability of other pricing models would be an advantage of government control. See supra note 95 and accompanying text. He seems to believe that usage pricing necessitates a single gatekeeper for all messages, but usage pricing is not inconsistent with a distributed system. See supra note 93 and accompanying text. Benkler argues that usage pricing would not confer any advantages on an abundant network (because it could only slow things down), but in so asserting he fails to focus on the possible importance of such pricing for the successful development of the network in the first place.

179 Abundant networks depend on the operation of many user devices, as each user on the network creates additional capacity. If I want to send a message across the city but there is no nearby user who can repeat my signal, then my message may not reach its destination. It is crucial, then, to the success of an abundant network that user device manufacturers are enticed to enter the market, and that the network appeals to a wide range of users.

Price differentiation aids this cause in three ways. First, it allows companies to subsidize the up-front costs as a way of building out the network. In light of the importance of companies making, and people buying, the user devices, this can be crucial to the ease of building out a network, and therefore to the likelihood that it will be built out. Potential buyers of user devices are often hesitant to pay significant amounts of money to join a new network, and a common way for networks to overcome that is through subsidizing the price of the hardware via higher charges for usage. This is, for example, the pricing strategy that most cellular telephony, cable television, and direct broadcast satellite providers have used: They offer the initial equipment for low cost and recoup their losses on subsequent charges. This makes the build-out of a network more likely. See Michael Weingarten \& Bart Stuck, The Upcoming Revolution in Consumer Demand, Bus. Comm. Rev., May 1999, at 53-54 (noting that companies provided discounts on end-user products as way of encouraging build-out of their networks, and discussing why this is good strategy for build-out). Note that this also benefits those who do not have the funds available to pay the full costs up-front. That is, those with less money will benefit from a lower start up cost.

Second, and relatedly, pricing differentiation allows for the accommodation of the preferences of more users. If the only way to utilize an abundant network is to buy a $\$ 200$ user device, and then use it free of charge, those who would use such a device only rarely might not purchase one. Even if the network was fully built out and successful, some potential users who have the $\$ 200$ might nonetheless conclude that access to the network is worth only, say, $\$ 50$. If an owner could offer different packages (e.g., pay $\$ 200$ for the device and get your usage free, or pay only $\$ 10$ for the device but also pay $\$ 0.01$ per message you generate), then it could attract users who wanted to use the network only sparingly. See David Friedman, In Defense of Private Orderings, 13 Berkeley Tech. L.J. 1151,1169 (1998) ("The more flexible the pricing options, the easier it is for the seller to charge a high price to the high-volume, high-value user, and a low price to the low-volume, low-value user, capturing revenue from the former without losing sales to the latter."); Eli M. Noam, Beyond Liberalization II: The Impending Doom of Common Carriage, 18 Telecomm. Pol'y 435, 442-45 (1994) (noting advantages of differentiated pricing); Eli M. Noam, Will Universal Service and Common Carriage Survive the Telecommunications Act of 1996?, 97 Colum. L. Rev. 955, 967 (1997) (same).

Third, flexibility allows for greater capture of revenue via peak load pricing. That is, a company could charge more for transmissions at times of peak usage-which, notably, is how Noam's proposal of spot markets for access would operate, but not how the proposed government-created abundant networks would operate. This would allow the company to 
competitive firms an incentive to find the most efficient pricing regime, and the one most conducive to the successful deployment of the network. Government actors would lack a similar incentive.

\section{Concentration of Private Power}

The Sections above indicate that the benefits of competition are great, and that private ownership has several advantages over government regulation. But what if we can't have both private control and competition? That is, there is a significant potential disadvantage to private ownership of abundant networks: concentration of economic power leading to anticompetitive behavior. If the available spectrum is controlled by one entity, that entity may have an incentive to freeze out potential competitors as a way of capturing monopoly profits. The idea is that if, say, company $X$ controls the one slice of spectrum that is available for creating an abundant network, it may try to block other companies from gaining access to its network. Benkler articulates this as the fear that a vertically integrated, monopolist spectrum owner would want to manufacture all the user devices itself, rather than leaving room for competitors to sell them as well. ${ }^{180}$

It is not at all clear that a monopolist owner of spectrum would discriminate in the equipment market, however. There is a robust debate about the circumstances under which a vertically integrated entity that controls supply would have an incentive to harm potential competitors in related markets, and many commentators contend that no such incentive exists as long as the monopolist can capture the value of its monopoly in the primary market. ${ }^{181}$ Assuming, though, that a monopolist would have such an incentive, there is still little

reap more revenue from those willing to pay a higher price and thus enable it to charge lower prices at other times. See Noam, supra note 55.

180 See Benkler, supra note 1, at 363-64.

181 See, e.g., David Gilo, Retail Competition Percolating Through to Suppliers and the Use of Vertical Integration, Tying, and Vertical Restraints to Stop It, 20 Yale J. on Reg. 25, 43-54 (2003) (discussing this debate); Christopher S. Yoo, Vertical Integration and Media Regulation in the New Economy, 19 Yale J. on Reg. 171, 187-205 (2002) (same). There is disagreement, for example, about the degree to which cable Internet providers will have an incentive to prevent unaffiliated Internet service providers (ISPs) from providing Internet service to customers with cable modems. The argument is that cable Internet providers might not be able to capture all the value of their networks simply by renting out their cable lines, in large part because of fears about regulation of the prices they can charge for those lines, and that cable Internet providers might fear losing control over their network and thus want the control afforded by having an affiliated ISP. See Glenn A. Woroch, Open Access Rules and the Broadband Race, 2002 L. Rev. Mich. St. U.-Det. C.L. 719, 73441; Lemley \& Lessig, supra note 134, at 948-51. These arguments, though, would not apply to spectrum. Spectrum ownership rights presumably would entail control over the prices that the owners can charge, and the whole point of the algorithms for abundant networks is that there is nothing to fear from adding users (because each additional user adds capacity) 
reason for such discrimination to occur because such a monopoly can and should be avoided in the first place.

The government can, and should, auction enough spectrum rights to support five to ten abundant networks. As I noted above, there is no magic number of megahertz necessary for an abundant network. It could be 10 or 1000 or anything in between. But, as I also noted, 100 megahertz would allow for massive throughput (1 gigabit per second or more). ${ }^{182}$ One hundred megahertz is a big slice of frequencies. Fortunately, there are huge swaths of spectrum that are unutilized or underutilized. If spectrum rights were auctioned as private property, those swaths could be available for abundant (or other) networks.

A recent paper from the FCC's Office of Plans and Policy identified portions of spectrum that can easily be restructured. ${ }^{183}$ They limited themselves to big bands that are currently underutilized, are not allocated to broadcasting, are not set aside for governmental use, and are located in the "prime beachfront" of the spectrum-so designated because it is the frequency range that is currently most in demandcovering the 2700 megahertz from $300 \mathrm{MHz}$ to 3 gigahertz $(\mathrm{GHz}$ ) (or $3000 \mathrm{MHz}){ }^{184}$ Even with those limitations, the paper identified 438 megahertz that would be available and suitable for highly valued new services, and that we could expect would be devoted to such services if the owners had the flexibility to provide them. That alone would create room for several 100-megahertz-wide abundant networks.

Then there is the spectrum devoted to broadcast television. Nicholas Negroponte long ago noted that wireless frequencies are more appropriate for services that require mobility (such as telephony) than for services that rarely use it (such as broadcast tele-

and no reason to fear heavy users (because those users would not transmit at high enough power levels to create interference problems).

More generally, as long as the spectrum owner could gain its profit (whether supracompetitive or not) from its control over the spectrum, it would have little reason to try to monopolize the equipment market. A spectrum owner presumably would be able to capture all of its rents from its control over the spectrum, and thus should be happy to let other companies make the user devices. See Yoo, supra. In fact, having other companies make those devices could increase the market for the owner's spectrum, and thus increase its profits more quickly, and to a greater extent, than single-source supply would. See James B. Speta, Handicapping the Race for the Last Mile?: A Critique of Open Access Rules for Broadband Platforms, 17 Yale J. on Reg. 39, 80 (2000). Indeed, cellular service providers have generally followed this model, reaping their profits from the purchase of cellular time and letting other companies make the telephones that can access their spectrum.

182 Moreover, higher bit rates would be of limited use because the real difficulty with abundant networks of any size is the delay due to the many hops. See supra note 36 .

183 See Kwerel \& Williams, supra note 17, at 25.

184 See id. 
vision). ${ }^{185}$ Thomas Hazlett persuasively argues that society would be better off if we auctioned the spectrum used for broadcast television. ${ }^{186}$ Auctioning all spectrum currently devoted to broadcast television would easily fund the provision of multichannel (i.e., cable or satellite) service to the fifteen percent of households that lack it and still leave many billions of dollars left over for the public fisc. ${ }^{187}$ That would free up another 324 megahertz.

This does not even touch the spectrum above $3 \mathrm{GHz}$. Commons advocates have proposed abundant networks for frequencies in the upper part of the $5 \mathrm{GHz}$ band. ${ }^{188}$ This puts on the table another 3000 or so megahertz that would be suitable for many uses, including abundant networks. The frequencies between $3 \mathrm{GHz}$ and $6 \mathrm{GHz}$ are less heavily utilized than the frequencies below $3 \mathrm{GHz}$, and can more easily be restructured (and therefore auctioned). Most of the government's relatively mild steps toward spectrum flexibility, and its relatively few instances of restructuring existing services in order to make room for new ones, have generally occurred in the $3 \mathrm{GHz}$ to $6 \mathrm{GHz}$ range. ${ }^{189}$ The relatively free spectrum above $3 \mathrm{GHz}$ should thus yield hundreds more megahertz that could be auctioned.

Yet another big category is spectrum controlled by the military, which consists of hundreds of megahertz, much of which is rarely, if ever, utilized. The military has been reluctant to release much of this spectrum, for fear of losing it forever. ${ }^{190}$ As a result, there has been little use of huge swaths of spectrum. ${ }^{191}$ But the military can always

185 See Nicholas Negroponte, Being Digital 24 (1995) (identifying "Negroponte Switch" as idea that "the information currently coming through the ground (read, wires) will come in the future through the ether, and the reverse. Namely, what is in the air will go into the ground and what is in the ground will go into the air.").

186 See Thomas W. Hazlett, The U.S. Digital TV Transition: Time to Toss the Negroponte Switch 21-22 (AEI-Brookings Joint Ctr. for Regulatory Studies, Working Paper No. 01-15, 2001).

187 The FCC found that, in 2002, slightly more than eighty-five percent of households subscribed to multichannel video (principally cable and satellite). See Annual Assessment of the Status of Competition in the Market for Delivery of Video Programming, 17 F.C.C.R. 26,901, App.B (2002).

188 See Benkler, supra note 2 , at $76-77$.

189 Indeed, the government's creation of unlicensed spectrum (effectively a regulated spectrum commons) has been in the $5 \mathrm{GHz}$ range, specifically $5150-5350$ and $5725-5825$ $\mathrm{MHz}$. See U-NII Order, supra note 21. Unfortunately, this experiment with unlicensed spectrum has not had the success that its backers had hoped to achieve. See Buck, supra note 26, II 87; Hazlett, supra note 9, at 498-501; see also supra note 28.

190 See, e.g., Thomas Frank, A Failure to Communicate, Newsday, Dec. 8, 2002, at A6 (noting Defense Department's reluctance to give up any of its unused spectrum).

191 See, e.g., Glenn Bischoff, Gasping for Air, Wireless Rev., Mar. 1, 2002, at 50 (noting FCC Commissioner Kevin Martin's identification of broadcasters and Department of Defense as entities "sitting on large swaths of spectrum that are underutilized or not used at all"). 
obtain spectrum via eminent domain, and much quicker methods also are available. For instance, a recent paper by an engineer and an economist from the FCC suggested that the military could instantaneously reclaim spectrum it wanted to use via a beacon system that it would control. ${ }^{192}$ The military would send out a signal over its frequencies every few seconds, and the devices using those frequencies would not work if the military stopped sending this signal. ${ }^{193}$ The spectrum would thus be interruptible, but given the rarity of the military's use of most of its spectrum those interruptions likely would be few and far between. In this way, the system would be similar to interruptible electricity and interruptible gas, both of which are widely used for delivering services but allow for government preemption in an emergency. The upshot of all this is that, even short of a massive "big bang" auction (in which all spectrum rights would be available for sale as private property), the government could fairly easily make enough spectrum available to supply many networks, abundant or otherwise. ${ }^{194}$

All the arguments about the dangers of vertical integration rely on the existence of a monopoly or collusive oligopoly. ${ }^{195}$ But in this case there is no reason to leave ourselves in a position where any entity has such market power. There can be a bunch of available slices large enough to support an abundant network. And, given that supply, there is no reason to assume that this market will operate any differently from any other competitive market. We worry about vertical integration, and losing the benefits of competition more generally, only when a monopolist is present, and here there would be none.

But, a skeptic might ask, what if one company buys up all that spectrum? There is no more reason to expect such a development than there is to expect that one company will buy up all of Manhattan. It is simply too expensive, especially given the presence of so many bidders who will not want to be frozen out of the lucrative markets offered by abundant (and other) networks. Experience supports this

192 Mark M. Bykowsky \& Michael J. Marcus, Facilitating Spectrum Management Reform via Callable/Interruptible Spectrum (2002), available at http://intel.si.umich.edu/ tprc/papers/2002/147/SpectrumMgmtReform.pdf; see also Report of the FCC Spectrum Policy Task Force, supra note 16, at 20 (recommending that government allow access to underutilized spectrum on interruptible basis).

193 See Bykowsky \& Marcus, supra note 192, at 18 (explaining how beacon system would work).

194 See supra note 18 and accompanying text (discussing possibility of big bang auction).

195 See Richard A. Posner \& Frank H. Easterbrook, Antitrust 870 (2d ed. 1981); Michael H. Riordan \& Steven C. Salop, Evaluating Vertical Mergers: A Post-Chicago Approach, 63 Antitrust L.J. 513, 516-19 (1995); Sam Peltzman, Issues in Vertical Integration Policy, in Public Policy Toward Mergers 167, $169-70$ (J. Fred Weston \& Sam Peltzman eds., 1969) (discussing foreclosure of market to rivals). 
point. Right now a good deal of spectrum is available for sale via private auctions (i.e., by buying it from the current licensee). And yet no one entity owns more than a small fraction of the available spectrum. Even with free transferability of spectrum, no one can afford to buy even a significant portion of it. And there is no reason to believe that a private company would have more success at purchasing all the spectrum at public auction than at private auction.

Moreover, insofar as there is any danger of one party gaining control of too much spectrum, the government can easily prevent such concentration. Antitrust law would kick in if a company tried to buy up all the spectrum, or tried to collude with other spectrum owners (and remember that collusion becomes dramatically more difficult with each new owner added to the equation). But we need not stop at antitrust law. If we wanted a limit on concentration below what antitrust would prevent, the government could easily impose one. That is, the government could limit the amount of spectrum that any one entity could control. This is not mere theorizing: The government in fact imposed limits-"spectrum caps"-on the amount of spectrum in which any given mobile wireless licensee could have an attributable interest. ${ }^{196}$ These spectrum aggregation limits might not be necessary, but they should be sufficient, as they prevent a company from having an interest in entities that control more than a defined portion of the available spectrum. ${ }^{197}$ Indeed, the FCC abandoned its spectrum limits for mobile wireless licenses because it found that they were more restrictive than was necessary to prevent concentration. ${ }^{198}$ Spectrum caps are a straightforward and direct means of prohibiting any company from obtaining a dominant market position. ${ }^{199}$

196 See 2000 Biennial Regulatory Review-Spectrum Aggregation Limits for Commercial Mobile Radio Services, 67 Fed. Reg. 1626, III 1-2 (Jan. 14, 2002) (explaining aggregation limits and "attributable interest").

197 See Owen \& Rosston, supra note 42, at 212-13 (noting that spectrum caps could ensure competitive market structure, but adding that such caps may not be necessary in light of availability of standard antitrust enforcement).

1982000 Biennial Regulatory Review-Spectrum Aggregation Limits for Commercial Mobile Radio Services, 67 Fed. Reg. 1626, ๆT 18-34 (determining that spectrum caps were no longer necessary because of competitive nature of marketplace, and that caps were interfering with marketplace's creation of incentives regarding choice of technology).

199 As I mentioned in the text, spectrum aggregation limits should be sufficient to prevent one company from acquiring monopoly power. It bears noting, though, that there are additional tools in the policymaker's arsenal. For instance, the government could impose upon the owners of these big blocks of frequencies an obligation to take the highest bidder for any given service that it allows on its spectrum. So if, for example, an owner created an abundant network and let companies pay it royalties for the right to make user devices that would work on that spectrum, the owner could not refuse a company that offered to pay higher royalties than one of the manufacturers that the owner approved. 
A different possibility bears mentioning: That competition may exist in the beginning, but that network effects may result in a single entity having monopoly power. The notion is that, for some goods, their value to consumers increases to the extent that others use it.200 With respect to networks, a big part of the value of being on any given network is the possibility of communicating with others on that network. The fear is that this might lead to market dominance by a single player. ${ }^{201}$ If one network has a large market share and does not allow its competitors to interconnect, then it might become a monopolist: New users (and existing users of its competitors) will join the big network, because it has more users and thus more value, and the process will continue until the big network controls virtually all the market. ${ }^{202}$

Alternatively, the government could sell spectrum to "band managers" who would act as brokers of the spectrum but would not be affiliated with any of the companies that actually provided services over it. See, e.g., Service Rules for 746-764 and 776-794 MHz Bands, 15 F.C.C.R. 5299 (2000) (setting out plan for band managers for certain frequencies); Implementation of Sections 309(j) and 337 of the Communications Act of 1934 as Amended, 16 F.C.C.R. 6803 (2000) (same). That is, the government would hold an auction for one or more bands, but would impose limits on the winning bidders-chief among them that the winning bidder could sell spectrum rights to companies that wanted to provide services but would not be allowed to provide those services itself.

This should eliminate any danger of anticompetitive behavior, but if the government wanted to add a level of assurance it could explicitly prohibit the band manager from discriminating among service providers. See, e.g., 47 C.F.R. $\$ 27.603$ (2002) ("A Guard Band Manager may not engage in unjust or unreasonable discrimination among spectrum users and may not unreasonably deny prospective spectrum users access to the Guard Band Manager's licensed spectrum."); Service Rules for 746-764 and 776-794 MHz Bands, 15 F.C.C.R. 5299, II 63-67 (2000) (suggesting mechanisms by which it can ensure "fair and nondiscriminatory access" to spectrum controlled by band managers).

Band managers thus represent a mechanism to preserve the main benefits of private ownership - the profit incentive to put spectrum to its most valued and efficient use combined with great flexibility in changing users and services-while also ensuring nondiscriminatory access for potential service providers. That said, the limitation on affiliation with service providers limits the revenue models available to band managers and thus may mitigate the profit motive and its attendant advantages. See Rosston, supra note 47, at 11-13 (discussing problems that FCC has faced with incentives for band managers). It also increases transaction costs insofar as a spectrum owner would be inclined to use some of its spectrum for its own purposes but would be prohibited from doing so. And utilizing band managers seems unnecessary in light of the likelihood of meaningful competition; even without band managers, there is little reason to expect discrimination against unaffiliated providers. But this system would prevent abuses arising from vertical integration by preventing vertical integration in the first place.

200 See Mark A. Lemley \& David McGowan, Legal Implications of Network Effects, 86 Cal. L. Rev. 479, 483 (1998) ("[A] network effect exists where purchasers find a good more valuable as additional purchasers buy the same good.").

201 See Katz \& Shapiro, supra note 141.

202 As Gerald Faulhaber explains it,

[I]f a network industry is dominated by a large provider, that provider could refuse interoperability, driving its competitors' customers toward its larger customer base and eventually (near-) monopolizing the industry. This phenomenon is colloquially referred to as the market "tips" in favor of the largest 
There are a number of reasons why network effects should not produce a monopoly in the context of abundant networks. One problem with this argument is that it assumes little differentiation among network providers. Total domination by one firm is unlikely to arise if networks offer differing services. If some consumers particularly value the services offered on each of several networks, then we would expect that each network would retain those customers. Having many different network providers increases both the probability of some networks providing distinctive services and the incentives for networks to do so. It is a smart business strategy for a network to offer its users capabilities that their competitors cannot match. Differentiation increases the chances of a network becoming a major player, and it reduces the chances of it losing its user base; consumers who value those services will likely remain with the network even if its competitor has more customers.

Moreover, even without these incentives we should expect that networks will have different capabilities. Separate from the desire to differentiate themselves for reasons of preserving market share, at least some networks are likely to choose standards that differ from others' standards, either because they believe their standard will work better or because the creator of the standard will not license it to them (e.g., if the creator has an exclusive licensing arrangement with another network provider). The relevance of this point is that different standards will have different properties. As I noted in Part III.A, there are lots of choices that lead to differences in protocols that impact the sorts of communications that a given set of protocols optimizes. These choices entail tradeoffs, making some forms of communication easier and others more difficult. ${ }^{203}$ All the major wireless

provider. "Tipping" occurs when a single provider reaches a critical mass of customers that are so attractive to others that competitors must inevitably shrink, in the absence of interoperation.

Gerald R. Faulhaber, Network Effects and Merger Analysis: Instant Messaging and the AOL-Time Warner Case, 26 Telecomm. Pol'y 311, 316 (2002). Note that the network effects would flow from the popularity of the network, not the mere fact of ownership of the spectrum. Property rights in spectrum could and should result in hundreds of available megahertz, so the fact of ownership would not pave the way for market dominance. Any dominance would flow from the desirability of a particular application that operated over the airwaves. See supra notes $182-95$ and accompanying text.

203 This is borne out by current events. Right now there are many different wireless networking standards, each with its own properties. Two leading wireless networking protocols, for example, are Wi-Fi and Bluetooth. Wi-Fi allows for greater distance between wireless devices, and greater download speeds, but at the cost of greater power consumption. See, e.g., Ken Noblitt, A Comparison of Bluetooth and IEEE 802.11, at http:// www.btdesigner.com/pdfs/KenNoblittComparison.pdf (last visited Oct. 19, 2003); The Kerton Group, A Businessman's Comparison of Bluetooth and Wi-Fi (802.11b) (2001), available at http://www.kerton.com/papers/bluetooth-wifi.pdf. Bluetooth thus might be 
networking standards have their own advantages and disadvantages. ${ }^{204}$ We should similarly expect that different abundant networks will have different protocols, with their own tradeoffs; and these protocols probably will optimize different kinds of uses.

The differing capabilities of different protocols should ensure the viability of competing networks. If users value a function that is optimized on a given network and provided less successfully on other networks, they will not lightly abandon that network. Even if a particular network has a majority of users among its customers, other networks can remain viable by responding to the desires of the market segment that values their services. Note that there are two possibilities: Consumers who value particular services may stay with their provider and no other, or they may choose to stay with their provider and join the big network. The difference between these two possibilities depends in part on the power of network effects, and in part on the differences between services. If the pull of being on the same network is very great for a particular user, but she still values the services available on a smaller network, she may choose to subscribe to both. This may sound strange-why would people pay twice to be on two different networks? But people do that with regularity. Users of text messaging still make telephone calls, because each service offers a different capability. Even when services are closer to being substitutesfor instance, text messaging and e-mail-people often stay on both networks. Indeed, even if the same service is involved, many consumers subscribe to more than one provider. Many consumers, for example, have Internet access through a home PC and a cellular phone or PDA. And most cellular phone users retain a landline phone as well. ${ }^{205}$ The point is that network effects may lead some to abandon their original provider for the biggest one, but others will

better for uses involving short-distance communications without access to a backup power source, whereas Wi-Fi might work better for longer-distance communications. See Michelle Man, Bluetooth and Wi-Fi 8-11 (2000), available at http://www.socketcom.com/ pdf/TechBriefWireless.pdf. These sorts of differences are typical.

204 See, e.g., Kenneth R. Carter et al., Unlicensed and Unshackled: A Joint OSP-OET White Paper on Unlicensed Devices and Their Regulatory Issues (FCC Office of Strategic Planning \& Office of Eng'g Tech., Working Paper No. 39, 2003) (comparing Bluetooth, Wi$\mathrm{Fi}$, and Home RF, and noting that each has different tradeoffs in terms of power versus speed and in terms of speed versus effective range), available at http:/ www.socketcom.comhraunfoss.fcc.gov/edocs_public/attachmatch/doc-234741 A1.pdf; Man, supra note 203, at 2 (comparing characteristics of Wireless Personal Area Networks (such as Bluetooth), Wireless Local Area Networks (such as Wi-Fi), Wireless Wide Area Networks (such as CDMA), Wireless Metropolitan Area Networks (such as Sprint fixed wireless), and Wireless Global Area Networks (such as GlobalStar)).

205 See FCC, Report and Order on Remand and Further Notice of Proposed Rulemaking: In the Matter of Review of the Section 251 Unbundling Obligations of Incumbent Local Exchange Carriers, 30 Communications Reg. (P\&F) 1 (Aug. 21, 2003) 
stay with their provider, either alone or in conjunction with a subscription to the biggest one..$^{206}$

There are other reasons to doubt that network effects will produce a monopoly. Network effects will result in monopoly only if the biggest provider denies interconnection to its competitors. In a competitive market, however, firms will want to interconnect, because it will be in their interest: A service provider that interconnects with another provider offers its customers more value-it offers them more people with whom they can interact. ${ }^{207}$ The enhanced value created by a bigger network leads providers to interconnect. ${ }^{208}$

(noting that only about three to five percent of wireless telephony subscribers use their service to replace their traditional residential landline service), WL 22175730 Il 445.

206 See Katz \& Shapiro, supra note 141, at 106 ("Consumer heterogeneity and product differentiation tend to limit tipping and sustain multiple networks. If the rival systems have distinct features sought by certain consumers, two or more systems may be able to survive by catering to consumers who care more about product attributes than network size. Here, market equilibrium with multiple incompatible products reflects the social value of variety."); S.J. Liebowitz \& Stephen E. Margolis, Should Technology Choice Be a Concern of Antitrust Policy?, 9 Harv. J.L. \& Tech. 283, 292 (1996) ("Where there are differences in preferences regarding alternative standards, coexistence of standards is a likely outcome."); Willow A. Sheremata, Barriers to Innovation: A Monopoly, Network Externalities, and the Speed of Innovation, 42 Antitrust Bull. 937, 966 (1997) (arguing that service differentiation can overcome advantage of strong network effect); Weiser, supra note 102, at 575 ("In markets where the critical mass is small enough to accommodate multiple providers of a particular product or service, multiple firms will compete at the platform level, as they currently do in the market for video game consoles and cell phones. Moreover, it is quite clear that consumers' demand for variety can compensate for a lack of a strong network effect.").

207 This raises an obvious question: Can there be interconnection between different abundant networks? As I noted above, they probably will have different protocols and will optimize different functions, so it might seem that there could be no interconnection. But interconnection is possible, because abundant networks would use packet-based transmissions with a network standard superimposed on them. The networking standard would be at a higher layer of the protocol stack, allowing for interconnection of the packets at a lower layer. See Kevin Werbach, A Layered Model for Internet Policy, 1 J. Telecomms. \& High Tech. L. 37, 58-64 (2002) (discussing layers of protocol stack); see also Akyildiz et al., supra note 113, at 104-14 (same). This is not a matter of theory. The desire for interconnection of packet-based systems has led to the successful development of initiatives to achieve this purpose, such as the Multiprotocol Label Switching initiative of the Internet Engineering Task Force. See Multiprotocol Label Switching, at http://www.ietf.org/ html.charters/mpls-charter.html (last modified Oct. 22, 2003).

208 See Gerald R. Faulhaber, Bottlenecks and Bandwagons: Access Policy in the New Telecommunications, in Handbook of Telecommunications Economics (Ingo Vogelsang \& Martin Cave eds.) (forthcoming 2004) (manuscript at 10), http://rider.wharton.upenn.edu/ - faulhabe/Bottlenecks\%20and\%20Bandwagons.pdf. Faulhaber notes that, in a competitive market, interconnection is the norm:

Is it likely that only some (or even none) of the market participants will interconnect in equilibrium? No; if two such firms interconnect, they will both offer their customers a higher value than the remaining non-interconnecting firms. These two firms will be in the enviable position of being able to charge higher prices and attracting customers from the non-interconnecting firms! In this 
A network has an incentive to deny interconnection only if it has managed to amass a market share greater than fifty percent, or failing that a market share near fifty percent and much smaller competitors that have difficulty reaching interconnection agreements among themselves. ${ }^{209}$ This is because, absent high costs of reaching interconnection agreements, those smaller competitors will likely agree among themselves to interconnect and thereby create a network with more users than the biggest provider has; the biggest provider will then find that it offers less value to its customers (unless it agrees to interconnect), because its customers will have access to a smaller network. ${ }^{210}$

Denial of interconnection is the exception, not the rule: Generally, a number of providers offer a service and none gains dominance, so none has an interest in denying interconnection. That is how e-mail networks have worked, and how the Internet backbone market has worked. ${ }^{211}$ In the context of abundant networks, with hundreds of megahertz sold at the same time and many different networks being created as a result, there is little reason to expect that any one net-

case, an interconnection arrangement helps each firm grow and increases its profitability. Non-interconnecting firms face a choice of interconnecting with the other firms or losing their customers to the more valuable interconnected network. In this case, the only stable outcome (that is, the market equilibrium) is for all firms to interconnect.

Id.

209 Id. at 11. Faulhaber suggests two additional requirements for a market leader to adopt a policy of denying interconnection: "The network effect must be strong, so that switching to the largest provider adds substantial value for customers. [And c]ustomer switching costs ('stickiness') must be low, so that switching to the largest provider is not too costly for customers." Id.

210 See id. at 10-13.

211 See Michael Kende, The Digital Handshake: Connecting Internet Backbones 15-16 (FCC Office of Plans \& Pol'y, Working Paper No. 32, 2000) (noting that, in absence of dominant provider, we would expect interconnection, and that this is exactly what has happened in Internet backbone market), available at http://www.fcc.gov/Bureaus/OPP/ working_papers/oppwp32.pdf; Patrick D. Curran, Standard-Setting Organizations: Patents, Price Fixing, and Per Se Legality, 70 U. Chi. L. Rev. 983, 983, passim (2003) (noting that competing providers often want interoperability).

It bears noting that the MCI-WorldCom merger, and the proposed MCI/WorldComSprint merger, raised concerns among antitrust regulators that the merged entity would have a dominant market position that might lead that market to tip toward monopoly. See James B. Speta, A Common Carrier Approach to Internet Interconnection, 54 Fed. Comm. L.J. 225, 226-27, 231-32 (2002); Marius Schwartz, Competitor Cooperation and Exclusion in Communications Industries, in E-Commerce Antitrust \& Trade Practices: Practical Strategies for Doing Business on the Web 41, 48 (2001). The government responded by requiring the divestiture of $\mathrm{MCI}$ 's backbone. This highlights the fact that, if one service provider does attempt to gain dominance and then deny interconnection, the government is able to respond. Ordinary antitrust law gives the government sufficient tools at its disposal. See A. Douglas Melamed, Network Industries and Antitrust, 23 Harv. J.L. \& Pub. Pol'y 147, 157 (1999) (stating that antitrust enforcement is available as means of eliminating anticompetitive behavior in network industries (as well as nonnetwork industries)). 
work will achieve sufficient market share to make denial of interconnection an attractive option. ${ }^{212}$

Let's assume, though, that, for whatever reason, one network does gain almost all the subscribers. Imagine that, whether because of network effects, the failure of competing networks to offer protocols with different capabilities, or the disinterest of consumers in sticking with networks that offer those capabilities, one company does become a monopolist. There is still no good reason why it should remain so.

First, its dominance may be short-lived. A number of commentators argue that where the rapidly changing technological world produces monopolists, they will produce serial monopolists. ${ }^{213}$ One person or company develops a product or service that people value highly, and consumers flock to it. It becomes dominant. But then

212 The most famous example of denial of interconnection-AT\&T's-differs because it involves a complementary good, and it was the complementary good that empowered AT\&T. The company successfully employed denial of interconnection as a strategy only when it had a complementary good-long distance service-to which its competitors did not have access (because AT\&T had patents on the technology for long distance). See Peter W. Huber et al., Federal Telecommunications Law 11-17 (2d ed. 1999).

The most visible recent example of a firm resisting interconnection was AOL's popular instant-messaging (IM) service. As the FCC noted, however, AOL was indeed the dominant player in the market, with a clear majority of the users. See Time Warner Inc., 16 F.C.C.R. 6547, II 160 (2001) (stating that " $\mathrm{AOL}$ has a mass of users . . that is several times larger than any other provider's and is larger than all other providers' combined"); id. I 129 (stating that "AOL, by any measure described in the record, is the dominant IM provider in America"). Thus its hesitation to interconnect was not surprising. It also bears noting that the FCC ordered AOL to interconnect its instant messaging with competitors as a condition of its merger with Time Warner. Id. II 325; see also infra notes 221-22 and accompanying text (discussing mandatory interconnection).

213 See, e.g., David S. Evans \& Richard Schmalensee, Some Economic Aspects of Antitrust Analysis in Dynamically Competitive Industries 12 (Nat'l Bureaus of Econ. Research, Working Paper No. W8268, 2001) ("[I]n many high-technology industries there are multiple, sequential races for market leadership. Major innovations occur repeatedly, and switching costs and lock-in do not prevent displacement of category leaders by better products. . . . It is not atypical for a fringe firm that invests heavily to displace the leader by leapfrogging the leader's technology."), available at http://papers.nber.org/papers/ w8268.pdf; see also John E. Lopatka \& William H. Page, Devising a Microsoft Remedy that Serves Consumers, 9 Geo. Mason L. Rev. 691, 706 (2001). Lopatka \& Page note:

A competitive market characterized by network effects is likely to exhibit a pattern of serial monopoly, with the winner in one period either giving way in the next period to another supplier with a better product or retaining its position by introducing a product better than the one developed by its competitors.

Id.; see also Howard A. Shelanski \& J. Gregory Sidak, Antitrust Divestiture in Network Industries, 68 U. Chi. L. Rev. 1, 10-11 (2001) (stating that "firms compete through innovation for temporary market dominance, from which they may be displaced by the next wave of product advancements"); Stan J. Liebowitz \& Stephen E. Margolis, Winners, Losers and Microsoft: Competition and Antitrust in High Technology 10-11, 15-16 (1999) (arguing that monopoly in high-technology industries is transitory). But see Gerald R. Faulhaber, ACCESS $\neq$ ACCESS $_{1}+$ ACCESS $_{2}$, 2002 L. Rev. Mich. St. U.-Det. C.L. 677, 700-01 (arguing that case for serial monopoly is not yet proved). 
someone else develops a better product or service, and users leave their previous favorite for their new favorite; and so on. ${ }^{214}$ This may sound overly optimistic, but in fact a similar pattern has already occurred with a number of services. ${ }^{215}$ Pagers were a killer application until analog cellular came along, and that was a killer app until digital cellular. Visi-Calc was the dominant spreadsheet until Lotus introduced 1-2-3, and that was dominant until Excel came along. ${ }^{216}$ Similarly, Managing Your Money was the dominant personal finance software until Quicken displaced it. ${ }^{217}$

More generally, the problems discussed above for a single standard and for a monopolist apply here as well.218 Dominant providers tend to produce less innovation than their upstart rivals do. They tend not to modify their standard to accommodate newly developing market niches. And, in any event, no single standard can satisfy all market niches, so there is always room for new ones. The result is that new entrants can arise and thrive even in the face of a seemingly entrenched incumbent. ${ }^{219}$

214 See Stuart Minor Benjamin, Stepping into the Same River Twice: Rapidly Changing Facts and the Appellate Process, 78 Tex. L. Rev. 269, 296-97 (1999) (discussing this phenomenon).

215 See Timothy J. Muris, The FTC and the Law of Monopolization, 67 Antitrust L.J. 693, 721 (2000). Muris notes:

Although the strong network effects theory emphasizes the difficulty that even a superior technology has in replacing a "locked-in" one, evidence of change is everywhere. The 20 th century has produced a blizzard of such change, from prominent examples like the automobile replacing the horse and buggy to more simple ones, such as ballpoint replacing fountain pens. More recently, cassettes replaced eight-track tapes, compact discs replaced vinyl records, and video games have witnessed rapid change with Atari, Nintendo, Sony, Sega, and others vying to be the standard.

Id.

216 See Evans \& Schmalensee, supra note 213, at 21 (discussing these examples and similar examples in other fields, such as pharmaceuticals and handheld devices); Plugged into a New Millennium, InfoWorld, Oct. 26, 1998, at 9 (noting that Microsoft Excel displaced Lotus 1-2-3, which in turn displaced Visi-Calc).

217 See Muris, supra note 215, at 720-21; Evans \& Schmalensee, supra note 213, at 60. Word processing programs constitute another example. WordStar was the dominant word processing program until WordPerfect displaced it, and WordPerfect was eventually displaced by Word. See Muris, supra note 215, at 720-21; Evans \& Schmalensee, supra note 213 , at 21 .

218 See supra Part III.B.

219 Weiser notes that:

Even where an incumbent company establishes an early lead and installed base of users, new entrants still will often find a niche and be able to enter the market. To be sure, switching costs will often limit the new entrant's ability to attract customers, but unless the economies of scale give the incumbent an extraordinary cost advantage, the incumbent's natural tendency to exploit its installed base will create openings for new entrants.

Weiser, supra note 102 , at 587-88. 
Second, and more important, if policymakers conclude that a monopoly will not be transitory, there are remedies available. ${ }^{220}$ Most obviously, the government could mandate interconnection among networks. The government could require that all networks allow for interconnection with other networks (and, if necessary, that the dominant network license its protocol to other providers).221 Mandatory interconnection is a familiar tool in telecommunications law, and it avoids the problems created by monopolies. It eviscerates the leverage that a monopolist can assert, and allows for multiple providers to coexist. ${ }^{222}$ The availability of regulatory arrangements such as this means that more interventionist solutions are not necessary. Indeed, the government could require interconnection before a company gained a monopoly: In this way, the government could avoid the monopolization in the first place. Interconnection is not only a solution to the problems created by monopolists but also a means of eliminating the impact of network effects that would give rise to a monopolist. ${ }^{223}$

\section{E. Benefits of Government Control: The Value of a Free Network}

The discussion so far has indicated that there are costs to the government controlling an abundant network, benefits to having competition among abundant networks, and benefits to having that competition be carried out by private firms. But we have not squarely addressed the advantages of the government creating an abundant network.

Recall that there could be one or more government-controlled abundant networks in addition to privately controlled ones, or one or more government-controlled networks and no privately controlled ones. The latter possibility raises significant concerns about rentseeking and capture, and it raises the same sort of monopoly problems

220 See generally Melamed, supra note 211 (discussing availability of antitrust enforcement in context of industries subject to network effects).

221 On achieving interconnection with different protocols (thereby obviating need to license the most popular one), see supra note 207. Phil Weiser notes that a dominant network can be toppled from its position by removing intellectual property protections against reverse engineering. See Weiser, supra note 102, at 591.

222 See Speta, supra note 211, at 252, 264-67.

223 More drastic options are available to the government, but it seems unlikely that they would be necessary. But even if the government took the most heavy-handed approach and simply took over the network (with payment, of course), that result would still seem preferable to having a single network from the outset. Either way, the government would end up controlling the network, but by beginning with private control, the creators of the standards would have a profit incentive to create the best ones possible, and users would get to choose among those competing standards. 
that apply to a single network (or set of networks) controlled by a private firm.

Having a government-controlled network operate alongside privately-controlled ones eliminates the monopoly problem and reduces the incentive for rent-seeking, but it creates distortions of its own. Government control can have harmful effects on the market even if the government actors seek only to maximize social welfare, as the presence of a government network might lead private competitors to offer less variety, or not to enter the market in the first place. ${ }^{224}$ Moreover, government actors would have reason to ensure that government-controlled networks were successful, and would have the ability to create a regulatory environment that would facilitate this goal. Such success not only would ratify the decision to create the network, but also, perhaps more importantly, would justify the continued involvement of the government actors. And note that a government actor who, in good faith, believes that government-created networks are valuable might well believe that doing what it takes to keep that network operating has considerable value as well. Private firms thus might reasonably fear that the government would have an interest in tilting the playing field on behalf of its own network, and government actors would be in a position to create regulations to achieve that end.225 More disturbingly, government actors might pursue their own interests more directly. 226 Instead of responding to the public's interest (or to the profit motive), they might respond to their desire for more power, prestige, or rewards from those above them in the political hierarchy. In fact, studies indicate that this is exactly what happens with government enterprises. ${ }^{227}$

More generally, having a government-controlled abundant network alongside private competitors raises the obvious question of the benefits that are likely to accrue. Once there is a competitive market, what is the benefit of adding the government to the mix? Indeed, we

${ }^{224}$ See Helmuth Cremer et al., Mixed Oligopoly with Differentiated Products, 9 Int'l J. Indus. Org. 43, 44 (1991) ("[H]aving a public firm maximizing social surplus is not necessarily socially desirable, even when this firm is as performant as its private competitors in terms of costs ...."); Gianni de Fraja \& Flavio Delbono, Alternative Strategies of a Public Firm in Oligopoly, 41 Oxford Econ. Papers 302 (1989).

225 See David E. M. Sappington \& J. Gregory Sidak, Incentives for Anticompetitive Behavior by Public Enterprises, 22 Rev. Indus. Org. 183, 198 (2003) (noting that "[a] public enterprise's special position as a government entity can afford it power to set industry rules that raise rivals' costs directly").

226 See infra notes $241-48$ and accompanying text for a fuller discussion of the possibility of government actors seeking to maximize their private interests.

227 See André Blais \& Stéphane Dion, Are Bureaucrats Budget Maximizers?, in The Budget-Maximizing Bureaucrat: Appraisals and Evidence 355, 357 (André Blais \& Stéphane Dion eds., 1991). 
can frame the question a bit more broadly: In light of the possible costs of having a government-controlled abundant network, are the benefits large enough to overcome them?

The central benefit that commons advocates suggest is that a government-controlled abundant network will be a free network. ${ }^{228}$ This seems to incorporate several concepts, including that: People will not have to pay to use it; the network will serve us as citizens, rather than as consumers; and people will be able to communicate without any filters imposed upon them.

\section{Should Spectrum for Abundant Networks Be Free of Charge?}

Let's begin with the first point: Some commons advocates seem to believe that these networks should be created so that people can use them free of charge. ${ }^{229}$ On this reasoning, a major problem with the auction model is precisely that there is an auction where someone pays for the spectrum necessary to create an abundant network; and the problem with spectrum rights more generally is that they allow private owners to charge money for access to spectrum. Isn't it an advantage of government control that no one will have to buy spectrum, and no one will have to pay to use it? Why not have the government simply create an abundant network and let people use it without charge?

Commons advocates seem to believe that it is essential to these networks that they not involve payment for spectrum or for access to spectrum. But why, exactly? The government could take control (after purchase, if necessary) of any resource and then turn around and offer free access to it. Why here? One possible answer is that these networks create additional capacity, and thus impose no costs. But that entails too narrow a definition of "cost." The cost of creating an abundant network is the lost opportunity for someone to create a different kind of network. That other network may not use spectrum as efficiently, but it may provide a service-say, broadcast televisionthat would not be provided with the same quality of service (if it was provided at all) by an abundant network. ${ }^{230}$ Adding users to an abun-

228 See Benkler, supra note 33, at 84-85 (discussing benefits of free access to information); Werbach, supra note 26 , at 3 (emphasizing that unlicensed spectrum involves free access to airwaves).

229 See Benkler, supra note 2, at 70-71 (discussing benefits of spectrum being used free of charge).

230 The viability of providing real-time streaming video might depend in part on the protocols chosen. See supra note 110 and accompanying text. But the envisioned packetbased low-power transmissions would not have the same quality of service as a dedicated stream. See supra note 36 and accompanying text (noting delays resulting from many 
dant network may not displace other users of that abundant network, but it displaces other networks (and those who would use them).

A related possible answer is that abundant networks render spectrum valueless (in that no one would pay anything for it), and therefore there is no basis for putting a price on it, or on access to it. But that is pretty far-fetched. Abundant networks will not be optimized for all forms of communication. Notably, transmissions that are sensitive to delay will have a lower quality of service in abundant networks, because of the delays that multiple hops introduce-delays that get bigger as the network gets bigger. ${ }^{231}$ As I noted above, this means that real-time transmission of messages containing many packets (for example, streaming video) will be difficult on abundant networks, and will not have the quality of service that television viewers have come to expect. Commons advocates do not assert that all services will be sufficiently well-provided by abundant networks that the remaining spectrum will lose value, and it is hard to imagine that this would occur. There will still be demand for services to be provided on networks other than abundant networks, so there will still be a positive price for spectrum. ${ }^{232}$

hops); supra notes 33 and 89 and accompanying text (highlighting services that Benkler envisions for abundant networks).

231 See Shakkottai et al., supra note 36, at 10.

232 Even if we indulge this assumption, however, this does not mean that we must jettison auctions. There are two possibilities: Either abundant networks will render spectrum worthless, and the bids for the remainder of the frequencies drop to zero; or they will not leave spectrum with no value, in which case the bids will remain at positive prices. If the former occurs, then the commons advocates have nothing to fear from auctions, because there will be no bids and no prices paid. The prospect of abundant networks will have ended the role for auctions, and all the spectrum will, effectively, be free. If, instead, the price for the remaining spectrum remains positive, then that will indicate that spectrum is not worthless. That is, if some uses are not fully accommodated by the abundant networks, the providers of those services will bid in order to control frequencies to allow them to provide those services.

There is a possible rejoinder (and third possibility): Abundant networks would create infinite spectrum if they were created, but they will never be created if spectrum is privately owned. But, as I discussed at some length in Part II.B, there is every reason to expect that a private owner would create such a capacious network. If such networks work as advertised, it is hard to imagine that no private owner will try to create one.

This relates to another possible argument against payment, namely that it would not be fair for the creators of the abundant networks to have to pay for spectrum if they are then going to render spectrum valueless. On this theory, they are conferring a positive externality on the rest of us (eliminating the price of all other frequencies) and are not being rewarded for it. This is a plausible argument, and it is even conceivable that a potential creator of an abundant network might refrain from creating one for fear of conferring this externality and being unable to capture it. This concern, however, entails a level of wild success for abundant networks that seems fanciful: They will be so successful that a bidder will not be able to recoup its spectrum fees before it has driven the price of spectrum to zero and then will watch as new competitors create their own abundant networks without being encumbered by those fees. Still, if that really is a concern, there is a 
Commons advocates might concede that abundant networks will not render spectrum valueless but nonetheless argue that the government should let people use the frequencies for those networks gratis. This would constitute a major subsidy to abundant networks. ${ }^{233}$ If these frequencies retain value, the government could gain revenue by selling the rights to that spectrum. And, of course, the government has done exactly this in recent years, receiving billions of dollars to fund government activities. ${ }^{234}$ A government decision to forego such revenues by giving the right to transmit-or any other valuable good-to a given set of people or entities is a significant subsidy to those recipients. The government would be choosing to bequeath the

response tailored to the danger-one that applies to all positive externalities: Let the company capture some of the value of that externality. In some cases, it may be difficult to set up a mechanism to capture some of that value, but here it would be easy. The government could stipulate for any auction that, in the event that any new network renders the spectrum valueless, the creator of that new network would be reimbursed for its bid. This would eliminate the disincentive created by the possibility (however remote) of the success of an abundant network hampering its owner. And, more important, it would leave auctions in place for the possibility that, just maybe, the abundant networks did not render all spectrum worthless. Given the overwhelming likelihood that the spectrum will retain some value, this is preferable to abandoning auctions altogether on the assumption that spectrum will be valueless.

233 The reference to a subsidy raises an issue of baselines. Why should payment for spectrum be the norm? Why shouldn't the presumption be that all spectrum rights (however configured) are distributed without charge, so that the real question becomes why anyone would ever be charged for it? There is no ultimate answer to this question: As with all questions of baselines, there is no reason why we couldn't have a different default. But there are good reasons for this baseline. As I noted in the text, even if abundant networks create effectively infinite spectrum for certain uses, spectrum will retain value because other uses will require other kinds of networks. In other words, spectrum is rivalrous, and spectrum rights contain a good deal of value. The government is going to have to choose some mechanism for determining how those valuable rights are distributed. So the government has something of value that it will distribute, and it seems fair to treat those who benefit from that distribution as having received something from the government.

This question of baselines also implicates the allocation of spectrum. The government could distribute spectrum rights without payment, for instance via comparative hearing or lottery (which is how most spectrum was distributed until the 1990s). See supra text accompanying notes 12-13. But distributing something free of charge does not deprive it of value; on the contrary, it just gives potential recipients a huge incentive to game the system so that they can be the recipients of these valuable rights. See supra note 131 and accompanying text. Indeed, the problematic incentives created by free distribution led the government to switch to a more transparent form of payment for spectrum, in the form of auctions. See Kwerel \& Felker, supra note 13 (discussing advantages of auctions); Thomas W. Hazlett, Assigning Property Rights to Radio Spectrum Users: Why Did FCC License Auctions Take 67 Years?, 41 J.L. \& Econ. 529 (1998) (same).

234 See Buck, supra note 26, I 15 ("As of March 5, 2002, the [FCC] had conducted 45 separate spectrum auctions with a total of 21,853 licenses awarded and governmental receipts of nearly $\$ 42$ billion."). The FCC has a summary of the amount of the winning bids in its auctions online. FCC, Auctions Summary, at http://wireless.fcc.gov/auctions/ summary.html (last modified Sept. 29, 2003). 
value of the foregone auction revenue on the chosen beneficiaries, rather than spending it on government services.

Why this subsidy? Everyone who creates or benefits from a network (whether cellular telephony, broadcast television, or car dealerships) wants the government to contribute, free of charge, some otherwise expensive element of that network. And every network operator claims that its network creates benefits for society. The norm for communications networks today-including most wired and wireless networks-is that the government does not devote spectrum, or wire, to them gratis. ${ }^{235}$ So why should the government donate spectrum for abundant networks?

One possible answer is that lower costs will allow the providers of products for those networks to charge lower prices to users. ${ }^{236}$ Giving spectrum away, one might argue, will enable providers to make communications cheaper for end users. 237 But that is always possible. Giving away wire to cable companies, and spectrum to cellular and satellite providers, will similarly reduce their costs and give them room to reduce prices. Indeed, giving away land to car dealerships will provide such room.

Maybe we should want free access to spectrum because abundant networks will work better as more people join. Adding users creates positive externalities, and so it would increase social welfare to subsi-

235 See supra note 13 and accompanying text (noting that, since 1997, most spectrum has been allocated via auction).

236 This relates to another possible argument, namely that avoiding payment for spectrum will help people with low incomes by making room for the cost to be lower. This argument suffers from the problem identified in the text-namely that this is true for any network (or any good). But the difficulties of this particular argument are even greater. If the goal is to help those who cannot afford to pay market rates for communications services, why subsidize an unproven network rather than one that has already been established as providing valuable services? It would make more sense to subsidize a network that has proven its worth, so that we can be confident that the poor are actually gaining something of value. This is an especially powerful point given that abundant networks depend on the existence of many users. Not only may the protocols not work as planned, but there may not be enough users to serve as repeaters and thus relay messages. See supra notes $74-75$ and accompanying text; infra note 264 and accompanying text. A more effective way to help those with low incomes would be to give them funds to purchase services from the network of their choice (or perhaps simply give them funds outright and let them make the choice as to how to spend it). Subsidizing an abundant network is one of the least effective means of helping them.

237 It bears noting that giving spectrum free of charge may not lead to lower prices. The cost of spectrum is a sunk cost, and in a competitive market prices reflect marginal costs. Sunk costs' main effect is on market structure, with high sunk costs leading to fewer entrants. See Ralph S. Brown, Design Protection: An Overview, 34 UCLA L. Rev. 1341, 1386 (1987); William M. Landes \& Richard A. Posner, Trademark Law: An Economic Perspective, 30 J.L. \& Econ. 265, 265-66 (1987); Thomas W. Hazlett, Private Monopoly and the Public Interest: An Economic Analysis of the Cable Television Franchise, 134 U. Pa. L. Rev. 1335, 1349-52 \& n.73 (1986). 
dize the growth of that network by having the government supply a key element-spectrum-free of charge. But this is true of most networks. Each additional fax machine, or e-mail user, or Web page adds value for everyone else who is on that network, and thereby creates positive externalities. In order to distinguish abundant networks from other networks, one would need to explain why their positive externalities are particularly valuable-why ensuring free access to abundant networks is particularly valuable. So these answers do not advance the argument, and instead simply beg the question: What is so special about abundant networks that the government should choose to subsidize them? Why do they merit this special treatment?

The only way to answer this question is to point to something special about abundant networks. Every new network differs from the other networks, so merely identifying a distinction is not sufficient. The question is whether there is some difference between abundant networks and other networks -in particular the cellular networks that most resemble them-great enough to justify a special subsidy for abundant networks.

\section{Is Government Control More Likely to Produce Neutral Networks?}

This brings us to the other claimed advantages of abundant networks that I laid out at the beginning-namely that they will serve our interests as citizens and will not impose any filters on us. Benkler in particular emphasizes these potential advantages. He contends that autonomy is a central value for the First Amendment and for a democratic society. He further argues that regimes relying on private ownership will undermine autonomy because those owners will act in their commercial interests, rather than in the public interest. ${ }^{238}$ Private ownership will, Benkler fears, produce networks aimed at consumers, not users. According to Benkler, "As the digitally networked environment matures, regulatory choices abound that implicate whether the network will be one of peer users or one of active producers who serve a menu of prepackaged information goods to consumers whose role is limited to selecting from this menu."239 He thus argues not only that government-created abundant networks are more efficient (the central assertion to which I respond), but also that they will produce different, and better, kinds of networks and communications.

The motivating idea is that we can have the networks that we as citizens want and need, rather than networks that are aimed at us as

238 See Benkler, supra note 33, at 57-72.

239 Benkler, supra note 89 , at 562 . 
consumers. Government control, on this theory, will produce networks that are not focused on advertising, or on revenue more generally. More fundamentally, government control will let citizens communicate with each other more freely than private control will. The commons advocates' point is that the profit motive has a downside-the distortions created by the need to gain revenue. There is little reason to believe, however, that privately controlled networks will be less responsive to users' autonomously chosen interests than government-controlled networks would be.

A key point from Part $I$ is worth reiterating: The choice is not between a controlled network and an uncontrolled one. Truly open access-in which people can transmit according to whatever methods they choose-would not produce the desired networks. Some entity must determine how the abundant networks will be structured. The real question, then, is how control will be divided between the government and private parties.

To put the point differently, abundant networks will not be truly open platforms, in the sense of allowing individuals to design their own protocols and transmit using whatever methods they see fit. The most they will be is what I will call neutral platforms, meaning that they allow people to communicate as freely as possible consistent with the limits inherent in abundant networks. People will not be able to create their own communications systems, but they can communicate without filters, advertising, or other limitations above and beyond the algorithms and power limitations entailed by abundant networks.

This comparative point leaves open the possibility that the government will better respond to users' preferences (and, therefore, presumably impose fewer limits ${ }^{240}$ than a private party will. Maybe government control will in fact be more responsive to users' desires than private control will be. This position, though, understates both the government's incentives and the possibility that the market will provide citizens with the networks that they want.

There is a debate among theorists about how much of public actors' motivations are guided by their private interests. Public choice theorists argue that everyone tries to maximize her own interests, and that the question regarding public actors is what exactly they want to maximize (e.g., power, money, limousines, etc.). ${ }^{241}$ Critics of public

240 This presumption will be accurate only if it turns out that users are, in fact, interested in having truly neutral platforms. See infra text accompanying notes 250-51.

241 See, e.g., Roger G. Noll, Economic Perspectives on the Politics of Regulation, in 2 Handbook of Industrial Organization 1253, 1262-63 (Richard Schmalensee \& Robert D. Willig eds., 1989); Terry M. Moe, The Positive Theory of Public Bureaucracy, in Perspectives on Public Choice: A Handbook 455, 456-58 (Dennis C. Mueller ed., 1997). 
choice theory argue that these theories are too sweeping. By excluding the possibility of ideology, or the public interest more generally, as motivating factors for government actors, public choice theory (according to its critics) misdescribes the actions of government officials. In the view of the critics, unselfish interests also motivate government actors. ${ }^{242}$ But no one argues that private interests play no role in the decisions of government officials. All agree that government actors are motivated, at least in part, by their own goals and desires. ${ }^{243}$ It thus seems fanciful to suggest that private owners will want to manipulate their networks for their own benefit, but government officials will be free of such motivation. The goals, and thus the manipulations, will likely be different: Private companies will tend to promote purchases of their goods, and government officials are more likely to promote their own re-election (or retention in office). But the manipulations are likely to be present in either event.

Moreover, even if this were incorrect, it should not necessarily make us more comfortable with government control. The main alternative to private interests that public choice theory's critics have identified is ideology; some elected officials seem to act on behalf of sincere convictions about the value of advancing a particular political agenda. ${ }^{244}$ The problem is that the desire to advance an ideology might lead to the creation of networks that advance that ideology. So, rather than having a network that subtly endorses the private interests of a government actor, it would instead subtly endorse the substantive vision of that actor. Either way, the manipulation is present. 245

This is not purely a matter of theory. Regulatory decisions about technology platforms often reflect the substantive preferences of government officials. For instance, the government has pursued a policy of "localism" in broadcasting that initially thwarted the expansion of

242 See, e.g., Cynthia R. Farina \& Jeffrey J. Rachlinski, Foreword: Post-Public Choice?, 87 Cornell L. Rev. 267, 268-70 (2002) (noting that behavior research portrays people as less self-centered than public choice suggests).

243 See, e.g., John F. Manning, The Absurdity Doctrine, 116 Harv. L. Rev. 2388, 2415 (2003) (noting that "recent criticisms of public choice theory merely question its utility as a comprehensive explanation of legislative behavior. It may be simplistic to assume that legislators routinely 'sell' their votes to interest groups, but few would deny that the goals of competing interest groups play a role, and often an important one, in shaping legislation."); Jerry L. Mashaw, The Economics of Politics and the Understanding of Public Law, 65 Chi.-Kent L. Rev. 123, 146 (1989) (noting that critics of public choice have shown only that ideology plays some role in legislative behavior; critics "merely limit[ ] the appropriate claims that can be made for an economic theory of politics").

244 See Daniel A. Farber \& Philip P. Frickey, Law and Public Choice 29-33 (1991) (noting that ideology is strong predictor of legislators' votes).

245 If the answer is that it would be difficult for the government to engage in such manipulations, then the question is why it wouldn't be just as difficult for a private actor to engage in its own manipulations. 
cable television and has required the carriage of local broadcasters, in significant part because of the desires of members of Congress to ensure that their constituents would have access to local news coverage-including, of course, coverage of the local member of Congress. ${ }^{246}$ The government also prohibited broadcasters from using the radio waves to send point-to-point communications or to offer subscription services. 247 There was no technological limit on such services. The FCC decided that they were inconsistent with its goals for radio communications, and so it prohibited them. ${ }^{248}$

246 See Stanley M. Besen \& Robert W. Crandall, The Deregulation of Cable Television, Law \& Contemp. Probs., Winter 1981, at 81-91 (1981) (noting FCC actions that limited growth of cable, in attempt to protect local broadcast stations); see also Amendment of Subpart L, Part 91, to Adopt Rules \& Regulations to Govern the Grant of Authorizations in the Business Radio Service for Microwave Stations to Relay Television Signals to Community Antenna Sys., Second Report and Order, 2 F.C.C.2d 725, 774-78, III 123-30 (1966) (placing limits on growth of cable, in light of concerns about local UHF broadcasters); Thomas G. Krattenmaker \& L.A. Powe, Jr., Converging First Amendment Principles for Converging Communications Media, 104 Yale L.J. 1719, 1736 (1995) (noting that FCC's allocation plan "gave great weight to factors such as placing at least one transmitter in as many communities (and, therefore, congressional districts) as possible. ... The allocation plan sacrificed viewer interests in access and diversity to narrow political concerns and entrenched industry goals."). The Court in Turner Broadcasting System, Inc. v. FCC, 512 U.S. 622 (1994), split over the question whether the protections for local television should be understood as reflecting a congressional preference for local television's content or a conclusion that local broadcasting "ha[s] some intrinsic value," id. at 648; see also id. at 675-80 (O'Connor, J., dissenting). It seems clear, though, that the preference for localism in broadcasting encompasses, whether directly or indirectly, a recognition of the kinds of communication local broadcasters offer. See Cable Television Consumer Protection and Competition Act of 1992, Pub. L. No. 102-385, §2(a)(8)(A), 106 Stat. 1460, 1461 (presenting as finding in support of requiring cable operators to carry local stations that "[b]roadcast television stations continue to be an important source of local news and public affairs programming and other local broadcast services critical to an informed electorate"); Ashutosh Bhagwat, Of Markets and Media: The First Amendment, the New Mass Media, and the Political Components of Culture, 74 N.C. L. Rev. 141, 186 (1995) (stating that "the view that 'localism' is advanced more by broadcasters than cable programmers, clearly motivated Congress when it passed the must-carry rules. Otherwise, Congress' statements about the value of diversity [in its findings] would be nonsensical."); Clay Calvert, Free Speech and Content-Neutrality: Inconsistent Applications of an Increasingly Malleable Doctrine, 29 McGeorge L. Rev. 69, 85-86 (1997) (quoting Edwin Baker as stating that "[i]t is difficult to imagine that Congress would justify the must-carry rules except in part on grounds that the content is expected characteristically to differ from that on cable and that this different content has value," and adding that "[f]or Kennedy, however, the fact that the justification 'in part' was content based was not determinative. Instead, he focused on what he considered to be the 'overriding objective' and 'overriding congressional purpose' of preserving free access to messages" (citations omitted; emphasis added by Calvert)).

247 See Shelanski, supra note 11, at 1054-57. There was one exception to the prohibition on subscription services: The FCC allowed the Muzak Corporation to conduct a limited and temporary trial of a subscription radio service in 1941. See id. at 1057.

248 Government decisions regarding broadcasting licenses are another example: Franklin D. Roosevelt's administration sought to give broadcasting licenses (mainly in radio) to Democrats who supported the New Deal, and it supported the build-out of radio networks; licenses distributed in the Eisenhower administration (mainly in television) 
Just as the commons advocates understate the government's incentives, they overstate the likelihood of private actors advertising in abundant networks or restricting users' freedom. Economic theory tells us that if individuals want a neutral platform and/or a commercial-free environment in which they can communicate as they please, profit-maximizing companies will provide it to them. One potential response to this argument is that this theory does not play out in real life-look, for example, at the advertisements on many websites. But this evidence is too narrow. There are lots of situations in which companies have foregone advertising and received revenue from other sources. Pay-per-view and pay-per-channel cable television fall into this category. Better examples, though, are networks that do not support advertising or alter users' messages in any way. Obvious examples include cellular networks and instant messaging systems. Private companies created both. Both provide real-time communications through which people say whatever they like, without any filtering. Both, indeed, seem to provide exactly the sort of neutral platform for communications that commons advocates hail as the networks that citizens want and need. They may not be as capacious as commons advocates hope the abundant networks will be, but they allow people to communicate messages as they see fit. ${ }^{249}$

tended to go to Republican supporters of the administration, and that administration strongly supported the build-out of television networks. See Lucas A. Powe, Jr., American Broadcasting and the First Amendment 74-77 (1987) (describing favors granted by partisan Republicans on FCC); William B. Ray, FCC: The Ups and Downs of Radio-TV Regulation 45 (1990) (stating that Republican newspapers received TV licenses while Democratic newspapers did not); Bernard Schwartz, The Professor and the Commissions 162-64 (1959) (noting that Eisenhower-appointed FCC was influenced by political affiliations of applicants); Bernard Schwartz, Comparative Television and the Chancellor's Foot, 47 Geo. L.J. 655, 690-94 (1959) (same).

Meanwhile, government decisions about where and how to locate radio stations reflected substantive policy goals of overserving (relative to their populations), and thereby benefiting, small and rural communities. See Act of Mar. 28, 1928, Pub. L. No. 70$195, \S 5,45$ Stat. 373, 373-74 (1928) (establishing equal allocation of broadcasting licenses to all zones); Benjamin et al., supra note 4, at 19.

Government websites are an example of a more direct kind of manipulation. Many of them present themselves as nonpartisan but in fact contain elements that, subtly or not, advance the agenda of the entity sponsoring the site. See, e.g., Adam Clymer, Critics Say Government Deleted Sexual Material From Web Sites to Push Abstinence, N.Y. Times, Nov. 26, 2002, at A18 (noting changes in government websites that advance administration's agenda); Adam Clymer, U.S. Revises Sex Information, and a Fight Goes On, N.Y. Times, Dec. 27, 2002, at A17 (same).

These are only a few examples of regulatory decisions involving telecommunications that were influenced by considerations other than the public interest. For other examples, see Powe, supra, at 69-74, 83-84, 112-16, 121-29, 131-41.

249 The same points apply to another possible argument in favor of government control, namely that it will protect consumers' privacy. First, there is little reason to assume that the government will be more protective of privacy than a private company will be. Private 
One further example is also illustrative. Recall that in the early 1990s the main online service companies-Prodigy, CompuServe, and America Online-offered only closed proprietary content. Users dialed in to the company's computers and received only material created by or affiliated with that company; users could not go directly onto the World Wide Web. As the Web developed, however, these companies found that they could not attract customers (or keep the ones they had) unless they provided open access to it. The companies provided such access, of course, thereby giving their users the opportunity to join the most participatory and open platform the world has yet known. 250

Maybe commons advocates, instead, fear that companies will not provide truly neutral platforms because there will be insufficient demand for them. That is, maybe they fear that what citizens want is not what citizens need; they will happily use networks that push them toward commerce and will not demand neutral platforms, because they will not sufficiently prefer neutral platforms to pay for them. But if that is the case, then commons advocates are making the paternalistic argument that they know what is good for citizens, and the citi-

companies have an incentive to discover users' buying habits, but government officials have their own incentives, and one of them is monitoring antigovernment behavior. Second, there is every reason to believe that, if people want their privacy to be protected, private companies will create networks that protect their privacy.

Again, these are not matters of pure theory. Government officials have, in fact, attempted to require that networks be configured to allow them access to individuals' communications (e.g., the Clipper Chip and, more recently, Carnivore as well as post-9/11 regulations), and private companies have often resisted these attempts. See, e.g., Frank J. Eichenlaub, Carnivore: Taking a Bite Out of the Fourth Amendment?, 80 N.C. L. Rev. 315, 317 (2001) (noting that Carnivore allows FBI to monitor suspect's e-mail); Daniel J. Solove, Digital Dossiers and the Dissipation of Fourth Amendment Privacy, 75 S. Cal. L. Rev. 1083, 1089-1101 (2002) (describing increasing flow of personal information gathered by private sector to government). If the government controlled the various networks, this source of opposition would be eliminated. More generally, private companies have created networks that specifically protect individuals' privacy, because they have found that it is a good (i.e., more profitable) business practice to do so. Internet service providers, for example, have set up privacy controls, and indeed often resisted-to the point of litigation-attempts to gain access to users' communications. See, e.g., Nadine Strossen, Protecting Privacy and Free Speech in Cyberspace, 89 Geo. L.J. 2103, 2105-09 (2001) (discussing recent government attempts to obtain information about users, and ACLU's support for individuals and Internet service providers that have resisted such attempts); see also Recording Indus. Ass'n of Am. v. Verizon Internet Servs., 240 F. Supp. 2d 24 (D.D.C. 2003) (rejecting Verizon's arguments that it was not obliged to reveal identity of anonymous user who was alleged to have infringed copyrights).

One final point bears emphasis: Insofar as we are afraid that companies will ignore our preferences and trample upon our privacy, Congress obviously can legislate to prevent such intrusions-whether the networks are controlled by the government or by private entities.

250 See Speta, supra note 181, at 86 (recounting this history); Benjamin, supra note 214 , at 297 n.112 (discussing transformation of these companies). 
zens themselves do not-or in any event do not want what is "actually" good for them. This is not the place to recite the wellknown arguments for and against such paternalism, but it bears noting that this argument is particularly weak in the context of abundant networks.

It may be that few people desire neutral platforms, so that the vast majority will not flock to them even if such platforms are offered. If so, these neutral platforms will not be created by private firms and will never be a highly valued use of spectrum (other than for the elite few who, unlike the vast majority of users, do value neutrality). ${ }^{251}$ If the great bulk of people will never prefer neutral platforms, creating one seems a poor use of government largesse, not to mention its creators' time and energy. It would constitute a very large governmental subsidy for relatively few users. I might like the government to subsidize such a network (because I would prefer the neutrality), just as I might like the government to subsidize all sorts of unpopular preferences that I have. But it would be quite arrogant for me to claim that the government should devote its resources to satisfying my preferences rather than those of the masses, because I would be saying that my definition of value should prevail-forever-over that of the vast majority.

For the reasons highlighted in the previous paragraph, paternalistic arguments usually do not assume that the masses will never want what is being offered. Instead, paternalistic arguments are at their strongest (or perhaps their least weak) in situations in which people have never been exposed to the proffered alternative that is supposedly best for them. The idea is that people have become so conditioned by society/corporations/their parents/etc. that they simply do not realize that other options are available, and (in part as a result of this conditioning) such other options are not in fact on the market; but if such other options were made available, then people would realize their value. On this reasoning, once people see the value of these networks, they will flock to them (and thank the farsighted creators for developing them). The problem here is that, as I noted above, people

251 Note that it would need to be the vast majority. If, say, twenty-five percent of users would prefer a neutral platform (i.e., were willing to contribute as much for a neutral platform as they would contribute to a nonneutral one, including in-kind contributions to the latter), and enough spectrum rights were auctioned as private property to support four abundant networks, then we would expect that one of the successful bidders would create a network with a neutral platform. Note that this assumes that abundant networks are as superior to all other uses of spectrum as their supporters promise, so that all auctioned spectrum would be used for that purpose. If that is not the case, then perhaps no neutral platform will be created. But this raises a far more serious-indeed fundamentalproblem for the argument for such networks in the first place. See supra p. 2042. 
have been exposed to all sorts of platforms, some of which allow people to transmit as they see fit. Cellular networks have no advertising or filters, and they have added capabilities (e.g., text messaging, video, e-mail, web surfing, even digital photography) that allow people to structure their communications quite freely. There is no reason to believe that people need additional exposure to neutral networks in order to understand their benefits. To put the point more sharply, there is no basis for concluding that any lack of desire among citizens for neutral abundant networks would flow from unfamiliarity with the benefits of such neutrality. If they do not want such a neutral platform, we would need to be prepared to impose one upon consumers indefinitely, with no realistic hope of some future point of enlightenment at which most citizens will come to thank us for forcing them to eat their metaphorical spinach.

This does not mean that private ownership is necessarily more likely to produce neutral platforms than government control would be. It is conceivable that a majority of citizens would desire neutral platforms but not find them offered by private networks, and also conceivable that we can overcome principal-agent problems between us and our representatives such that the government will create the neutral platforms that we want and otherwise will not get. The point of this discussion is that the benefits of government control are uncertain at best.

That brings us back to considerations about which we can have more confidence: Competition among private firms has distinct advantages in terms of innovation and flexibility in creating and modifying abundant networks. Government control, meanwhile, has the advantage of avoiding the creation of a private monopoly. As to the concentration of power, though, the benefits are less clear: A government monopoly entails its own risks; and the risk of, and therefore dangers posed by, a private monopoly seem fairly small. Still, there is some risk of private monopoly, and we are left to draw the balance. In my view, the more certain disadvantages of government control outweigh the more speculative disadvantages of property rights. But the matter does not end there. There is one more uncertainty that looms large: the uncertainty over whether an abundant network will work as planned and be embraced by users. This uncertainty constitutes a cost of imposing an abundant network. And that cost tilts the policy balance more strongly in favor of property rights. 


\section{IV}

\section{Should the Government Allot Frequencies IN LARGE BANDS?}

The discussion above indicates that if abundant networks work as promised, we should expect private ownership to yield several of them as long as the government holds a big auction and allots spectrum in large bands. Furthermore, the discussion suggests that, on balance, private control of an abundant network is probably preferable to government control. But that does not necessarily mean that the government should, in fact, create such big allotments. Just because the government can allot frequencies in large bands does not mean that it should. We still have the question whether any of these options is preferable to a similarly big auction that adopts the current system of small allotments. To answer that, we have to evaluate the costs of allotting such big bands versus the benefits of doing so.

\section{A. Parcel Size, Transaction Costs, and Combinatorial Bidding}

Insofar as the highest and best use of all the auctioned spectrum is for abundant networks, there are significant benefits to allotting spectrum in large parcels and no costs: The winning bidders will be able to put the networks to their most valued use without having to aggregate or disaggregate frequencies. But if abundant networks are not the most valued use of all the auctioned spectrum (or, worse yet, any of the spectrum), then costs become an issue. Unless a private owner finds that some other use of a big swath of frequencies is the most valued use, it will be faced with the choice of either keeping its allotment together in a suboptimal use or incurring the transaction costs of dividing up the spectrum it has purchased. If, for example, the spectrum is divided into 100-megahertz allotments for auction purposes, but the winning bidder in each case will find that the most profitable use is to subdivide its allotment into pieces of varying smaller sizes (e.g., one to ten megahertz), the costs of choosing the size of each slice and auctioning them will be significant.

The transaction costs of dividing up spectrum per se are not the problem. Those are costs that would be borne by the government if it allotted spectrum in smaller bands. If the ultimate result is going to be that spectrum will be allotted in a variety of smaller sizes, someone-either the government or a private party-is going to bear those costs. ${ }^{252}$

252 Consider an entity that is interested in purchasing the right to transmit over a fivemegahertz channel. If the FCC allots spectrum in parcels of that size, the entity will take part in an FCC auction and bid for its desired spectrum. If the FCC instead allots spectrum 
It may then be tempting to argue that holding an auction for bands in 100-megahertz slices imposes no costs. The idea would be that, if the cost of holding the auction for, say, twenty-five separate parcels totaling 100 megahertz is $X$ and the total value of these parcels to the highest bidders is $\mathrm{Y}$, then either the government pays $\mathrm{X}$ to conduct the auction (because it auctions the twenty-five separate parcels) and the highest bidders offer, in total, $Y$, or the high bidder for the bundle of 100 megahertz bids $Y$ minus $X$ and then conducts its own auction. ${ }^{253}$ The problem with this analysis is that it ignores the fact that we may be needlessly creating a two-stage auction process. This analysis merely demonstrates that a private party can hold an auction according to the same rules (and with the same costs) as the government.

Each auction entails costs for the auctioneer and the bidders. So, if the most valued use of spectrum is in small bands, having an auction for much bigger bands creates additional costs by creating an unnecessary additional auction. For the auctioneer, it has to set up the arrangements for the auction and conduct it. These may not be huge costs, but they are not likely to be trivial, either; each auction entails a fair amount of administrative time and energy. For each bidder on a large allotment (which I will call the "big-swath bidders"), their costs of evaluating the spectrum and gaining financial backing for their bid would not exist if that spectrum were directly auctioned to the ultimate purchasers ("small-parcel bidders"). Big-swath bidders may expend significant resources determining how much spectrum is worth to them. And, because the prices paid for spectrum have been so great and the costs of borrowing can be high, many bidders may conclude that they want to conduct negotiations before the auction with potential buyers of parts of the allotment up for bid. At first blush, this might not seem to increase costs, as it just pushes up the time when the small-parcel bidder cuts a deal with the bidder: The smallparcel bidder wants to buy a portion of the allotment, and it will conduct that negotiation either before or after the auction is completed.

in bands of, say, 100 megahertz, the entity desiring five megahertz will contact the winning bidder in order to enter the winner's private auction. Indeed, the entity desiring the five megahertz might well contact the entities bidding for the entire 100-megahertz allotment before the auction, thereby allowing a bidder for the 100 megahertz to bundle the bids of its buyers into the price that it can offer for the spectrum. The private auctioneer can choose to use the exact same bidding system and protocols as the government uses, and thus can mimic virtually every aspect of the government auction. If so, the costs for the bidder wanting five megahertz will be the same whether it makes its bid to the private auctioneer or to the government auctioneer.

253 On this reasoning, the government receives $\mathrm{Y}$ minus $\mathrm{X}$, and the bidder pays, in total, $\mathrm{Y}$ (and the people who administer the auction receive $\mathrm{X}$ ) under both scenarios. 
But the difference is that, for all the unsuccessful bidders for the 100 megahertz allotment, the time spent negotiating with small-parcel bidders is time wasted. They will have nothing to sell, so the costs of arranging their secondary auction will be a deadweight loss.

These various costs of holding an unnecessary auction may not be massive, but in combination they could be significant. That is why, after all, we would expect less total money to be paid for spectrum if the highest valued use was 1-megahertz allotments but there was first an auction for a 400-megahertz allotment, then a second auction conducted by the winner for four 100-megahertz allotments, then another auction conducted by those winners for 25-megahertz allotments, and so on. Each auction might not cost a huge amount of money for the auctioneer and the bidders, but there are real costs involved. And if we know that the most valued use of the frequencies is that they end up in one-megahertz allotments, then the many different auctions that it takes to get to one-megahertz allotments are largely a deadweight loss. The efficient outcome would be for the auctioneer to proceed immediately to auctioning one-megahertz allotments. ${ }^{254}$

This discussion highlights the fact that not only are there costs of dividing spectrum into pieces that are too small (i.e., the transaction costs of aggregating), but also there are costs of failing to divide spectrum into small enough pieces (i.e., the costs of disaggregating). There are no easy ways to minimize these costs. The government can attempt to gain information about the value that bidders place on small versus large swaths per megahertz, but in so doing it faces the problem that bidders usually guard that information jealously. The government can try to obtain that information by actually auctioning a portion of spectrum in different size swaths and then auctioning the remainder based on the results of the first auction, but this entails two separate auctions and thus eliminates the benefits of a single auction. ${ }^{255}$ And the smaller the number of megahertz offered in the first auction, the more likely bidders will not reveal their true preferences or otherwise will game the system; but the bigger the number of megahertz in the first auction, the less will be available for auction after the government has obtained the information.

Auction theorists have considered this question, and some have proposed combinatorial (or package) bidding as a promising option:

254 Note, though, the existence of countervailing considerations. One advantage of having the two-stage auction is that the big-swath bidders may do a better job of distributing spectrum to small-parcel bidders who have the highest and best use. The profit motive will lead them to pick the services that have the greatest interest to potential end users. The bigger advantage, though, is that it leaves room for abundant networks.

255 See Kwerel \& Williams, supra note 17, at 11-13. 
The government could let entities bid on individual parcels (e.g., allotments of 6 or 10 megahertz each) and on a package of parcels (e.g., allotments containing 10 or so of the individual parcels, for a total of 60 to 100 megahertz). ${ }^{256}$ If the total bid on the package was greater than the total for the individual parcels, then the spectrum would be assigned to the single winning bidder; otherwise, the parcels would be assigned to the entities that were the highest bidder for each of the individual parcels. ${ }^{257}$ The idea is that, when it is not clear whether a given set of properties (here, frequencies) has more value as a single unit or a set of separate pieces, it makes sense to leave that determination to the market by letting entities bid for either the package or for individual parcels. The FCC has, in fact, introduced package bidding into some of its auctions for spectrum. ${ }^{258}$ As the FCC notes, package bidding "would allow bidders to better express the value of any synergies (benefits from combining complementary items) that may exist among licenses, and to avoid exposure problems-the risks bidders face in trying to acquire efficient packages of licenses."259 Package bidding is thus a response to uncertainty about the most valued use that allows for aggregation of spectrum without the transaction or holdout costs of an entity putting spectrum together on its own. ${ }^{260}$

But combinatorial bidding also creates some costs. As the FCC acknowledged, there is a danger that package bidding can bias the outcome. Most notably, a bidder for the whole package might have a slight advantage because "bidders for parts of a larger package each have an incentive to hold back in the hope that a bidder for another piece of the larger package will increase its bid sufficiently for the bids on the pieces collectively to beat the bid on the larger package."261

256 See Procedures Implementing Package Bidding for Auction No. 31, 65 Fed. Reg. 43,361 (July 13, 2000) (describing package bidding).

257 Brian C. Fritts, Note, Private Property, Economic Efficiency, and Spectrum Policy in the Wake of the C Block Auction, 51 Fed. Comm. L.J. 849, 881-82 (1999) (explaining that combinatorial bidding allows entity to enter package bid for group of licenses).

258 See Auction of Licenses on the 747-762 and 777-792 MHz Bands Scheduled for June 19, 2002, Round Results Process and Results Replication, 17 F.C.C.R. 8128 (2002) (discussing package-bidding process); Procedures Implementing Package Bidding for Auction No. 31, 65 Fed. Reg. 43,361 (describing procedures for package bidding); Auction of Licenses in the 747-762 and 777-792 MHz Bands Scheduled for September 6, 2000, 15 F.C.C.R. 8809 (2000) (same)

259 Comment Sought on Modifying the Simultaneous Multiple Round Auction Design To Allow Combinatorial (Package) Bidding, 65 Fed. Reg. 35,636 (June 5, 2000).

260 See Kwerel \& Williams, supra note 17, at 15 ("Package bidding could provide for a market test of mutually exclusive band plans. Bidders could bid on two or more mutually exclusive band plans at the same time and the auction process would determine the single band plan that maximizes auction revenue.").

261 Comment Sought on Modifying the Simultaneous Multiple Round Auction Design to Allow Combinatorial (Package) Bidding, 65 Fed. Reg. 35,636, IT 3. 
The government can structure auctions (as the FCC has done) to overcome biases such as these, but creating and administering such rules is a cost of holding an auction with package bidding. Perhaps of greater concern, the FCC has never attempted package bidding on anything like the scale that a big bang auction would entail, and the complications of such an auction procedure would be great. Holding two separate, simultaneous auctions, one of which contains many different parcels, involves a level of sheer complexity that imposes significant coordination and administration costs. The additional complications increase the amount of time and effort that the government would need to expend in designing and running the auctions, and it is possible that the government would not be able to design a satisfactory auction procedure. ${ }^{262}$

Failing to auction the optimal size swaths thus entails costs-in the form of aggregation and disaggregation costs, and/or in the form of administrative costs from creating package bidding or from trying to obtain information about bidding from private parties. These costs can be significant, and the aggregation or disaggregation costs might well forestall what would be the highest valued use of spectrum. Much thus depends on the likelihood of abundant networks being the highest and best use of spectrum. The greater the likelihood, the lower the cost of allotting frequencies in big bands (and, concomitantly, the greater the cost of allotting it in small ones).

\section{B. The Importance of Uncertainty}

The problem with making this determination is that significant uncertainty surrounds abundant networks. First, we do not know if they will work as planned. Engineers will have to try to design appropriate protocols, which is no mean feat. Then the networks will have to work in the real world. Nobody has yet implemented one and the engineering difficulties of such implementation could be very great. This is no small hurdle. The challenges facing the designer of an abundant network are enormous. ${ }^{263}$ Second, even if the networks operate

262 See Kwerel \& Williams, supra note 17 , at $16-17$; see also Owen \& Rosston, supra note 42 , at 212 (suggesting that package bidding makes sense for small numbers of licenses).

263 See Piyush Gupta \& P. R. Kumar, Towards an Information Theory of Large Networks: An Achievable Rate Region (2001), available at http://decision.csl.uiuc.edu/ $\sim$ prkumar/ps_files/net_info.pdf. Gupta and Kumar use the term "ad hoc wireless networks" to refer to networks that communicate with each other without centralized routing, and that cooperate in routing each other's messages. Id. at 2. They state that, under current technology,

an ad hoc wireless network furnishes an average throughput to each user for non-vanishingly far away destinations that diminishes to zero as the number of 
exactly as planned, people may not flock to them. At the outset, note that if there are not a fair number of users (we do not know how many because no abundant network has yet been developed), the system will not work. ${ }^{264}$ The network depends on the presence of repeaters, as without them messages will not travel very far. So user adoption is necessary for the network to transmit messages effectively. But assuming that enough people buy user devices to make the network function as planned, there is the much larger hurdle of the networks being so wildly successful that they are better than the other possible uses of spectrum that would involve smaller allotments of frequencies. The question, remember, is whether the possibility of abundant networks should lead the government to auction spectrum in big swaths. If it turns out that people value having any (and every) set of 100 megahertz providing a bunch of television broadcast channels more than they value having 100 megahertz devoted to an abundant network, the case for making room for abundant networks will have been eviscerated. 265

nodes increases in the network. This suggests that only small ad hoc networks or networks supporting mainly nearest neighbor communications are feasible with current technology.

Id. at 3; Sanjay Shakkottai \& Theodore S. Rappaport, Research Challenges in Wireless Networks: A Technical Overview, 2002 Proc. Int'l Symp. of Wireless Personal Multimedia Comm. 6 (noting "many open problems in both the fundamental nature of these networks (for example, capacity and scaling with reliability issues, time-varying channels, spatial distribution of users, etc.) as well as practical, distributed algorithms for routing, congestion control and secure communication over such networks"), available at http:// www.wirelessvalley.com/Assets/presentations/Research_Challenges.pdf; Zaher Dawy \& Pornchai Leelapornchai, Optimal Number of Relay Nodes in Wireless Ad Hoc Networks with Non-Cooperative Accessing Schemes, 2002 Proc. Int'l Symp. on Info. Theory \& Its Applications 5 (stating that "there exists an optimal number of relay nodes to be used between any source-destination pair that achieves the least sum transmit power. This optimal number of relay nodes decreases as the transmission rate increases, which interestingly shows that multihop transmission might not be suitable for very high data rate networks."); O. Lévêque, Upper Bounds on the Capacity of Large "Ad-Hoc" Wireless Networks (2002), available at http://thiwww.epfl.ch/ leveque/Publications/resday02.pdf; Li et al., supra note 71, at 61; Gupta \& Kumar, supra note 37.

264 See supra note 75; see also Seapahn Meguerdichian et al., Coverage Problems in Wireless Ad-Hoc Sensor Networks (2001) (paper presented at IEEE Infocom 2001) (noting difficulty of determining right number of nodes and hops in abundant network), available at http://www.ieee-infocom.org/2001/paper/843.pdf.

265 Of course, if it turns out that an abundant network is not the highest and best use of any portion of the spectrum but a similarly bandwidth-intensive use is the highest and best use, then auctioning spectrum for that other use might result in swaths as big as those that would be appropriate for abundant networks anyway. Note, though, that in this situation the government would not be making room for abundant networks, but instead for the ones with the highest value. It would be mere happenstance that the allotment sizes appropriate for abundant networks would also be appropriate for the highest and best use. Note also that we would not expect-or want, as an efficiency matter-to see any private entity 
This discussion raises two larger points: First, if we ultimately decide that the costs of allocating spectrum in a way that allows for private abundant networks are greater than the benefits of making room for them, then the government should not create them on its own. If allocation of spectrum in large bands for purposes of private property rights (with package bidding or without it) is unattractive, similarly large allocation for purposes of government-mandated abundant networks is even worse. If making it possible for private abundant networks is a worse use of spectrum than policies that make such networks prohibitively expensive, then there is no basis for preferring policies that not only make possible but in fact mandate the creation of such abundant networks.

Second, and more fundamentally, uncertainty about abundant networks goes to the heart of the argument for private, rather than public, control. The distinct possibility that the network either will not work as planned or will not be valued by many users creates a cost of imposing it. As with any proposition, we must discount the value of abundant networks by the possibility that they will fail. The discussion in the previous Parts focused on the advantages and disadvantages of private versus public control of abundant networks assuming that someone could design abundant networks that would work and would attract users. But the possibility that these abundant networks will not have this success adds considerably to the cost of the government imposing one. This is another way in which the greater flexibility of private parties confers an advantage on the property rights model. ${ }^{266}$ A government decision to create an abundant network can be undone by a subsequent government decision, but that entails a long and costly public process. Deliberative processes are part and parcel of our governmental decisionmaking, and that confers many advantages in terms of democratic legitimacy; but it also results in a slow-moving process. ${ }^{267}$ Benkler proposes a review of commons after ten years, but that still leaves open the possibility of valuable spectrum being poorly used for that period of time. ${ }^{268}$ Private parties, on the other hand, can freely choose not only to abandon or redesign an abundant network once built, but also can choose not to build one in the first place. If, after undertaking its own review of the options, a private entity decides to proceed with a different plan, it can do so

create an abundant network in such circumstances, because it would not be the highest and best use.

266 See supra Part III.C.

267 See supra notes $156-60$ and accompanying text.

268 See supra notes 162-66 and accompanying text. As I noted in Part III.C, even then the periodic review would likely take a long time. 
immediately. Thus a central difference between government and private control is that private entities can more easily choose what services to provide.

The government could reduce the uncertainty surrounding whether an abundant network would work as planned by letting private networks develop first. But such private development might increase the risk of the government network failing to be popular, as the government's network might not have enough perceived advantages to draw a significant number of users of other abundant networks and/or new users who were not attracted to the private networks. And the benefits created by the government network would likely be lower if it was one among many than if it was the only one. As I noted above, once there is a competitive market it is not clear what a new government-controlled abundant network would add, and it might create its own distortions. More generally, the benefits created by a new entrant (whether government or private) entering a competitive market are uncertain at best. The first entrant creates the market, and the second creates competition, but the fifth or tenth may not add anything.

Even if the points in this last paragraph are wrong, because the uncertainties for the government are much lower once private firms have created successful abundant networks and/or the benefits of the $n$th network are as great as the benefits of the first, that merely indicates that government creation of abundant networks may be efficient once private firms have been successful. It would still not justify the government creating an abundant network before private ones have been successful. Until successful abundant networks have been created, the costs created by uncertainty continue to exist.

It might make sense for the government to create an abundant network even before any were successful, if there were reason to believe that private firms would not create them. But, as I discussed above, private firms will have an incentive to create them if spectrum is allocated in large swaths. Given the alternative of private creation, the costs created by uncertainty loom large.

\section{$\mathrm{V}$ \\ Nonexhaustive Property Rights}

It is important to be clear about what the arguments in this Article do, and do not, suggest. One implication of my arguments is that frequencies that are subject to significant interference are not attractive candidates for spectrum commons. The biggest drawback to a spectrum commons has long been the danger of interference-and 
most proposed uses of spectrum entail a substantial risk of interference. Insofar as open access will lead to significant interference, the costs of such open access are very high. 269 Commons advocates do not contend otherwise, but instead argue that they have avoided these costs-and thereby rendered a government commons desirable-by eliminating the risk of interference. On this basis, they present abundant networks as ideal candidates for a spectrum commons. The unattractiveness of a government commons in the setting most conducive to such government control-where the tragedy of the commons should be least likely to occur, because heavy utilization will not create problems-undercuts the case for a government commons for any service that is more susceptible to interference than an abundant network would be.

The failure of the commons advocates' arguments does not mean that all usable spectrum should be subject to private control. My view is that government-created commons are not only efficient but also desirable in many situations-for example, the real property context (e.g., public parks), the intellectual property context (e.g., enlarging the public domain by narrowing patent applicability and copyright terms), and the spectrum context. As to spectrum, it may be that not all frequencies should be subject to property regimes, and that property rights should not be construed to extend to all transmissions on a given frequency. On the former point, commons are appropriate for bands in which interference would not arise and private ownership would create high transaction costs. 270 So, for example, the FCC's Spectrum Policy Task Force proposes a commons at very high frequencies (above $50 \mathrm{GHz}$ ), on the theory that there is little danger of interference, and that exclusive rights in that spectrum would create significant transaction costs. ${ }^{271}$ Assuming the Task Force's characterization of these factors is accurate, this seems to be a sensible proposal.

\footnotetext{
269 See supra Part I.A.

270 The FCC's Spectrum Policy Task Force emphasizes these considerations as well. See Report of the FCC Spectrum Policy Task Force, supra note 16, at 39.

271 The Report of the FCC Spectrum Policy Task Force recommends:

[The] use of the commons model in higher spectrum bands, particularly above $50 \mathrm{GHz}$, based on the physical characteristics of the spectrum itself. In these bands, the propagation characteristics of spectrum preclude many of the applications that are possible in lower bands (e.g., mobile service, broadcasting), and instead favor short-distance line-of-sight operation using narrow transmission beams. Thus, these bands are well-suited to accommodate multiple devices operating within a small area without interference. Moreover, administering these uses on an individualized licensed basis would involve very high transaction costs.
}

Id. at 39-40. 
We also may want to construe property rights not to cover all transmissions on a given range of frequencies. ${ }^{272}$ Recall that the commons advocates' main argument for the efficiency of abundant networks is that the transaction costs of spectrum aggregation make private ownership unattractive. That argument is not persuasive as to abundant networks, but it is persuasive in other situations. A recent Chief Economist and a recent Chief Technologist at the FCC, for example, have put forward a powerful argument in favor of treating all property rights in spectrum as entailing an easement for anyone to use a low-power wideband device that does not meaningfully interfere with the property owner's use of that spectrum, and the FCC's Spectrum Policy Task Force has similarly recommended. ${ }^{273}$ The key characteristic of such low-power transmissions is that they might have significant value as a secondary use, but might not be sufficiently valu-

272 We might define a property right as conferring complete control over a set of frequencies, or instead as providing a right to use those frequencies for the owner's transmissions. The latter formulation would not preclude other transmissions that did not interfere with the property owner's transmissions. Gerald R. Faulhaber and David Farber have conceptualized this as an easement: Users would have the right to use others' spectrum as long as they did not interfere. See Faulhaber \& Farber, supra note 18, at 14 . One can reach the same result by conceptualizing the property right as not extending to noninterfering transmissions. As I have noted previously:

This is purely a question of how the rights in the license are constructed and construed. If a license to broadcast television were construed as giving the licensee complete control over a given range of frequencies, then any potential user would have to obtain the existing licensee's agreement before it could offer a new service-just as someone who wanted to offer a new service on a portion of a parcel of land would have to gain the approval of the parcel's owner. If, on the other hand, a license to broadcast were construed as conferring only the right to broadcast on that range of frequencies without interference, and as not including a broader property right in that range of frequencies, then a potential new user would not have to gain the agreement of the licensee. Just as someone who held only the mining rights to land would have no claim if the owner of the surface allowed a new use that did not interfere with the mining, the holder of the broadcasting rights would have no claim against a new user; the licensee could not claim interference with her rights to that range of frequencies, because she would have no rights other than the right to broadcast.

Benjamin, supra note 6 , at 85 n.259.

273 See Faulhaber \& Farber, supra note 18 (discussing their proposal); Report of the FCC Spectrum Policy Task Force, supra note 16, at 27-30. The Task Force proposed that the government set an "interference temperature" limit that would protect devices from harmful interference, and then allow other users to operate in that band, "with the interference temperature serving as the maximum cap on the potential RF energy they could introduce in the band." Id. at 30 . Indeed, the Task Force recommended the creation of underlay rights for devices that operate below the interference limits. Id. at 40 . Furthermore, according to the Report, in light of the transaction costs of negotiating access and the fact that these devices will not cause interference, such underlay rights should be available to anyone-i.e., should be a commons. Id. 
able either to justify allotting spectrum in large swaths or to overcome the transaction costs of aggregating small allotments of spectrum. ${ }^{274}$

This proposal differs from that of the commons advocates. Instead of having spectrum set aside for unlicensed usage, it would be devoted primarily to conventional uses, with wideband services as an add-on that would be an underlay to the existing uses. The result would likely be that the abundance envisioned by the commons advocates would not materialize: The necessity of avoiding interference with an existing use on those same frequencies would limit the ability of the wideband service to operate freely. On this basis, Benkler opposes simply relying on easements, and pushes instead for spectrum devoted entirely to his envisioned networks. ${ }^{275}$ But the advantage of these easements is that these underlay uses would not displace any existing uses of spectrum, and instead would be consistent with them.

The difficulty for these underlay wideband services is the same as that for abundant networks: The transaction and holdout costs of aggregating spectrum are high, and without a big swath of spectrum these wideband services will not work as planned. The solution suggested in Part II.A-that the government can simply auction spectrum in wide bands-will not work for these underlay services, because they are not envisioned to be the main use of the auctioned spectrum and they might not support a bid for the entire band. That is, the underlay services may not be sufficiently valuable to entice a bidder to bid for the whole band, set up the underlay services, and then auction off spectrum in pieces for a primary use. ${ }^{276}$

274 There are a number of services that could operate at very low power over a broad range of frequencies without interfering with simultaneous high-power transmissions. These services would underlay the existing ones, operating at such a low power level that they would create only trivial interference (below the level of background noise) for the existing services operating on the same frequencies. See Benjamin, supra note 6, at 23-24 ("UWB [ultra-wideband transmission] operates at such low power, and over such a wide swath of spectrum, that 'to traditional receivers their signals are indistinguishable from background noise.'" (citation omitted)).

275 See Benkler, supra note 2, at 32, 62-65.

276 If the most valuable primary service would occupy small swaths of spectrum, and the transaction costs of parceling spectrum into small swaths and selling them to individual bidders were greater than the value of the underlay service, then we would expect bidders to seek small swaths. We would expect that bidders who could choose what band size to bid on would prefer to bid on smaller bands that they would use for themselves (thus making the creation of an underlay service difficult, given the transaction costs of aggregating spectrum), rather than bidding on larger swaths that would be suitable for wideband services and which they would then auction privately to other users for their primary use. Accordingly, for spread spectrum as a secondary use, there is a plausible argument that simply allocating the spectrum in large bands will not result in wideband secondary services, even if wideband service would be valuable. It might be less valuable than the transaction costs of disaggregating the spectrum, and if so we would not expect them to be created. Insofar, therefore, as we are confident that these services would be of value, but 
It thus might be that the best (and only) way to allow for such valuable, noninterfering transmissions is to limit the property rights of spectrum owners and leave room for unlicensed usage. But abundant networks are intended as the primary-indeed the only-use of the frequencies on which they would operate. If they are not sufficiently valuable to entice a private owner of a wide swath of spectrum to create such a network, that should be telling us something-and should dissuade the government from creating an abundant network on its own. The commons advocates argue that a government-created abundant network is the more efficient path, but they have not made their case. In this instance efficiency lies with private, not government, control.

\section{CONCLUSION}

The commons advocates put forward a straightforward narrative: Devices that repeat others' messages and utilize low-power wideband communications can provide effectively infinite network capacity. Creating these networks is the most efficient use of spectrum and will be valuable to users, but private owners will not create them. So the government should create these networks.

I take these arguments seriously, and in this Article I have sought both to respond to and build on them. In my view, there is a role for unlicensed spectrum, and the commons advocates' arguments help to make that case. It is not as large a role as they would like, but it is one that is informed by the insights that they have brought to the fore.

The commons advocates' main argument against private ownership is that allotment of spectrum into small parcels makes creation of a wideband network unlikely because abundant networks work best with a broad swath of spectrum and the costs of aggregating spectrum are significant. The goal of creating abundant networks is thus in tension with policies that keep the spectrum divided into small chunks of frequencies. This is not an argument against private ownership, however, but instead an argument against allotment in small bands. If spectrum is auctioned in large enough swaths, there is no impediment to creating abundant networks, and the more efficient solution should

not enough to overcome the transaction costs of disaggregation (or the costs of aggregation, which might be higher, see supra Part II.A), the best response is for the government to avoid the transaction costs of either aggregating or disaggregating by simply providing that existing licenses do not prevent noninterfering underlay uses. This reasoning would not apply, however, to abundant networks, as they are the only planned use for a given set of frequencies and thus there should be no need for disaggregation (and accordingly no fear of the costs of disaggregation). 
win out. Insofar as abundant networks really are more efficient, auctions of bigger slices should produce them.

The choice between privately and publicly created abundant networks entails some tradeoffs: Notably, concerns about the concentration of private power are matched against the likelihood that private firms will have a greater incentive and ability to implement and update successful protocols, to conserve spectrum, and to design desirable pricing schemes. The government's disadvantages-such as its susceptibility to rent-seeking behavior-might not outweigh those of private entities if the choice were between a truly unregulated commons and a regulated private network. But abundant networks require a significant amount of regulation in order to work as planned. Some entity is going to be in control, and a private entity probably is preferable to the government.

The advantages of private control are even more clear when we consider the possibility that these abundant networks will not work as planned or will not be as popular as hoped. The government could ensure the creation of abundant networks by setting aside spectrum for that purpose, but providing that certainty may be a bad idea. We should prefer a government-created abundant network only if we are confident that a particular set of protocols will work as planned, that the government will choose that design, and that users will flock to the abundant network that is created. The problem is that there is uncertainty on all three counts (and private parties are likely to have better information). It makes more sense to allow for experimentation; that consideration favors private entities, who can create new services, modify them, and/or abandon them very quickly. And, of course, the risk of failure would then fall on the private entities' owners, rather than on taxpayers. Thus the better course is to let engineers persuade those with an economic stake to create abundant networks. 